Portland State University

PDXScholar

7-1-1972

\title{
Moment-curvature-thrust relationships in hybrid members
}

Douglas Wrenn Fiala

Portland State University

Follow this and additional works at: https://pdxscholar.library.pdx.edu/open_access_etds

Part of the Computer and Systems Architecture Commons, Software Engineering Commons, and the Systems Architecture Commons

Let us know how access to this document benefits you.

\section{Recommended Citation}

Fiala, Douglas Wrenn, "Moment-curvature-thrust relationships in hybrid members" (1972). Dissertations and Theses. Paper 740.

https://doi.org/10.15760/etd.740

This Thesis is brought to you for free and open access. It has been accepted for inclusion in Dissertations and Theses by an authorized administrator of PDXScholar. Please contact us if we can make this document more accessible: pdxscholar@pdx.edu. 
AN ABSTRACT OF THE THESIS OF Douglas Wrenn Fiala for the Master of Science in Applied Science presented July 28, 1972.

Title: Moment-Curvature-Thrust Relationships in Hybrid Members APPROVED BY MEMBERS OF THE THESIS COMMITTEE:

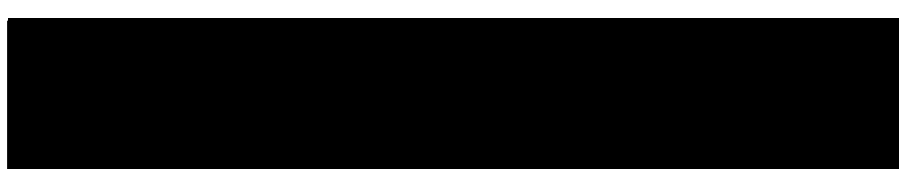

Hacik Erzuryonlu, Chairman

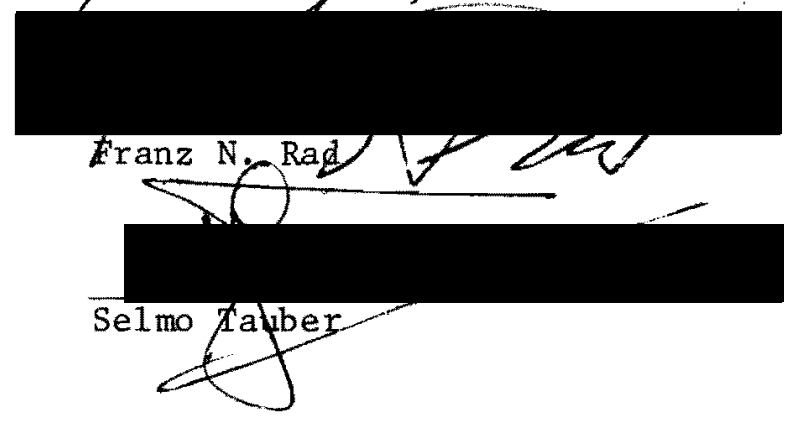

In order to overcome the difficulties encountered in closed form solutions, moment-curvature-thrust relationships are developed for hybrid and nonhybrid cross sections utilizing an open form method. The use of horizontal sectors permits the inclusion of residual stresses and/or nonbilinear stress-strain relationships, if desired. Theoretical and experimental data are compared. Applications to circular tubes and other cross sections are discussed.

Results indicate that open form solutions are feasible for calculating moment-curvature-thrust data. Hybrid cross sections are easily treated by open form solutions. 
MOMENT-CURVATURE-THRUST RELATIONSHIPS

IN HYBRID MEMBERS

by

DOUGLAS WRENN FIALA

A thesis submitted in partial fulfillment of the requirements for the degree of

\section{MASTER OF SCIENCE}

in

APPLIED SCIENCE

Portland State University

1972 
TO THE OFFICE OF GRADUATE STUDIES AND RESEARCH:

The members of the Committee approve the Thesis of Douglas

Wrenn Fiala presented July 28, 1972.

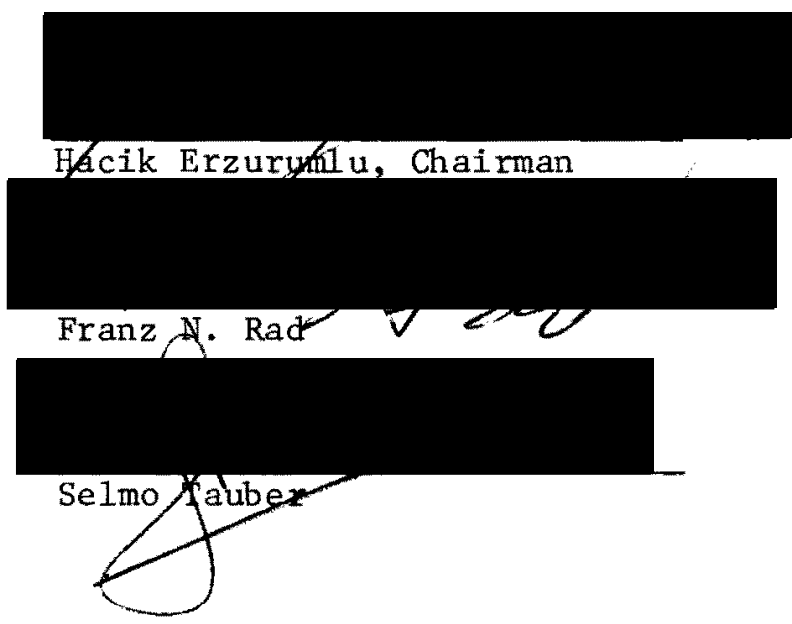

APPROVED:

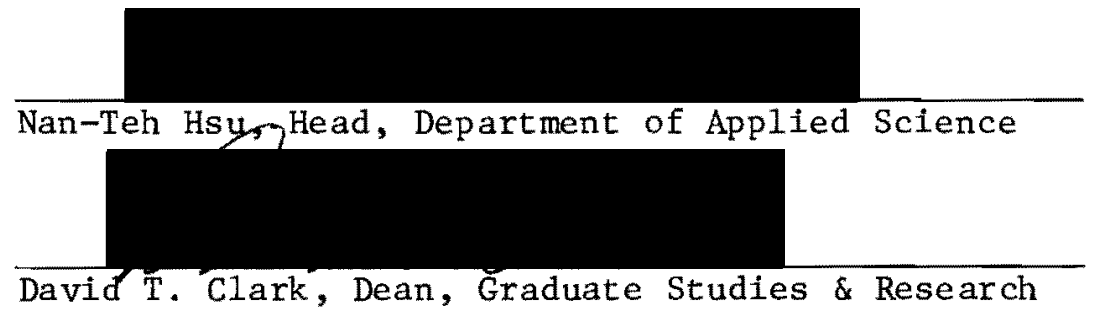


TO MY

PARENTS

JERRY FIALA

and

NELLIE WRENN FIALA 


\section{ACRNOWLEDGNENTS}

Most properly, thanks are extended to the faculty and staff of the Applied Science Department. Let it be sufficient to hope that I will treat people as fairly and courteously as they have treated me. I owe special gratutude to Dr. Harry J. White and Dr. Nan-Teh Hsu who started me in my graduate studies. This thesis was suggested and motivated by Dr. Hacik Erzurumlu, my supervising frofessor. Without his guidance this thesis would have been incomplete. To the other members of the Thesis Committee, Dr. Franz N. Rad, who introduced me to plastic analysis, and Dr. Selmo Tauber, who showed me that mathematics is a concept añ not just an operation, I thank very much for their constructive criticism and patience. Thanks are expressed to the Portland State University Computer Center for providing the necessary computer time to develop the programs. Thanks are also due to Larry F. Scott who provided the basic Aitken's iteration loop. 
CHAPTER

PAGE

ACKNOWLEDGIENTS . . . . . . . . . . . . . . . iv

NOMENCLATURE ..................... vii

I INTRODUCTION

1.1 GENERAL . . . . . . . . . . . . . 1

1.2 PROBLEM DEFINITION . . . . . . . . . . 2

a) CLOSED FORM SOLUTIONS . . . . . . . 3

b) OPEN FORM SOLUTIONS . . . . . . . . . 5

1.3 OBJECTIVES OF INVESTIGATION $\cdot \cdots \cdot \cdot \cdot \cdot \cdot \cdot 6$

II THEORETICAL CONSIDERATIONS

2.1 GENERAL . . . . . . . . . . . . . . 7

2.2 DEFINITION OF VARÍOUS CASES . . . . . . . 7

2.3 LIMITATIONS . . . . . . . . . . . . 9

2.4 MATHEMATICAL MODEL . . . . . . . . . . . 9

2.5 GOVERNING EQUATIONS ........... 10

2.6 NONDIMENSIONALIZATION . . . . . . . 12

III ANALYTICAL PROCEDURE

3.1 GENERAL . . . . . . . . . . . . 13

3.2 THE COMPUTER SOLUTION . . . . . . . . 15

3.3 SUBROUTINES . . . . . . . . . . . . 16

IV NUMERICAL EXAMPLES AND TEST RESULTS

4.1 WIDE FLANGE MEMBER . . . . . . . . . . . 19

4.2 HYBRID MEMBERS . . . . . . . . . . . 19

a) GENERAL . . . . . . . . . . . . . 19 
CHAPTER

PAGE

b) DATA COMPARISON ................. 19

4.3 EXTENSTON TO CIRCULAR TUBES . . . . . . 20

4.4 OTHER CROSS SECTIONS . . . . . . . . . . 21

V CONCLUSIONS AND RECOMMENDATIONS

5.1 CONCLUSIONS . . . . . . . . . . . 22

5.2 RECOMENDATIONS . . . . . . . . . . 22

REFERENCES . . . . . . . . . . . . . . . . 23

FIGURES . . . . . . . . . . . . . . . . . . 24

TABLES . . . . . . . . . . . . . . . 4 48

APPENDIX A: ZERO THRUST AXES EXTENSIONS . . . . . . 49

APPENDIX B: AITKEN'S PROCESS . . . . . . . . . . 51

APPENDIX C: COMPUTER PROGRAM LISTINGS

C.1 TOTALLT SYMETEIC FROGKAMi . . . . . . . 54

C.2 ASYMMETRIC PROGRAM ........... 56

C.3 SUBROUTINES . . . . . . . . . . . . 59

C. 4 DRIVERS . . . . . . . . . . . . 64

C.5 CiRCUlar TUBE PROGRAM .......... 68

APPENDIX D: FLOW DIAGRAMS

D.1 TOTALLY SYMMETRIC FLOW DIAGRAM . . . . . 75

D.2 ASYMETRIC FLOW DIAGRAM ......... 76

D. 3 SUBROUTINE FLOW DIAGRAMS . . . . . . . 77

D.4 DRIVER FLOW DIAGRAMS .......... 78

D.5 CIRCULAR TUBE FlOW DIAGRAM . . . . . . . 80 VITA . . . . . . . . . . . . . . . . . 81 


\section{NONENCLATLRE}

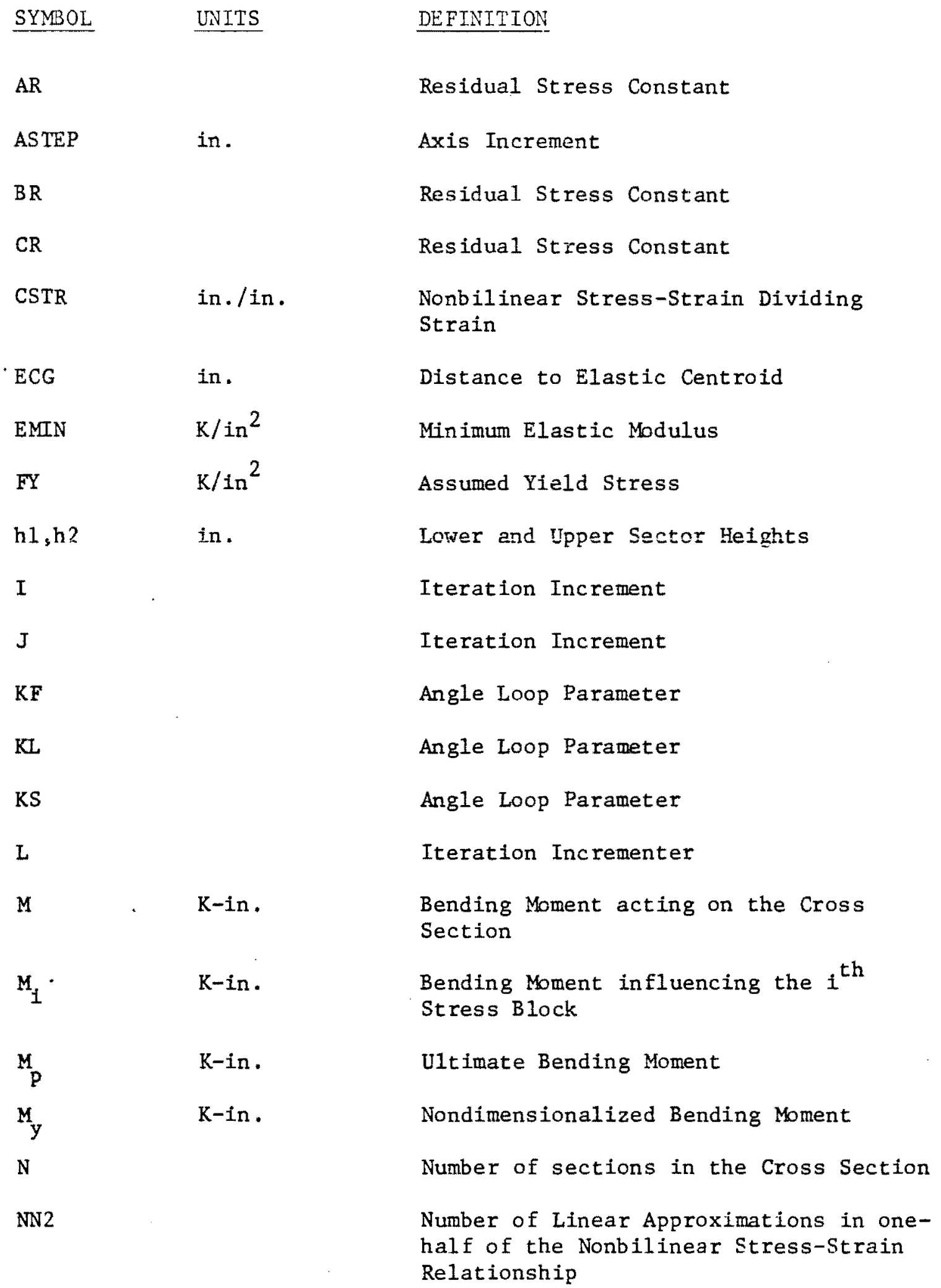




\begin{tabular}{|c|c|c|}
\hline SYMOL & U.ITS & DEFINITION \\
\hline $\mathrm{P}$ & $\mathrm{k}$ & Axial Thrust Acting on the Cross Section \\
\hline$P_{i}$ & k & Axial Thrust Acting on $i^{\text {th }}$ Stress Block \\
\hline$P_{y}$ & $\mathrm{~K}$ & Nondimensionalized Axial Thrust \\
\hline PCG & in. & Distance to the Plastic Centroid \\
\hline PM & $\mathrm{k}$-in. & Plastic Bending Moment \\
\hline $\mathrm{SF}$ & & Angle Loop Parameter \\
\hline s & $\mathrm{K} / \mathrm{in}^{2}$ & Stress \\
\hline$s 1, s 2$ & $\mathrm{k} / \mathrm{in}^{2}$ & Lower and Upper Stress Intensities \\
\hline SF1 & & Shape Factor \\
\hline TWD & in. & Transformed Section Width \\
\hline$[\mathrm{x}]$ & & Iteration Vector \\
\hline [Y] & & Iteration Matrix \\
\hline $\mathrm{y}$ & in. & $\begin{array}{l}\text { Distance from Moment Center to Point } \\
\text { of Stress }\end{array}$ \\
\hline$y_{i}$ & in. & $\begin{array}{l}\text { Distance from Moment Center to Centroid } \\
\text { of ith Sector }\end{array}$ \\
\hline w1, w2 & in. & Lower and Upper Sector Widths \\
\hline ZCG & in. & Distance to Infinite Zero Thrust Axis \\
\hline$\emptyset$ & Rad. & Angle of Curvature \\
\hline$\emptyset_{\mathrm{k}}$ & Rad. & General Angle of Curvature \\
\hline$\emptyset_{s}$ & Rad. & $\begin{array}{l}\text { Angle of Curvature whose Zero Thrust } \\
\text { Axis Lies on the PCG }\end{array}$ \\
\hline$\varepsilon_{\mathrm{y}}$ & in./in. & Strain that Produces the Stress, FY \\
\hline
\end{tabular}




\section{INTRODUCTION}

1.1 GENERAL

The advent of plastic analysis of structural members and braced frames has significantly broadened the scope of structural design. Because plastic design deals with ultimate member strength, information is needed for all possible stress conditions. Such information is available for most wide flange cross sections in the form of moment-curvature-thrust curves but is rare for most other structural shapes. Moment-curvature-thrust relationships are hereinafter referred to as $M-\emptyset-P$ relationships.

Although elastic deflections are determined routinely by small deflection theory, deformations and displacements in the elasto-plastic range may not be determined as easily because they depend on the changing angles of curvature of the cross section over the member length. Deflections are obtained by integrating these angles of curvature. Ultimate capacity is attained when all fibers of the cross section are completely plastified. All axial thrust and radius of curvature combinations require a finite bending moment to cause full plastification. If axial thrust and bending moment variations are known, the changing radii of curvature (strain slopes) are defined, and deflections are obtained as outlined above. 
Elasto-plastic response depends on material properties as we11 as member geometry. Menbers with similar configurations, such as wide flange shapes, generally exhibit similar $M-\emptyset-P$ relationships. However, these relationships are usually not available for all different cross sectional shapes. The possibility of finding such pertinent data is further reduced when hybrid menbers are used. A hybrid member is one constructed of two or more interconnected materials. The most common use of hybrid construction involves two different grades of steel, and is generally encountered in plate girders.

In some instances both strength and member geometry must be considered in design. If the selection of dimensions are left to the structural designer, no major problems are encountered. However, if sizes are limited by architectural considerations, common rolled shapes may not satisfy the design requirements. The engineer may have to resort to different structural shapes, such as tubes, built-up and hybrid members. Furthermore, the problem may be complicated by the presence of materials with nonlinear stress-strain characteristics.

If deflections are to be calculated and interaction curves produced, accurate $M-\emptyset-P$ relationships are necessary. Generation of $M-\emptyset-P$ relationships by longhand procedures is tedious even for the simplest shapes. Therefore, there exists a need for quick and accurate means of determining these relationships.

\subsection{PROBLEM DEFINITION}

Methods of producing M- $\emptyset-\mathrm{P}$ relationships include: 
a) Closed Form Solutions

b) Open Form Solutions

a. Closed Form Solutions

Closed form solutions, capable of incorporating idealized linear residual stress patterns were introduced for wide flange sections by Ketter, Kaminsky and Beedle (5)*. Their treatment required the use of an idealized bilinear stress-strain relationship, (Fig. 1a), with identical compressive and tensile stress properties. For closed form solutions, sets of bounded relationships are derived for the angle of curvature, axial thrust and

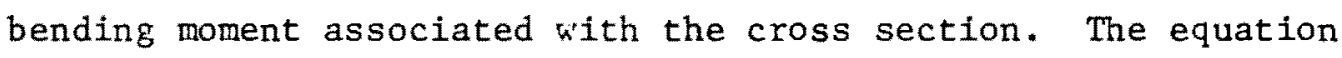
sets are bounded in that each set is valid only for one elastoplastic stress condition. Figures $2 \mathrm{~b}$ through $2 \mathrm{f}$ depict a wide flange member in progressive elasto-plastic stages. Figure $2 b$ shors the cross section in a fully elastic condition while Fig. $2 f$ illustrates complete plasticity caused by bending. Since the fully plastic stage (Fig. 2f) is a special case of the elastoplastic condition shown in Fig. 2e, only four sets of relationships are required for a wide flange member. Thus one elastic and three elasto-plastic conditions must be considered in deriving the necessary equations. These equations are then "nondimensionalized" by dividing curvature, thrust and moment equations by predetermined curvature, thrust and moment values. The nondimensionalization eliminates plotting wide ranges of curvature, thrust and moment values when $M-D-P$ diagrams are constructed.

\footnotetext{
* Numbers listed refer to references at the end of this thesis.
} 
For the purpose of this investigation a section is defined as a rectangular member component. For example, the member in Fig. 2a is composed of three sections. In general, if a member is composed of $\mathrm{N}$ sections, a total of $3 \mathrm{~N}+3$ equations are needed for curvature, thrust and bending moment calculations. To generate the $M-\emptyset-P$ data, the desired stress condition from Figure 2 is first determined and then the corresponding relationships are used to construct auxiliary curves as shown in Fig. 3. The M- $\emptyset-\mathrm{P}$ diagram (Fig. 4) is then plotted using data from the auxiliary curves. As previously mentioned, closed form solutions use bilinear stress-strain relationships because definite yield points are necessary for the bounded equations. In previous treatments, linear residual stress idealizations (Fig. 5a) have been adopted from the approximately parabolic residual stress patterns shown in Fig. 5b. This simplification is necessary because the manipulation of parabolic shapes in bounded equations is prohibitively difficult to treat mathematically. Similar arguments have also eliminated the consideration of nonbilinear stress-strain relationships by closed form methods.

It should be recognized that closed form solutions are not limited to wide flange members. Samani (8) presented relationships for general residual stress patterns in his study of $M-\emptyset-P$ relationships for built-up steel members. In the same vein, Matthys (6) presented closed form relationships for hollow circular tubes, From their work it is apparent that the more general the treatment, the more tedious the longhand application becomes. It is also 
possible to derive relationships for other conventional and hybrid cross sections in the same manner.

It is apparent that closed form solutions have many disadvantages as follows:

(1) The correct stress condition must be determined before data is calculated.

(2) Only linearly varying residual stress distributions can be treated.

(3) Nonbilinear stress-strain relationships tend to complicate the derivations, and are not feasible to incorporate.

(4) Closed form solutions for wide flange members are easily solved by digital computers,but as more complicated shanes and residual stress patterns are introduced, even computer solutions may become awkward.

(5) Derivation of equations for more complicated cases could be prohibitively long.

b. Open Form Solutions

Having considered the previously mentioned shortcomings, Erzurumlu, Bakir and Kok (1) initially proposed the concept of open form solutions for calculating $M-\phi-P$ data. An open form solution is a generalized computational procedure capable of treating any forseen combination of factors influencing the cross sectional behavior. Some of these influencing factors are:

(1) The use of materials with varying properties within the cross section; 
(2) Residual stress pattems in any or all sections;

(3) Nonbilinar stress-strain relationships for any or ali. naterials;

(4) Any combination of yield stress patterns;

(5) Any combination of the above factors.

In open form solutions one calculation procedure treats

all possible stress conditions. The open form approach as presented recently by Fiala and Erzurumlu (3) has proved useful in calculating M- $\emptyset-P$ data for circular tubes permitting the consideration of both residual stress patterns and nonbilinear stress-strain relationships. Open form solutions are feasible for most cross sectional configurations and seem to be applicable to most hybrid members.

\subsection{OBJECTIVES OF TNUTSTTGATTON}

The purpose of this investigation is to develop an open form computer solution for calculating $M-\emptyset-P$ data for cross sections of rectangular configurations. Nonbilinear stress-strain relationships and general residual stress patterns are treated in both homogeneous and hybrid members. Open form solutions are advantageous because one programed solution package is capable of treating many different types of cross sections. Steps taken to achieve the stated objectives are as follows:

(1) Investigation of bending moment axes and symetry relationships;

(2) Development of a mathematical model;

(3) Discussion of analytical procedures;

(4) Development of a solution package;

(5) Conparison of results with experimental data. 
THEORETICAL CONSIDERATIONS

\subsection{GENERAL}

The calculation of $M-\emptyset-\mathrm{P}$ relationships requires knowledge of the proper bending moment axis. The position of this axis depends on geometric and material symmetry. Geometric symmetry requires identical dimensions on both sides of the horizontal bending axis (Fig. 6a). Material symmetry is achieved when geometrically symmetric sections are constructed of identical materials (Fig. 6b). In this investigation, it is assumed that the cross section possesses both geometric and material symmetry about a vertical axis.

Locations of plastic and elastic centroids of a cross section are governed by variations of geometry and materials. If material and geometric symmetry exist about a.horizontal axis, the two centroids coincide and the cross section is referred to as totally symetric. Various examples of totally symetric cross sections are shown in Figure $7 \mathrm{a}$.

\subsection{DEFINITION OF VARIOUS CASES}

A proper moment center can now be considered for combinations of axial thrust and bending moment. If only elastic stresses influence the totally symmetric cross sections shown in Fig. 7a, the elastic centroid can be used as the proper moment center. On the other hand, when the cross section is totally plastified, the plastic centroid is used. For totally symmetric cross sections the cause of total plasticity is unimportant in that the moment center remains at the plastic centroid whether total plasticity 
is caused by arial thrust (Fig. 8a), bending moment (Fig. 8b) of a combination of the two (Fig. 8c). The coincident centroid position can be used as the moment axis for elastic, elastoplastic and plastic stress configurations.

Analysis of the asymmetric cross sections shown in Fig. $7 \mathrm{~b}$ is more complex because the elastic and plastic centroids are not coincident and their treatment is beyond the scope of this investigation. The elastic centroid is used as the moment center for elastic stress conditions. Therefore, only pure bending cases will be considered for asymetric cross sections. Stresses produced by pure bending are easily treated since all moment centers yield identical bending moments for a couple. For all angles of curvature a stress block can be constructed such that no axial thrust influences the cross section. The neutral axis of this stress block is defined as the zero thrust axis. For totally symetric cross sections all zero thrust axes lie at the coincident centroids.

For asymmetric cross sections the positions of the zero thrust axes vary between the elastic centroid (ECG) and the infinite zero thrust axis (ZCG). The ZCG is defined as the position of the zero thrust axis for an assumed infinite angle of curvature. At this stage the cross section is totally plastified by bending moments, and the stress block contains equal tensile and compressive component volumes. For example, the zero thrust axes for the asymmetric cross section shown in Fig. 9 vary between the ECG and ZCG for the angles of curvature indicated by $\emptyset / \emptyset \mathrm{y}$. Further implications 
conceming the shift of the zero thrust axis are discussed in Appendix A.

The computation of theoretical $M-\emptyset$ data for asymetric cross sections requires the location of zero thrust axes for all considered angles of curvature. These axes are easily determined by simple iterative procedures since they always lie between the ECG and ZCG.

\subsection{LIMITATIONS}

All totally symmetric cross sections are treated for all axial thrust percentages. Only pure bending is considered for asymmetric cross sections. The possibility of further treatments of asymetric cross sections is discussed in Appendix A.

\subsection{MATHEMATICAL MODEL}

For numerical calculations, a cross section is divided into a finite number of sectors (Fig. 10a). A section can be composed of more than one sector but a sector can contain area from only one section. Upper and lower sector boundaries are defined as stations. The stress block (Fig. 10b) influencing a cross section is numerically defined by calculating the height, stress intensity and width of the cross section at all stations. The bending moment and axial thrust contributions of all sectors are computed and added to produce the forces influencing the cross section.

A linear variation of stress is assumed between stations for moment and thrust calculations. Bilinear stress-strain relationships and linear residual stresses lie within this assumption but the calculation procedure must be altered for nonbilinear stressstrain relationships and/or nonlinear residual stresses. The 
number of stations needed to define the stress block volume for linear cases with no residual stress is a function of the number of sections in the cross section. A maximum of three station coordinates, two for sector boundaries and one for a yield point, could be required for each sector. For the general stress condition two additional stations could be required; one for a zero stress point and another for a second yield point in one sector. If the cross section contains $\mathrm{N}$ sections then $3 \mathrm{~N}+2$ stations could be required to define the stress block. If linear residual stresses are considered, the number of additional stations required depends on the linear variations and no general rule can be given for the required additional stations.

Nonbilinear stress-strain relationships (Fig. 1b) and/or nonlinear residual stresses (Fig. 5b) produce a nonlinearly varying stress distribution as shown in Fig 11a. This distribution violates the linearly varying stress assumption made for thrust and bending moment calculations. The treatment of this nonlinear case is based on approximating the general stress distribution with a series of linear approximations (Fig. 11b) that adequately estimates the actual relationship. An adequate number of sectors are placed in nonlinearly varying sections to produce the linear approximations. It should be noted that the method of producing the stress distribution dictates numerical accuracy. The remaining calculations, however, are independent of the stress block formation procedures.

\subsection{GOVERNING EQUATIONS}

The determination of thrust and bending moment relationships are based on the following well known equations of statics: 


$$
\begin{aligned}
& P=\int_{A} s d A \\
& M=\int_{A} y s d A
\end{aligned}
$$

where $P=$ the thrust acting on the cross section;

$$
\begin{aligned}
M= & \text { the bending moment acting on the cross section; } \\
s= & \text { the stress at any point on the cross section; } \\
y= & \text { the distance from the moment center to the point of } \\
& \text { stress. }
\end{aligned}
$$

- Each sector forms a finite stress block as shown in Fig. 10c. The thrust and moment contribution of each sector block can be defined as :

$$
\begin{aligned}
& \underline{p}_{i}=\int_{h 1}^{h 2} \text { swdh } \\
& M_{i}=\int_{h 1}^{h 2} \text { yswdh }=y_{i} P_{i}
\end{aligned}
$$

where $P_{i}=$ the thrust acting on the $i^{\text {th }}$ stress block;

$M_{i}=$ the moment caused by the $i^{\text {th }}$ stress block;

$y_{1}=$ the distance from the moment center to the centroid of the ith stress block;

h1, h2 = lower and upper station coordinates, respectively.

Considering the contributions of all sector stress blocks, the axial thrust and bending moment acting on the cross section can be represented as:

$$
\mathrm{P}=\sum_{i=1}^{n} \mathrm{P}_{i}
$$




$$
M=\sum_{i=1}^{n} y_{i} p_{i}=\sum_{i=1}^{n} M_{i}
$$

where $\mathrm{n}=$ the number of sectors used to build the stress block volume.

\subsection{NONDIMENSIONALIZATION}

In an effort to nondimensionalize the $M-\emptyset-P$ diagrams the following constants are defined. The thrust, $\mathrm{P}_{\mathrm{y}}$, is the thrust acting on the cross section when full plasticity is achieved by axial loading. The angle of curvature, $\emptyset_{y}$, is defined as the angle of curvature that causes the first assumed plastic stress at any fiber when the neutral axis passes through the elastic centroid. The moment, $M_{y}$, is the bending moment influencing the member when the strain angle $\vec{\phi}_{\mathrm{y}}$ is used. As a convenient check for output data, the nondimensionalized moment, $M / M_{y}$, should equal unity when $\emptyset=\emptyset_{\mathrm{y}}$. 
ANALYTICAL PROCEDURE

\subsection{GENERAL}

M- $\emptyset$-P diagrams show moment-curvature relationships for constant percentages of the thrust, $P_{y}$. A moment is computed for each selected radius of curvature and each selected thrust percentage. For each strain condition associated with a radius of curvature, a corresponding stress diagram is constructed such that a certain thrust percentage acts on the cross section. The axial thrust and the moment acting on the cross section can then be calculated using Eqs. 5 and 6 from which nondimensionalized values of $P / P_{y}, M / M_{y}$ and $\emptyset / \emptyset_{y}$ can be obtained.

The problem here is to determine the location of the neutral strain axis that yields the selected thrust percentage. Suppose the neutral axis originally passes through point 0 in Fig. 12a. If the calculated thrust percentage is not equal to that anticipated, the neutral axis is shifted either up or down along the vertical member axis and the thrust is recalculated. The proper neutral axis position is approached by a succession of axis shifts indicated by the points $0,1,2, \ldots, n$. When the proper neutral axis position is obtained, the bending moment can be calculated. The accuracy of the thrust estimation controls the reliability of the calculated bending moment for the selected thrust values. This process has proven to be computationally inefficient, especially for high thrust percentages associated with small angles of curvature where the neutral axis lies off the cross sectional area. Another approach is to select the initial position of the 
neutral axis at the zero thrust axis (Fig. 12c). After the thrust (initially equal to zero) and the bending moment are calculated, the neutral axis is raised by a predetermined amount, ASTEP, and new thrust and moment values are determined and stored for future reference. The shift of the neutral axis is terminated when the calculated thrust reaches within two percent of $\mathrm{P}_{\mathrm{y}}$. The values stored for reference are nondimensionalized thrust and moment percentages, and if plotted, result in thrust-moment relationships for constant angles of curvature, $\emptyset / \emptyset_{\mathrm{y}}$, as shown in Fig. 13 . If graphs similar to those shown in Fig. 13 are drawn, the moment corresponding to any thrust percentage can be graphically estimated with suitable accuracy. However, instead of constructing graphs, the open form solution employs iterative procedures to estimate the desired moments. Since the neutral axis is raised by predetermined increments, neither thrust nor moment values will be equally spaced tabulated points, and therefore, equal point interpolation formulas cannot be used. Aitken's process (7), a nonequally spaced linear interpolative procedure, is used for the iteration. It should be noted that the range around the desired point should be chosen for the iteration, thus increasing numerical accuracy. Iterations utilizing a complete graphical range lead to erroneous results because the thrust-moment relationship cannot be well representei by a single function. Series of short range approximations as shown in Fig. 14 are more appropriate. When a range is chosen around the desired moment value, Aitken's process adapts a function to that protion of the curve. 


\subsection{THE COMPUTER SOLUTION}

The computer program for treating totally symmetric cross sections is listed in Appendix C.I and is flow charted in Appendix D.1. The program for asymmetric cross sections is also listed in Appendix C.2 and flow charted in Appendix D.2. In both cases any number of cross sections may be treated in one run. Geometric and material inputs are identical for both processes and preliminary control calculations are similar.

Both procedures calculate preliminary values of thrust $\left(P_{y}\right)$, moment $\left(M_{y}\right)$, angle of curvature $\left(\emptyset_{y}\right)$, distance to the elastic centroid (ECG), plastic moment (PM) and the shape factor (SF1). For asymmetric cross sections the additional parameters EMIN (mininum elastic modulus), TWD (transformed section widths), ZCG (distance to the infinite zero thrust axis) and PCG (distance to the plastic centroid) are determined.

After data has been input and preliminary calculations made, a series of loops is comenced for various strain diagram slopes defined by the inputs KF (initial loop value), KL (final loop value), KS (loop increment) and SF (a dividing constant which, if equal to four, divides the loop into increments of one-fourth $\emptyset_{y}$ ). The neutral axis is incremented by intervals of ASTEP as shown in Fig. $12 \mathrm{c}$ and moments corresponding to predetermined thrust percentages are calculated. Geometric and sectional properties, nonbilinear stress-strain relationships, residual stress constants and $M-\emptyset-P$ data are printed in tabular form as shown in Fig. 15.

The asymmetric procedure varies from the totally symmetric 
process in calculating more preliminary constants. Asymmetric cross sections also require the determination of the zero thrust axes positions for various angles of curvature.

As revealed by the flow charts, both programs employ subroutines and driver subsections for most calculation procedures. The subroutines are listed in Appendix C. 3 with driver subsections in Appendix C.4. Driver subsections are used mainly for preliminary constant calculations and for sections common to both totally symmetric and asymetric programs. Flow diagrams are given for subroutines and driver subprograms in Appendices D. 3 and D.4, respectively. Brief explanations of the subroutines follow.

\subsection{SUBROUTINES}

Suhroutine RSTRS treats quadratic, lincar and constait residual stress patterns. The constants $A R, B R$ and $C R$ are input for all sections and correspond to $A, B$, and $C$, respectively, in the quadratic equation $A X^{2}+B X+C=0$. The constants are input to define the residual stress patterns for a section as a function of the station heights over the section. Appropriate constants are input as zero for nonparabolic stress idealizations. Because vertical sectors are not used, stress variations are not allowed over the width of the flange. Variations over the depth of the flange can be treated, however,

Subroutine XSTRS calculates stresses from given strains for materials having nonbilinear (Fig. 1b) stress-strain relationships. A series of linear approximations are programmed in lieu of exact stress-strain functions. Figure 16 graphically represents such approximations which are governed by $\mathrm{NN} 2$ defined linear portions in 
half the stress-strain diagram. The length of each approximation is governed by the strain range, CSTR. Equal numbers of compressive and tensile approximations are used. If strains outside the defined range are encountered, a signed constant stress, FY, is assigned. Although this procedure is valid for steel and some other materials, it is unacceptable for materials exhibiting stressstrain relationships as shown in Fig. 17. In this instance, yield stresses are input twice for all materials. Initial values are used for preliminary constant calculations. If stress-strain relationships similar to that of Fig. 17 are used, second yield stresses are input as zero to accommodate material fracture.

Subroutine SDIAG numerically defines the stress block volume in the computer. If only linear functions are used in volume construction, upper and lower station data are calculated for each section. If nonlinearities are employed, data are calculated for the number of sectors specified for each section by the programmer. Subroutines RSTRS and XSTRS are used in defining nonlinear cases. If necessary, yield point stations are provided for all sections. If nonlinear calculations govern a section, sufficient linearity is assumed and the yield point search is abandoned. Data for zero stress points are calculated as needed for linear sections. Subroutine MOMNT calculates the bending moment contribution of each sector stress block and forms the resultant moment. Counterclockwise moments are considered positive. Subroutine TSTRS sums block volumes to obtain the axial thrust influencing the cross section. Positive stresses are treated as tension. 
Subroutine SIIFT, used in conjunction with subroutine SDIAG, stores station data correctly in the dimensioned files. Subroutine AITKN is used to determine bending moments and zero thrust axes from calculated data points. A more complete explanation of Aitken's process and subroutine AITKN are presented in Appendix B. 


\section{NUMERICAL EXAMPLES AND TEST COMPARISONS}

\subsection{WIDE FLANGE MEMBER}

Open form $M-\emptyset-P$ relationships are compared to the well known closed form results for a W $8 \times 31$ published by Ketter, Kaminsky and Beedle (5). Such a comparison verifies open form theoretical accuracy. Cross sectional data and computer printout are given in Fig. 18. Both open and closed form solution $M-\emptyset-\mathrm{P}$ relationships are identical and are given in Fig. 19. Bilinear stress-strain relationships were used for both solutions.

\subsection{HYBRID MEMBERS}

\section{a) GENERAL}

General experimental data for $M-\emptyset-P$ relationships for hybrid cross sections are not available for comparison. Erzurumlu (2) has conducted experiments dealing with the moment-curvature relationships for selected hybrid cross sections. Theoretical open form results are compared to Erzurumlu's experimental data.

The static yield points as deternined by cupon tests (2) are $40 \mathrm{KSI}, 57.5 \mathrm{KSI}$ and $100 \mathrm{KSI}$ for A-36, A-441 and SSS-100 steels, respectively. Since no strain hardening is considered the theoretical ultimate moments of the open form solution should be somewhat less than the measured ultimate moments.

b) DATA COMPARISON

Cross section $\mathrm{T} 1$ is composed of an $\mathrm{A}-36$ web and $\mathrm{A}-441$ flanges. Experimental and theoretical $M-\emptyset$ relationships are shown 
in Fig. 20. For no thrust, the calculated plastic moment is $\mathrm{M}_{\mathrm{p}}=426 \mathrm{~K}-\mathrm{IN}$. The two curves are nearly identical in the elastic range but vary by up to $20 \%$ in the plastic region where the ultimate measured moment is $501 \mathrm{~K}-\mathrm{IN}$. The open form solution is conservative for bilinear stress-strain relationships. Actual stress-strain relationships produce more accurate results. M- $\emptyset-\mathrm{P}$ data is printed in Fig. 21 and the $M-\emptyset-P$ diagram is shown in Fig. 22 . Cross section $\mathrm{T} 2$ has an $\mathrm{A}-441$ web and SSS-100 flanges. Experimental and theoretical $M-\emptyset$ curves are shown in Fig. 23. - The expected plastic moment was $\mathrm{M}_{\mathrm{p}}=1054 \mathrm{~K}$-IN, and failure occurred at $1290 \mathrm{~K}-\mathrm{IN}$. , or a $23 \%$ increase. Again, bilinear stress-strain relationships were used in data calculations. The M- $\emptyset$-P diagram is given in Fig. 24 .

Cross section $\mathrm{T} 3$ is asymmetric with an $\mathrm{A}-441$ web and top and bottom flanges of SSS-100 and A-36 steel, respectively. Experimental and theoretical $M-\emptyset$ curves are given in Fig. 25 . The expected plastic moment was $M_{p}=595 \mathrm{~K}-\mathrm{IN}$. but the cross section withstood $987 \mathrm{~K}-\mathrm{IN}$. Bilinear stress-strain relationships were used in data calculations.

\subsection{EXTENSION TO CIRCULAR TUBES}

Since circular tubes are totally symetric (Fig. 7a), a computer program similar to the totally symetric program is used. Variations occur in preliminary constant calculations and in subroutines SDIAG, MOMNT and THRST. Nonparallel sector walls (Fig. 26a) necessitate changes in the subroutines. 
When lines ac and bd are considered to be straight, a rhombus is formed as shown in Fig. 26a. The resulting stress block volume is shown in Fig. 26b. Because $w 1$ and $w 2$ are not equal, changes must be made in the moment and thrust calculation procedures. Subroutine SDIAG is altered to account for changing circular widths. While ovaling (4) has not been considered, it could easily be incorporated in the subroutine. Because of ovaling, computed data for large angles of curvature, $\emptyset / \emptyset_{y}$, may, in most cases, overestimate actual behavior.

The circular tube program is listed in Appendix C.5 and is flow charted in Appendix D.5. Mwall thickness standard tube is given in Fig. 27 and the results are plotted in Fig. 28.

\subsection{OTHER CROSS SECTIONS}

As long as cross sectional widths are definable in terms of station coordinates no undue hardship is forseen in treating any cross section by open form solutions. The two possible configurations for stress block volumes are solved in the totally symmetric program (parallel vertical walls) and the tube program (nonparallel vertical walls). Subroutines MOMNT and THRST will never vary from these two cases. Subroutine SDIAG will need modification if cross sections other than vertical parallel walled cross sections or tubes are encountered. 
CONCLUSIONS AND RECOMMENDATIONS

\section{$5.1 \quad$ CONCLUSTONS}

Due to the success and applicability of open form solution techniques, the following conclusions may be drawn.

1. Open form computer solutions can be successfully used for tubes, hybrid and nonhybrid cross sections, and can be extended to almost any cross sectional configuration.

2. General stress-strain relationships can be handled by the proposed mathematical model.

3. Nonlinear residual stress patterns can also be incorporated.

4. The use of bilinpar stress-strain relationships is conservative and more accurate results could be obtained by using general stress-strain relationships.

5. The theoretical results generated by this solution are generally limited to low values of $\emptyset / \emptyset_{\mathrm{y}}$ as at higher values of $\emptyset / \emptyset_{y}$ local buckling and ovaling may occur.

\subsection{RECOMMENDATIONS}

1. Methods of theoretically uncoupling bending moments and axial thrust from a plastic stress distribution need to be developed, thus leading to the proper moment center for elasto-plastic stress conditions.

2. Experiments to measure the influence of axial thrust and bending moment on the strength of hybrid cross sections need to be conducted. 


\section{REFERENCES}

1. Erzurumlu, H., Bakir, N., Kok, N., "Moment-Curvature-Thrust by Iteration", Unpublished Seminar Report, Department of Civil Engineering, The University of Texas at Austin, May, 1969.

2. Erzurumlu, H., "The Ultimate Strength of Hybrid Steel Beams", Thesis presented to the University of Texas, at Austin, Texas, 1962, in partial fulfillment of the requirements for the degree of Master of Science in Civil Engineering.

3. Fiala, D. W., Erzurumlu, H., "Moment-Thrust-Curvature of Tubular Members by Iteration", Paper presented at the 1972 offshore Technology Conference at Houston, Texas, May 1972, OTC 1668.

4. Jirsa, J. 0., Lee, Fook-Hoy, Wilhoit, J. C., Merwin, J. E., "Ovaling of Pipelines under Pure Bending", Paper presented at the 1972 offshore Technology Conference at Houston, Texas, May 1972 , OTC 1569.

5. Ketter, R. L., Kaminsky, E. L., Beedle, L. S., "Plastic Deformation of Wide-Flange Beam-Columns", Transactions of the American Society of Civil Engineers, Vol. 120, pp. 1028-1061, 1955.

6. Matthys, R., "Theoretical Analysis of Circular Pipe Columns in the Inelastic Range", Thesis presented to the University of Texas, at Austin, Texas, in 1962, in partial fulfillment of the requirements for the degree of Master of Science.

7. Milne, W. E., NUMERICAL CALCULUS, Princeton University Press, Princeton, N. J., 1949 .

8. Samani, F., "Moment-Curvature Relation for Built-Up Steel Sections", Thesis presented to Iowa State University at Ames, Iowa, in 1968, in partial fulfillment of the requirements for the degree of Master of Science in Structural Engineering. 


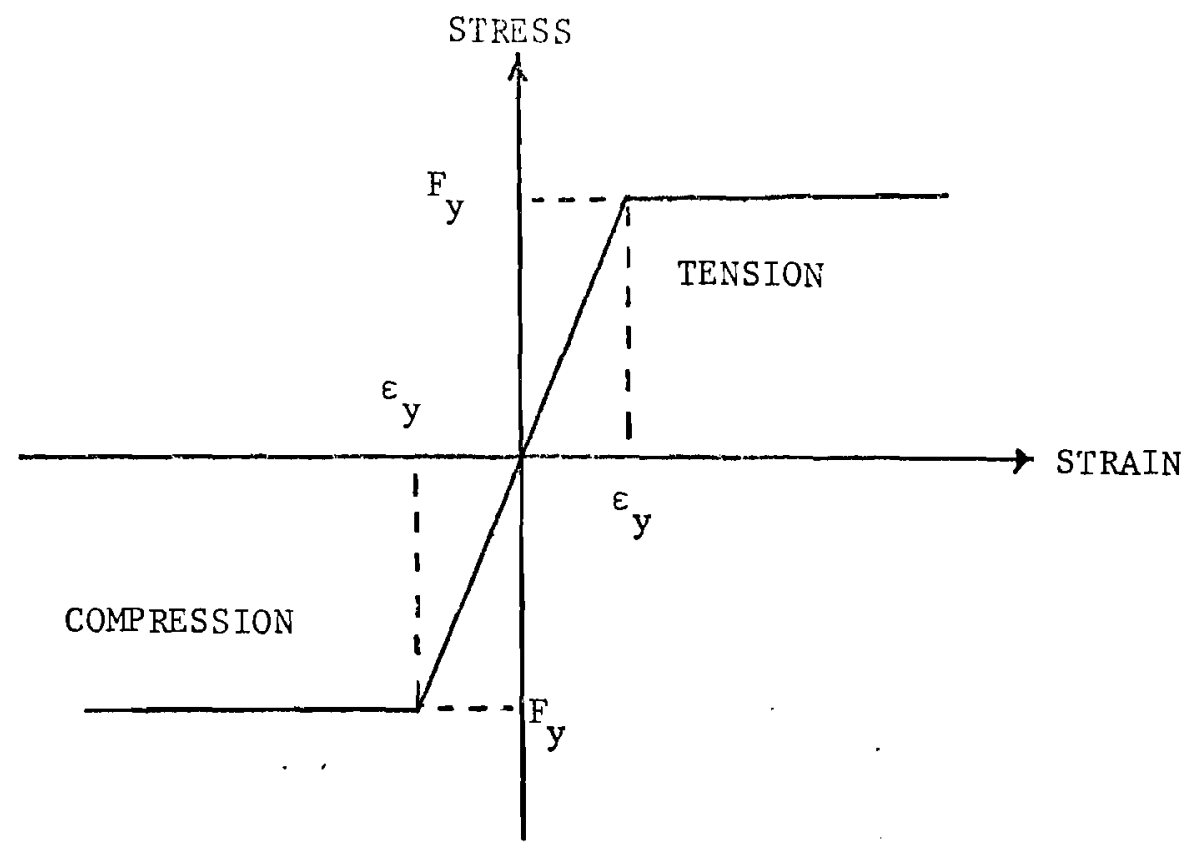

(a) Idealized Bilinear Stress-Strain Relationship

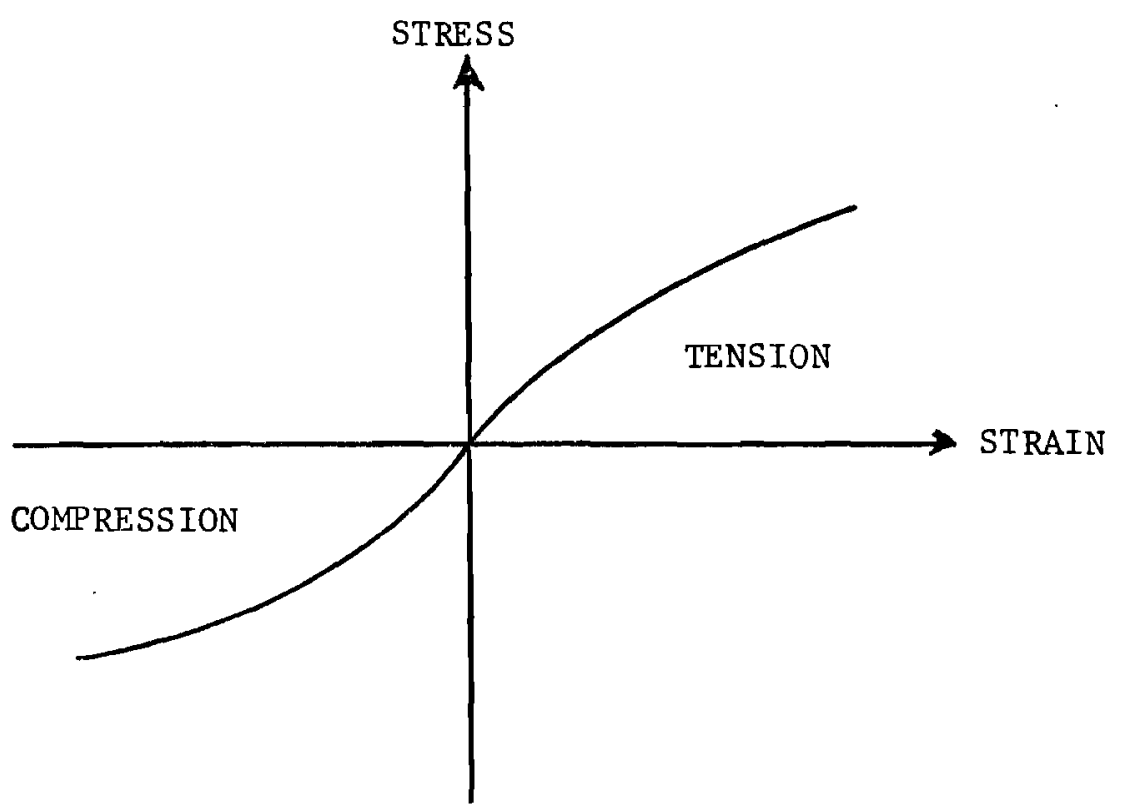

(b) Generalized Stress-Strain Relationship

Fi.g. 1 Stress-Strain Relationships. 
STRAIN

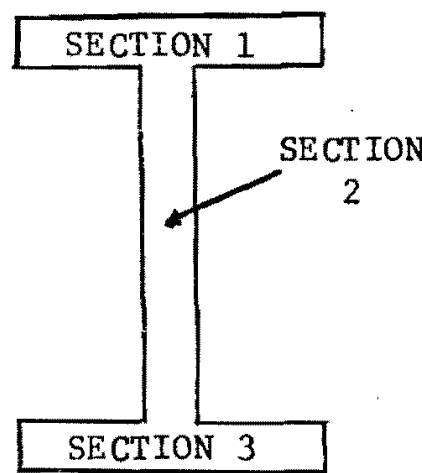

(a)

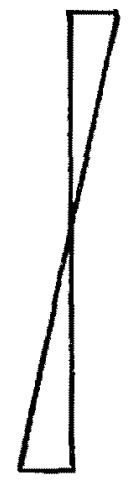

(b)

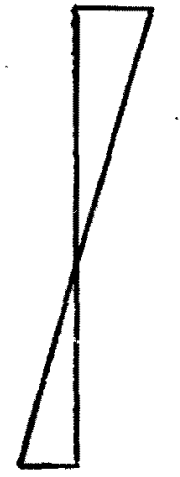

(c)

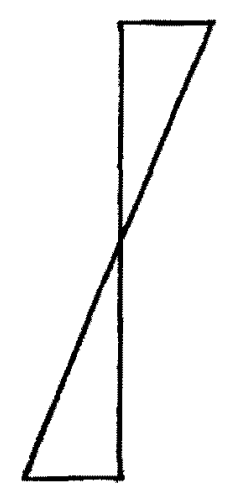

(d)

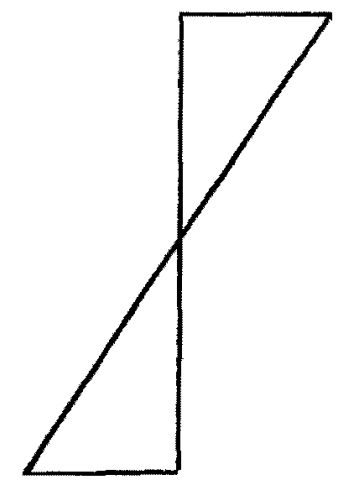

(e)
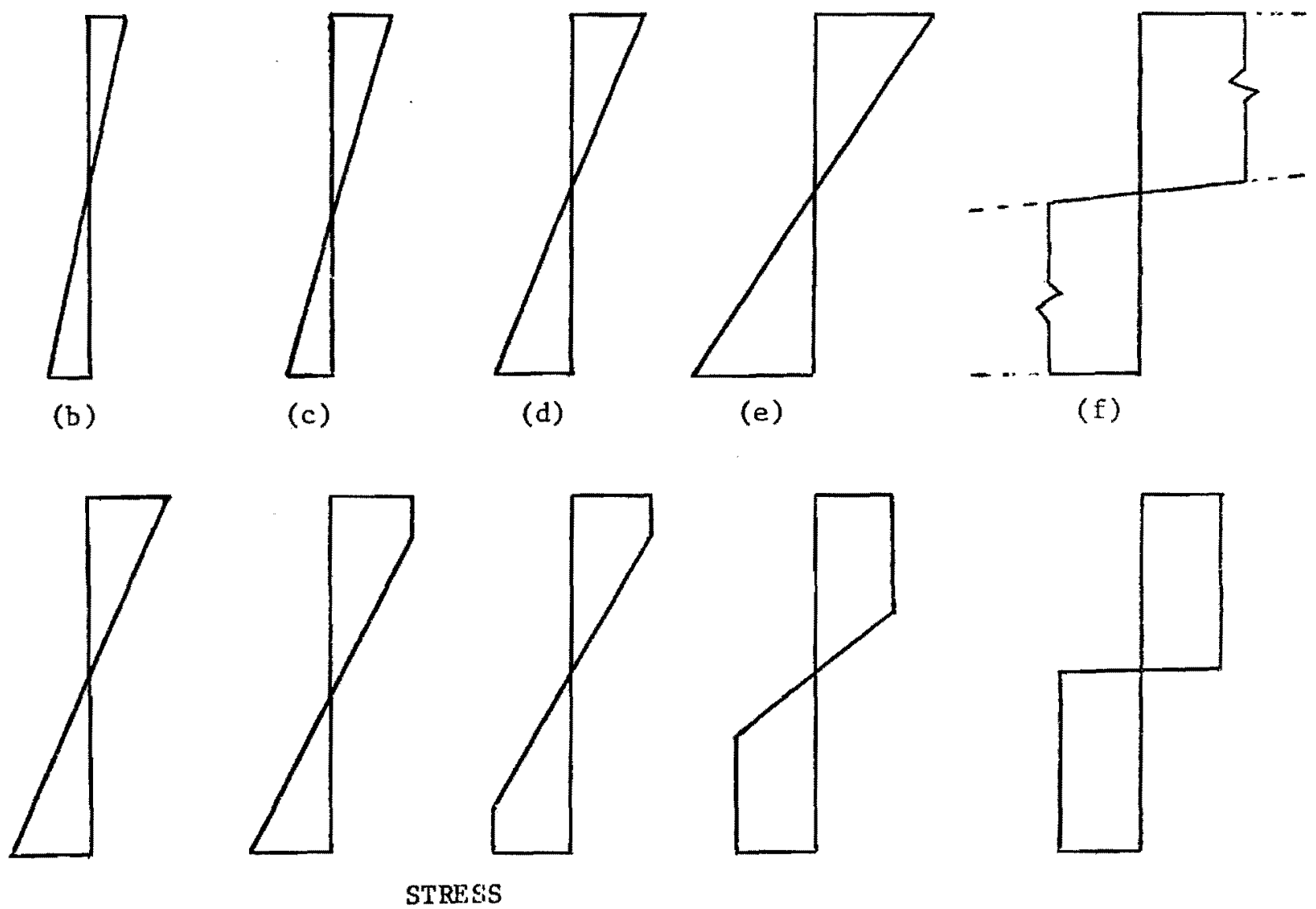

Fig. 2 Possible Strain and Stress Conditions of a Typical Wide Flange Cross Section Subject to Bending Noment. 


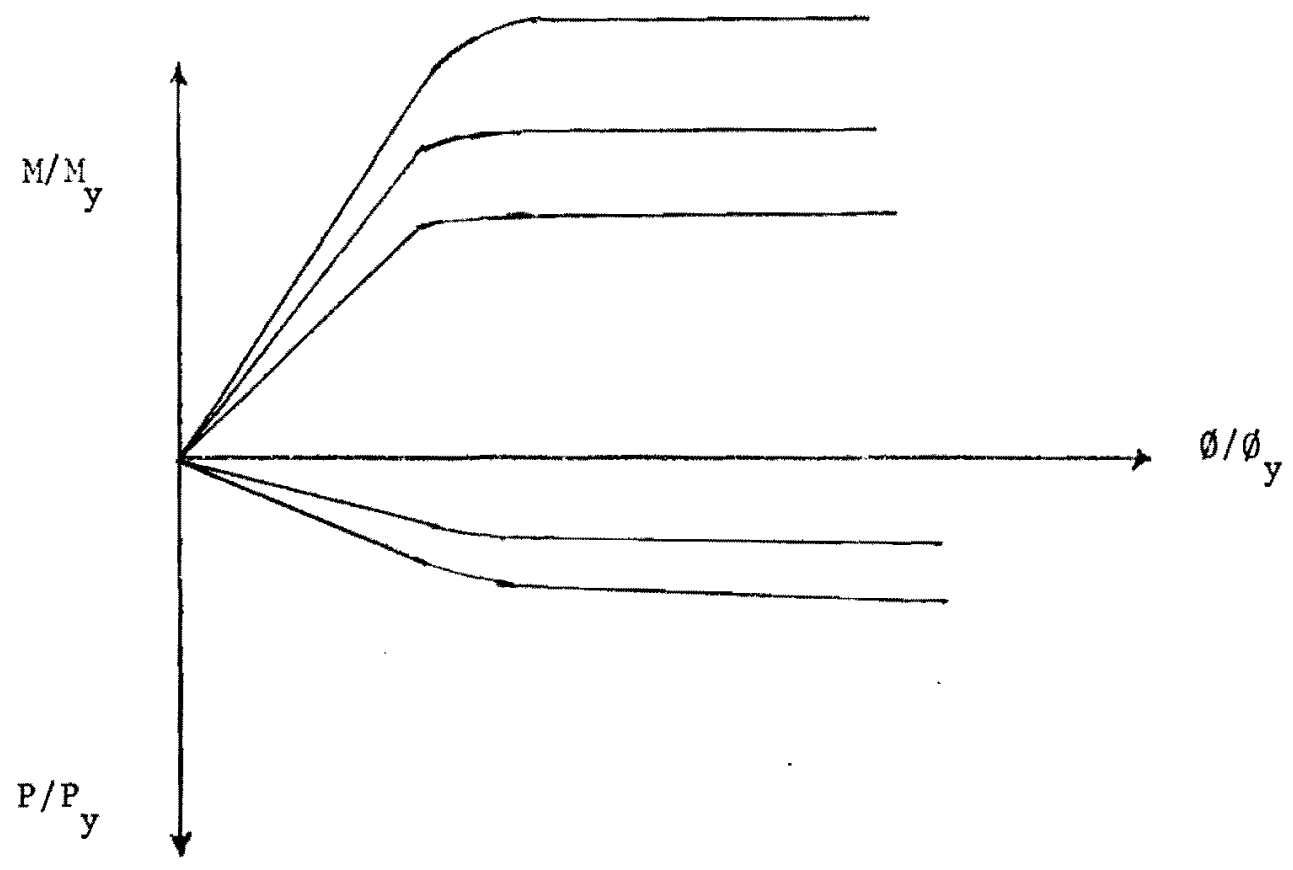

Fig. 3 Typical Auxiliary Curves.

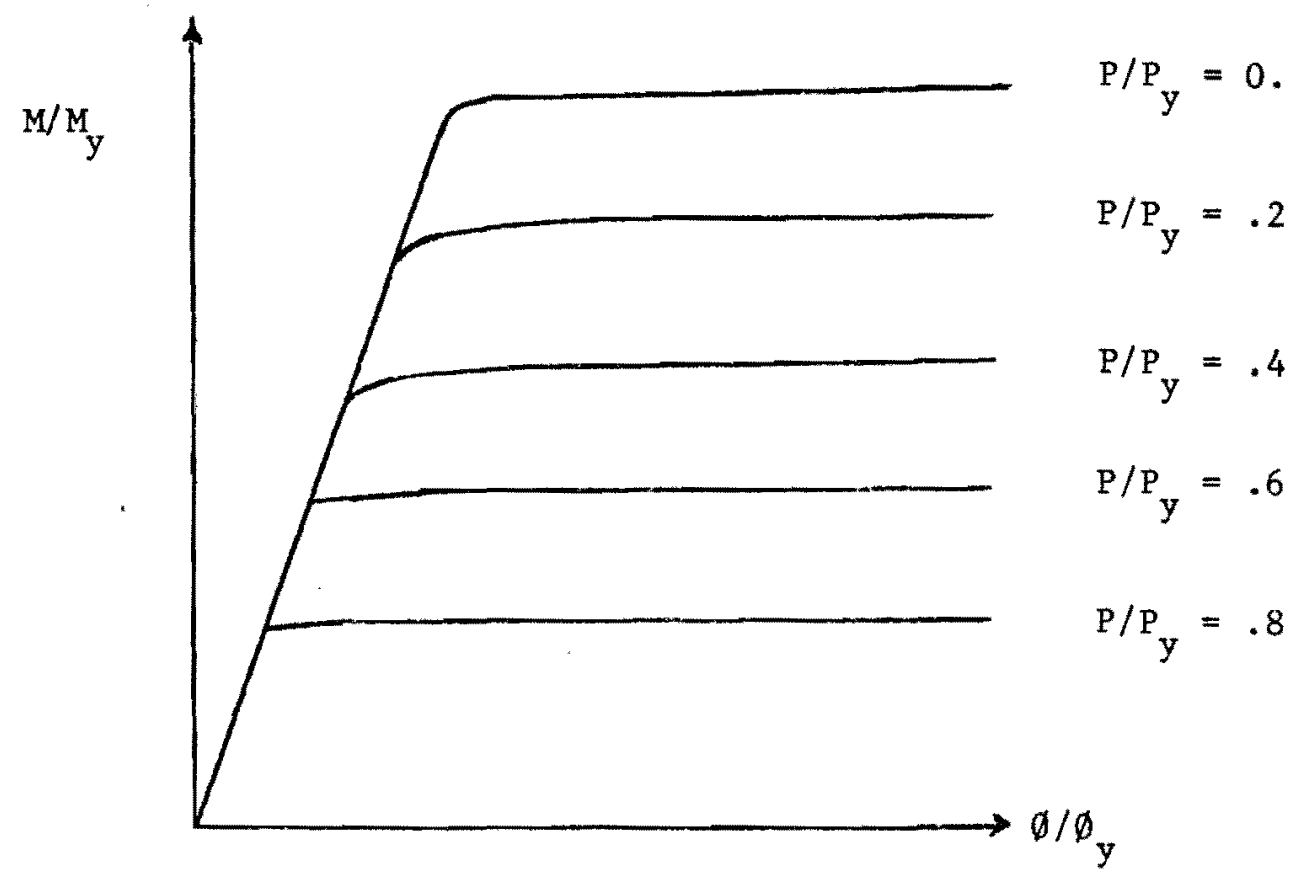

Fig. 4 Typical M- $\emptyset-\mathrm{P}$ Relationship for a Wide Flange Shape. 

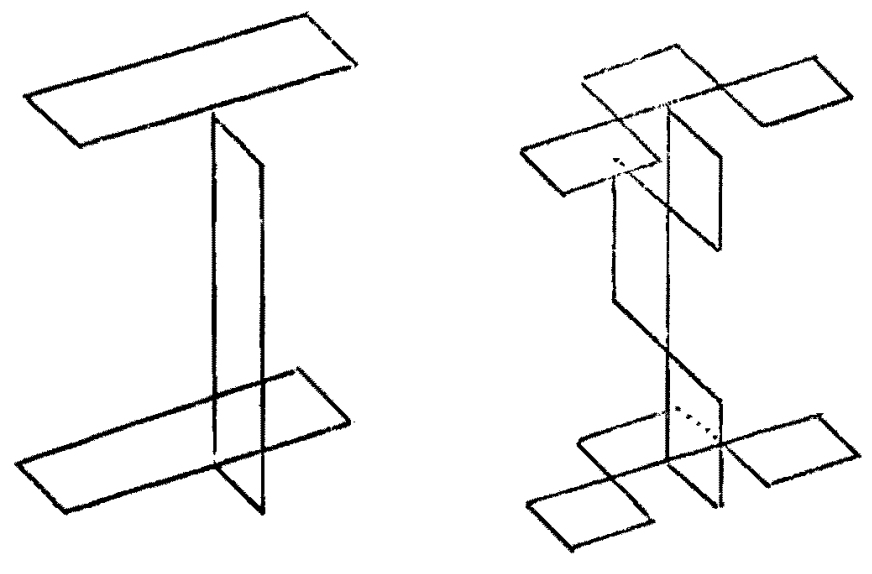

(a) Idealized Linear

Residual Stress

Patterns.

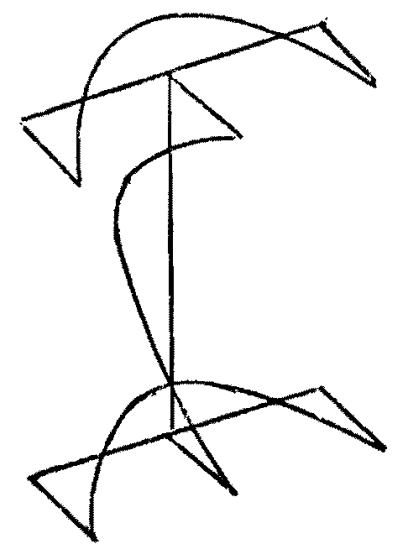

(b) Parabolic

Residual Stress

Pattern

Fig. 5 Various Types of Residual Stress Pattems.

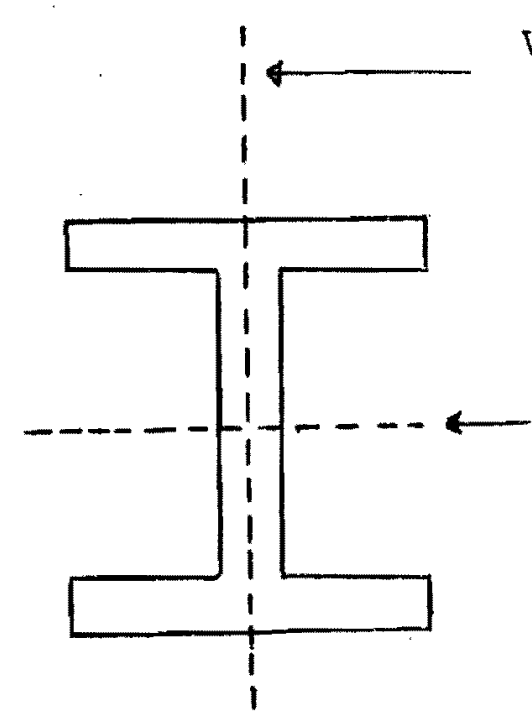

(a) Geometrically symmetric Cross Section.
VERT ICAL AXES

OF SYMMETRY

HORIZONTAL

AXES OF

SYMMETRY

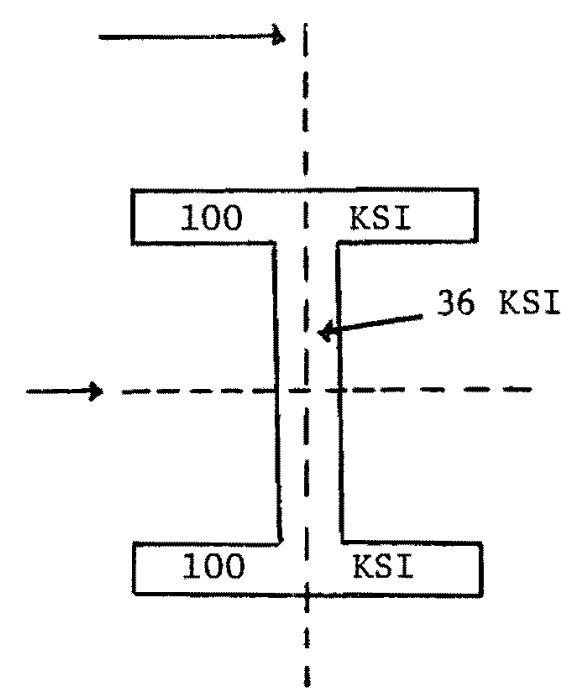

(b) Materially

Symmetric Cross Section.

Fig. 6 Horizontal and Vertical Symmetries. 

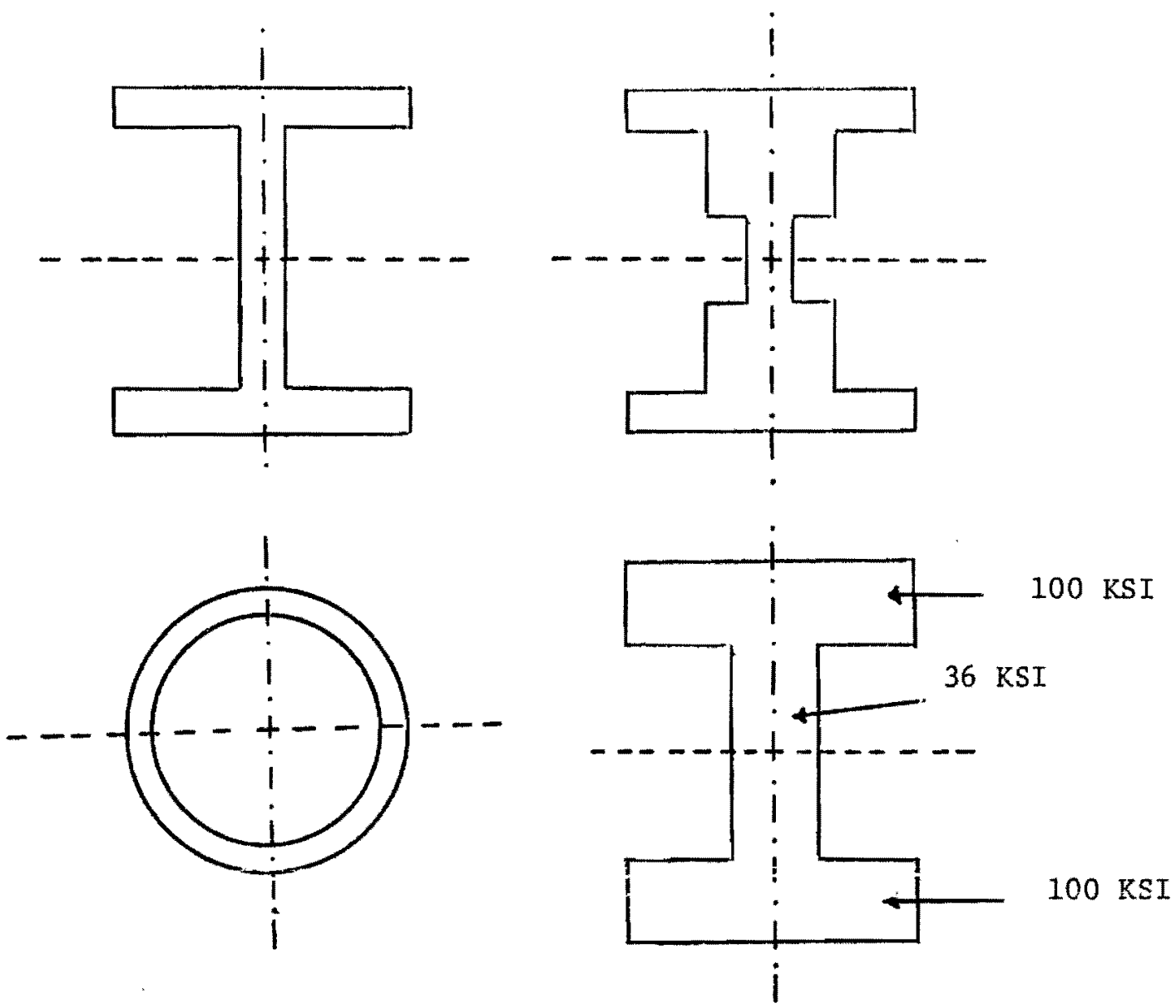

(a) Totally Symmetric Cross Sections.
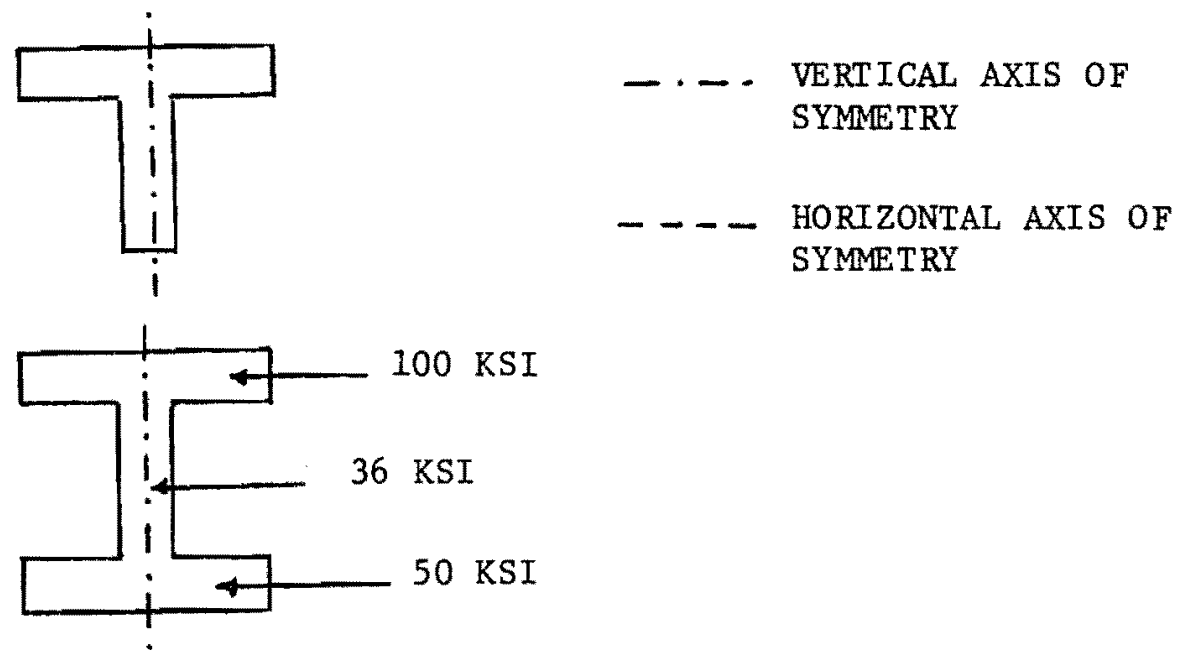

(b) Asymmetric Cross Sections.

Fig. 7 Totally Symmetric and Asymmetric Cross Sections. 


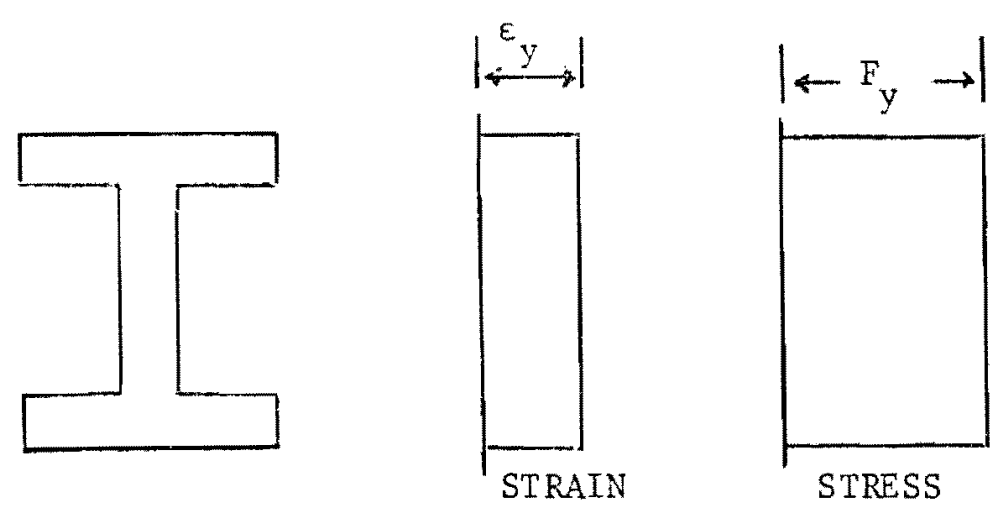

(a) Total Plastification Caused by Axial Thrust.

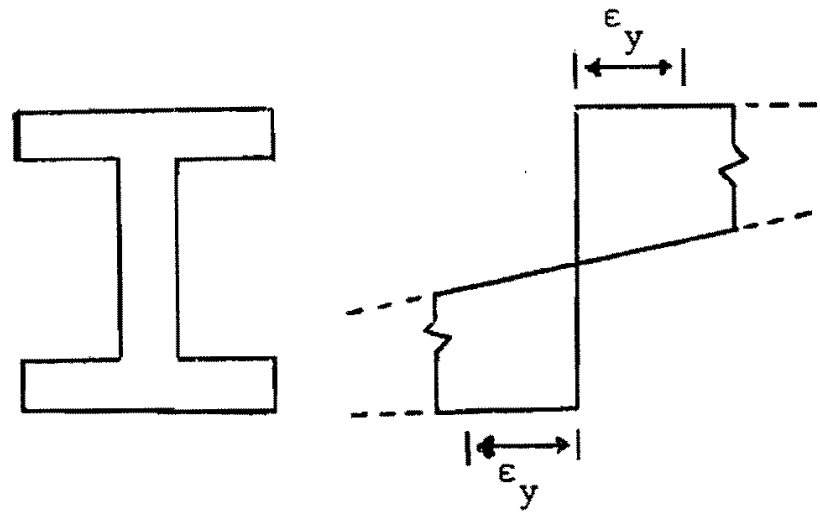

$\operatorname{STPATXi}$

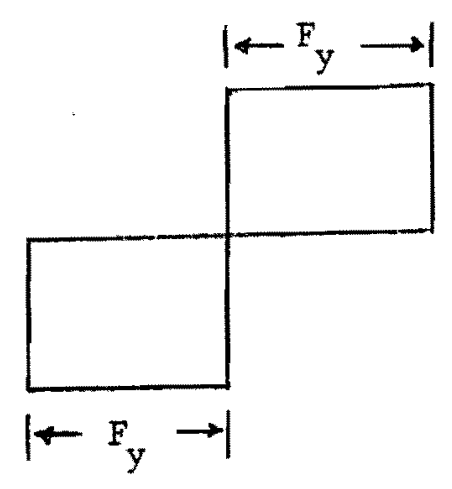

Gings

(b) Total P1astification Caused by Bending Moment.

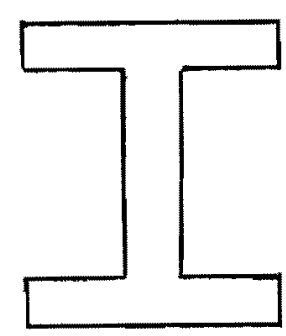

.

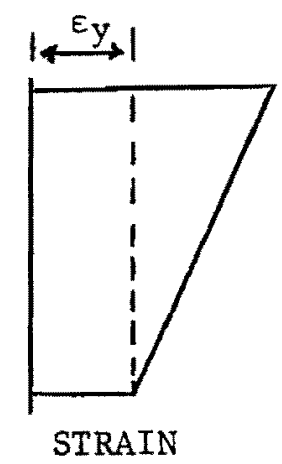

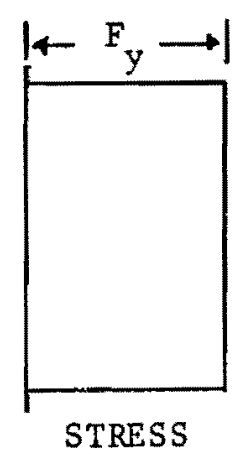

STRESS

(c) Total Plastification Caused by Bending Moment and Axial Thrust.

Fig. 8 Causes of Total Plastification. 


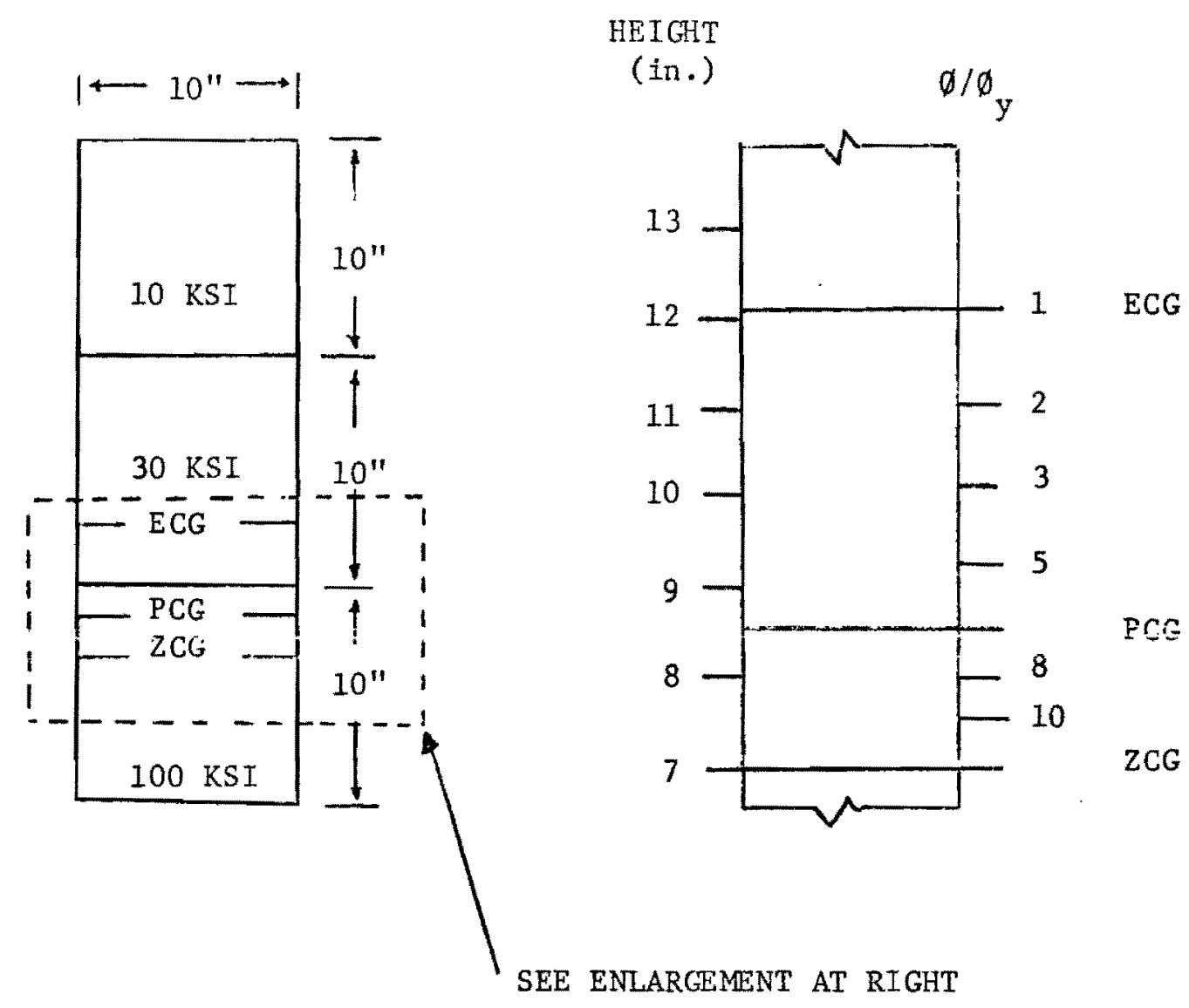

Fig. 9 Positions of the Zero Thrust Axis for Various Angles of Curvature, $\emptyset / \emptyset_{y}$. 


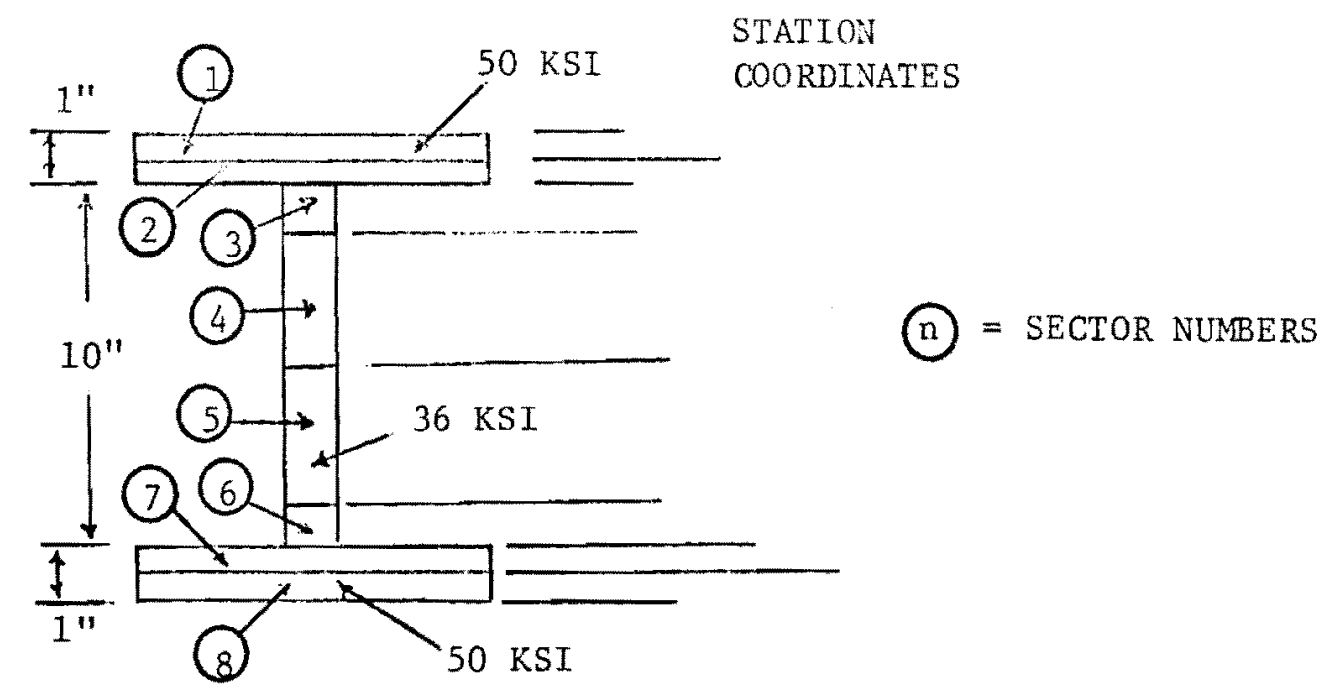

(a) Possible Required Sectors and Station Coordinates.

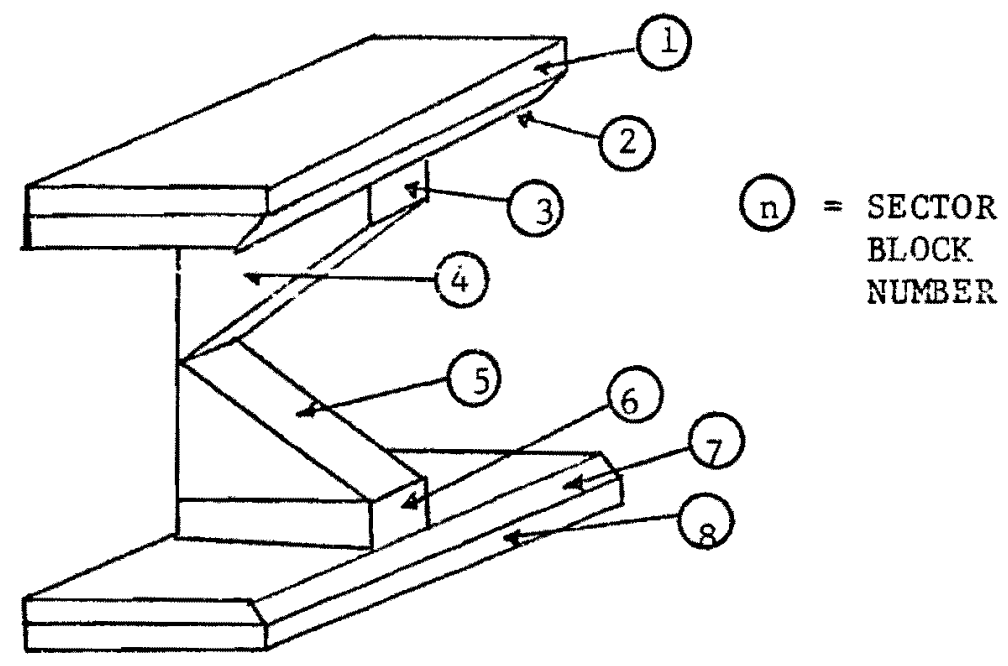

(b) Stress Block Influencing the Cross Section.

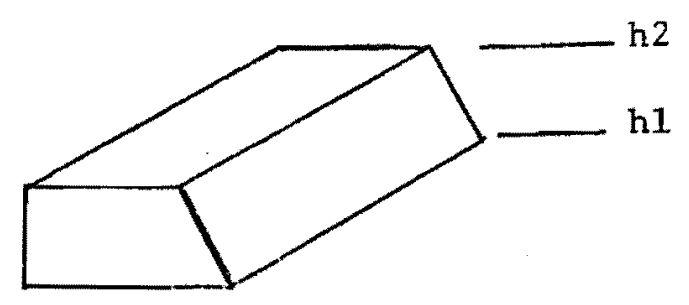

(c) Typical Finite Sector Stress Block Volume.

Fig. 10 Division of a Cross Section into Sectors. 


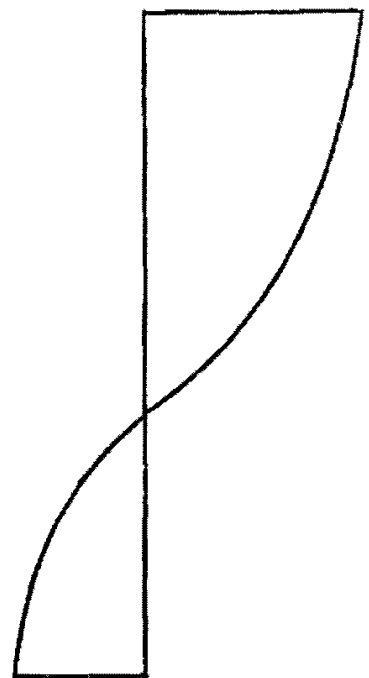

(a) True Stress Distribution.

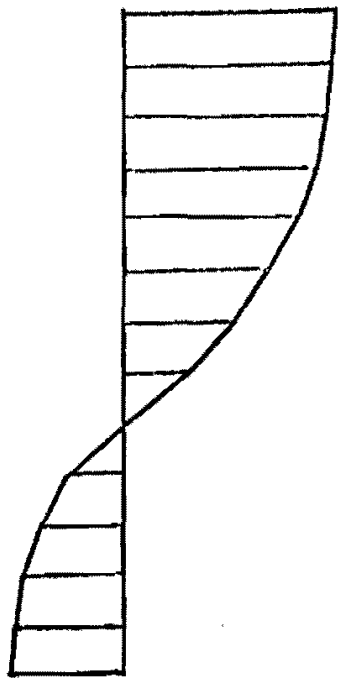

(b) Idealized Stress Distribution.

Fig. 11 Stress Distributions.

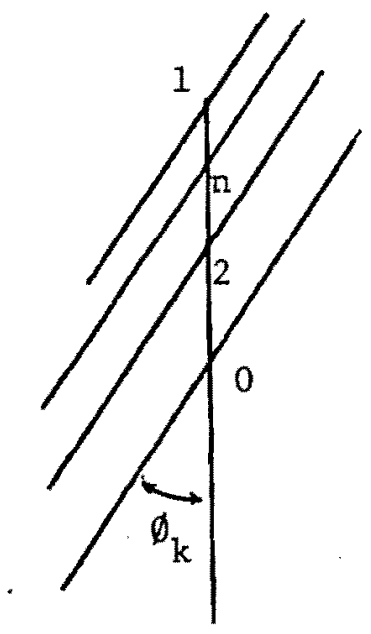

(a) Axes Positions.

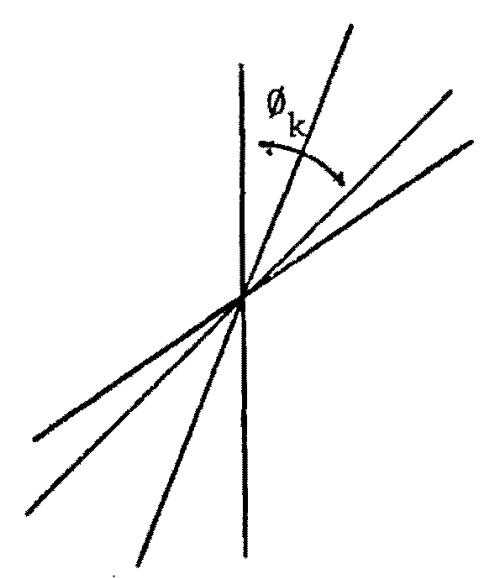

(b) Generalized Angle of Curvature, $\emptyset_{k}$.

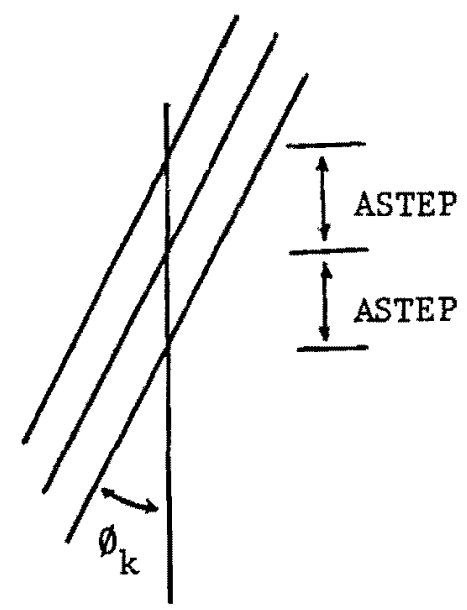

(c) Axis Increments by Determined Steps.

Fig. 12 Neutral Axes for Iteration Procedures. 


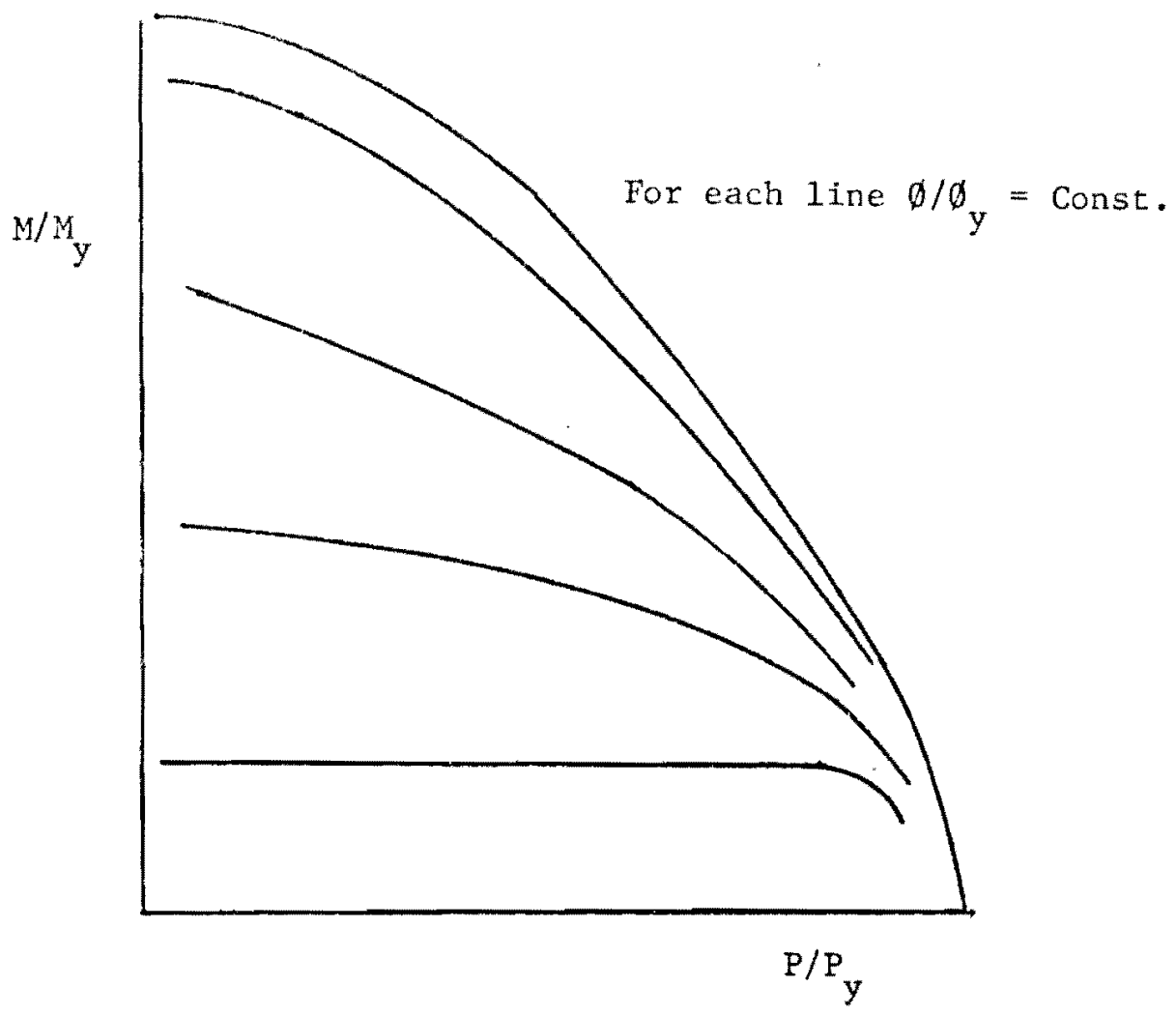

Fig. 13 Moment-Thrust Diagrams for Constant Angles of Cirvature,

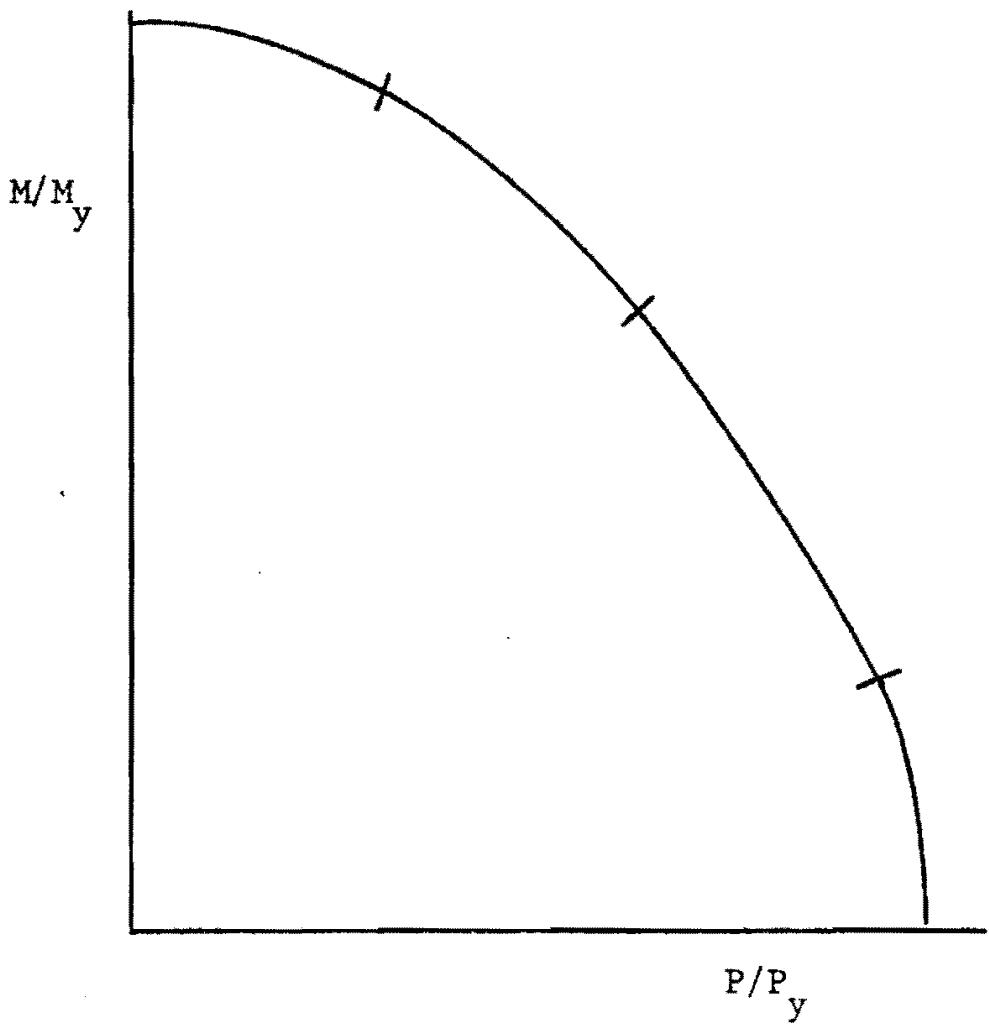

Fig. 14 Ranges of Applicability of Certain Estimation Functions. 


\section{SECTION PARAMETERS}

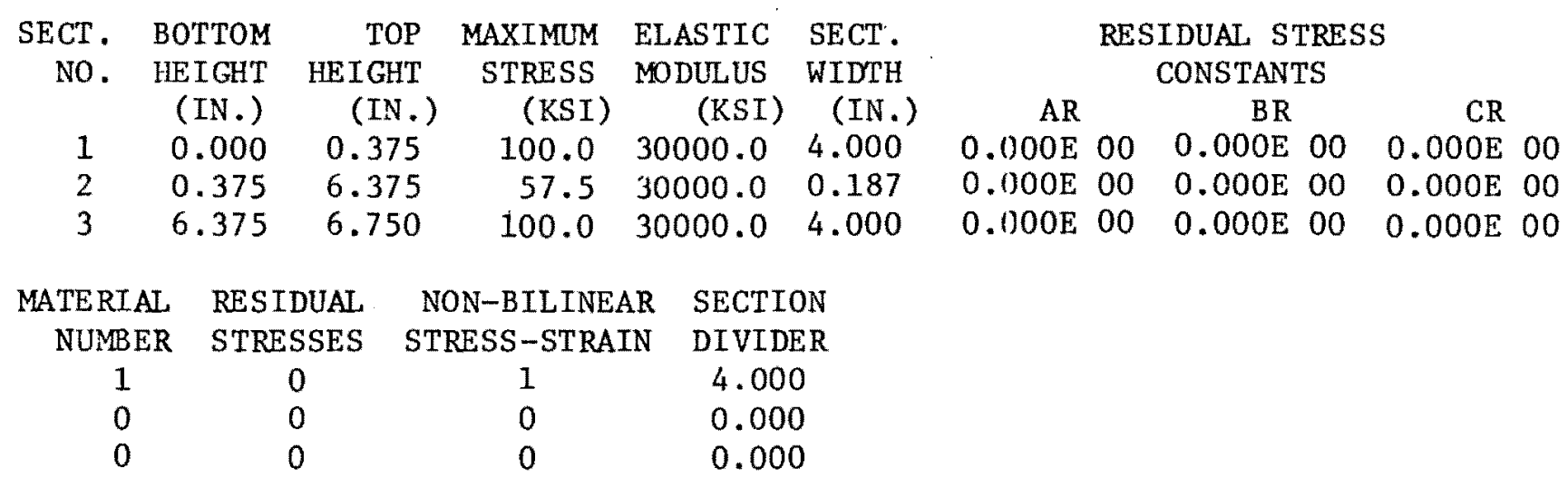

NONBILINEAR STRESS-STRAIN FUNCTIONS

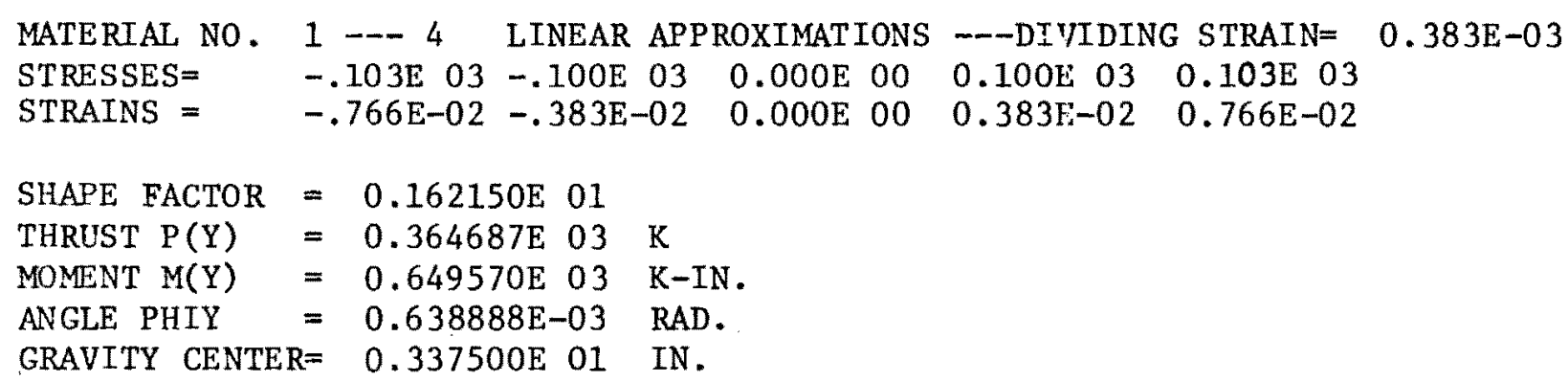

\begin{tabular}{|c|c|c|c|c|c|c|}
\hline & $M / M(Y) \quad F O R$ & $M / M(Y) \quad F O R$ & $M / M(Y)$ FOR & $\mathrm{M} / \mathrm{M}(\mathrm{Y}) \quad \mathrm{FOR}$ & $M / M(Y) \quad F O R$ & $M / M(Y) \quad F O R$ \\
\hline $\mathrm{PHI} / \mathrm{PHI}(\mathrm{Y})$ & $\mathrm{P} / \mathrm{P}(\mathrm{Y})=0$ & $P / P(Y)=.2$ & $P / P(Y)=.4$ & $P / P(Y)=.6$ & $P / P(Y)=.8$ & $P / P(Y)=1.0$ \\
\hline 1.000 & 1.6476 & 1.5015 & 1.1367 & 0.8133 & 0.4712 & 0.0000 \\
\hline 1.250 & 1.7067 & 1.5128 & 1.1718 & (1. 8218 & 0.4732 & 0.0000 \\
\hline 1.500 & 1.7167 & 1.5254 & 1.1738 & 0.8276 & 0.4809 & 0.0000 \\
\hline
\end{tabular}

Fig. 15 General Printout Format. 


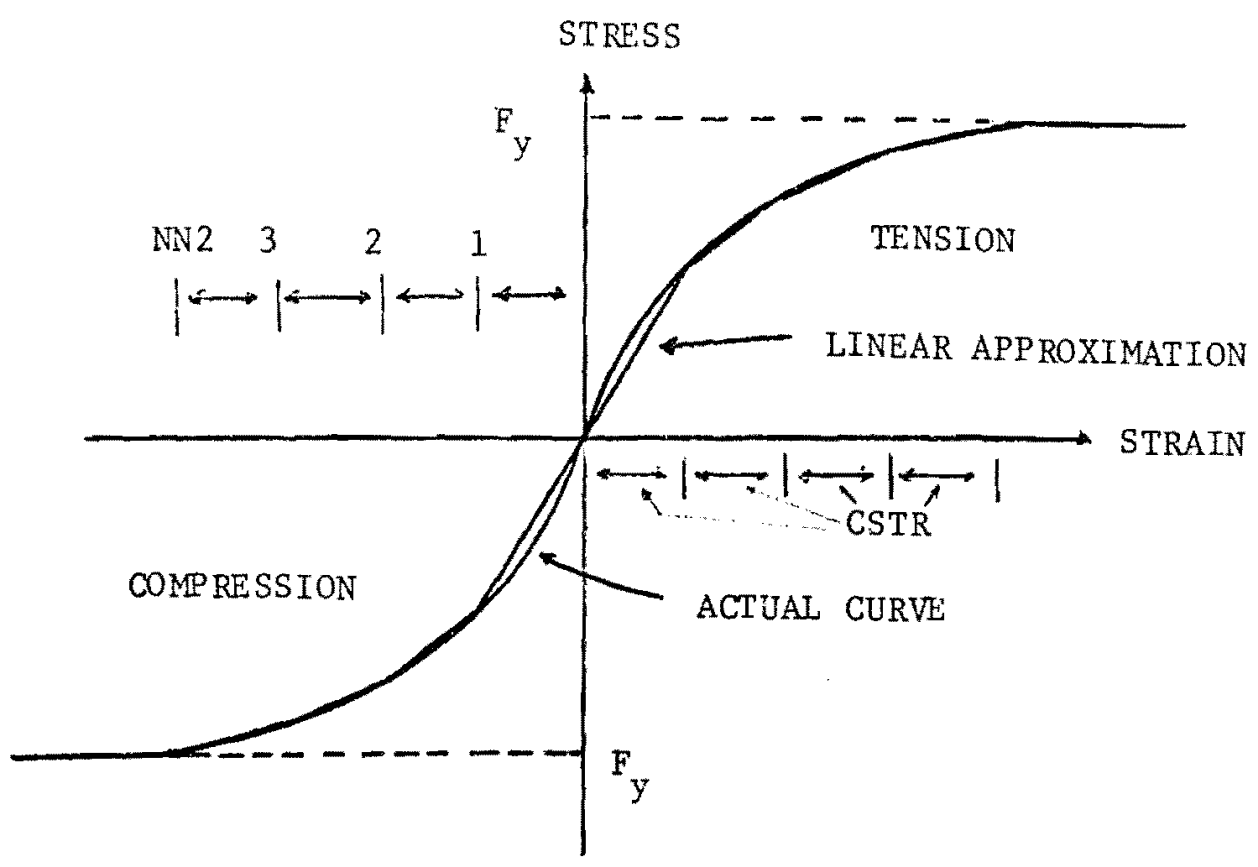

Fig. 16 Nonbilinear Stress-Strain Approximations.

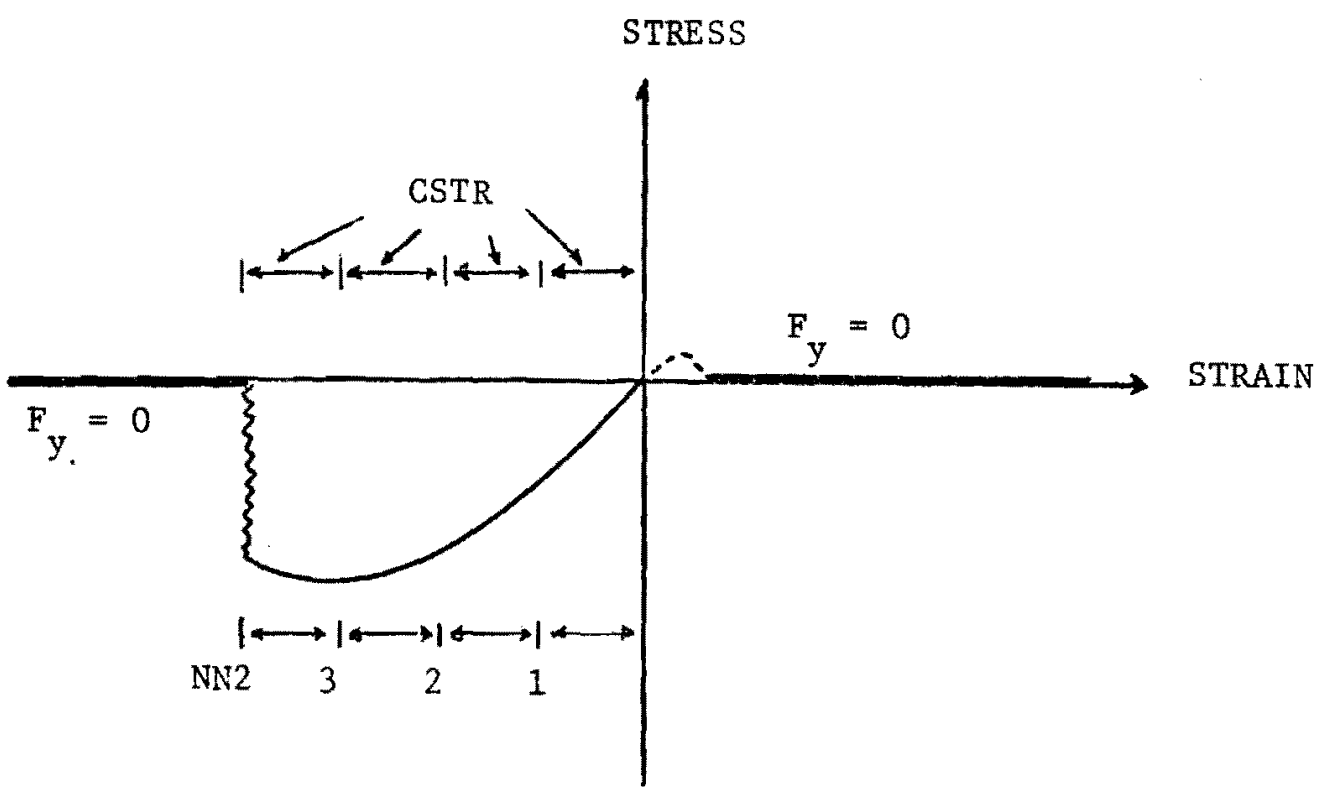

Fig. 17 Stress-Strain Approximation for Concrete. 


\begin{tabular}{|c|c|c|c|}
\hline \multicolumn{4}{|c|}{ SHADE HALDB: $=0.11005 \% 01$} \\
\hline $\operatorname{lig}_{x}+5(x)$ & $=0.323$ & 15103 & \\
\hline$\therefore \rightarrow \pm v 1(y)$ & 0.9719 & 503 & \\
\hline 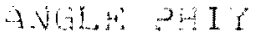 & $0.300:$ & $19-13$ & . \\
\hline 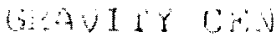 & (1) 4001 & $11: 01$ & \\
\hline & $4 /(Y)+j$ & $4 /(Y) \quad(1)$ & $y(x)+Y)=$ \\
\hline $\operatorname{PSI}: \ln (Y)$ & $\beta / Y(Y)=0$ & $P / P(Y)=.2$ & $P(x(Y)=4$ \\
\hline 0.250 & 0.2449 & 0.2449 & 0.2449 \\
\hline 0.500 & 0.4999 & $9 \cdot 4999$ & $(1.4994$ \\
\hline 0.750 & 0.7500 & 0.7323 & 0.6594 \\
\hline $1 \cdot 01) 0$ & $1 \cdot 11000$ & 1.8799 & 0.6938 \\
\hline $2 \cdot 000$ & 1.0903 & 0.948 & $0 \cdot 7364$ \\
\hline $3 \cdot 000$ & $1 \cdot 100 ?$ & 0.9870 & 0.7172 \\
\hline 4.000 & 1.1030 & 9.9943 & 0.7517 \\
\hline 5.000 & $1 \cdot 10193$ & $0.998:$ & $0.75 / 1$ \\
\hline & $A / A(Y)$ FUn & $\because(1(Y)$ fOll & $M / M(Y) F(38$ \\
\hline DIYIIS & $p / p(y)=.6$ & $p / p(y)=.8$ & $P / P(Y)=1 \cdot 0$ \\
\hline $0 \cdot 250$ & (1) .2199 & 0.2202 & 0.0000 \\
\hline 0.500 & 0.1101 & $0 \cdot 2 / 12$ & 0.0000 \\
\hline 0.750 & 0.4695 & 0.2467 & 0.0000 \\
\hline $1 \cdot 0110$ & 0.1324 & $0 \cdot 2 / 190$ & 0.0000 \\
\hline 2.000 & 0.4981 & 0.9519 & 0.0000 \\
\hline $3 \cdot 000$ & 0.5020 & 0.2529 & 0.0000 \\
\hline 4.0011 & 0.5038 & 0.2535 & 0.0000 \\
\hline $5 \cdot 000$ & 0.5050 & $0 \cdot 2541$ & 0.0000 \\
\hline
\end{tabular}

Fig. 18 Data for a W $8 \times 31$ 


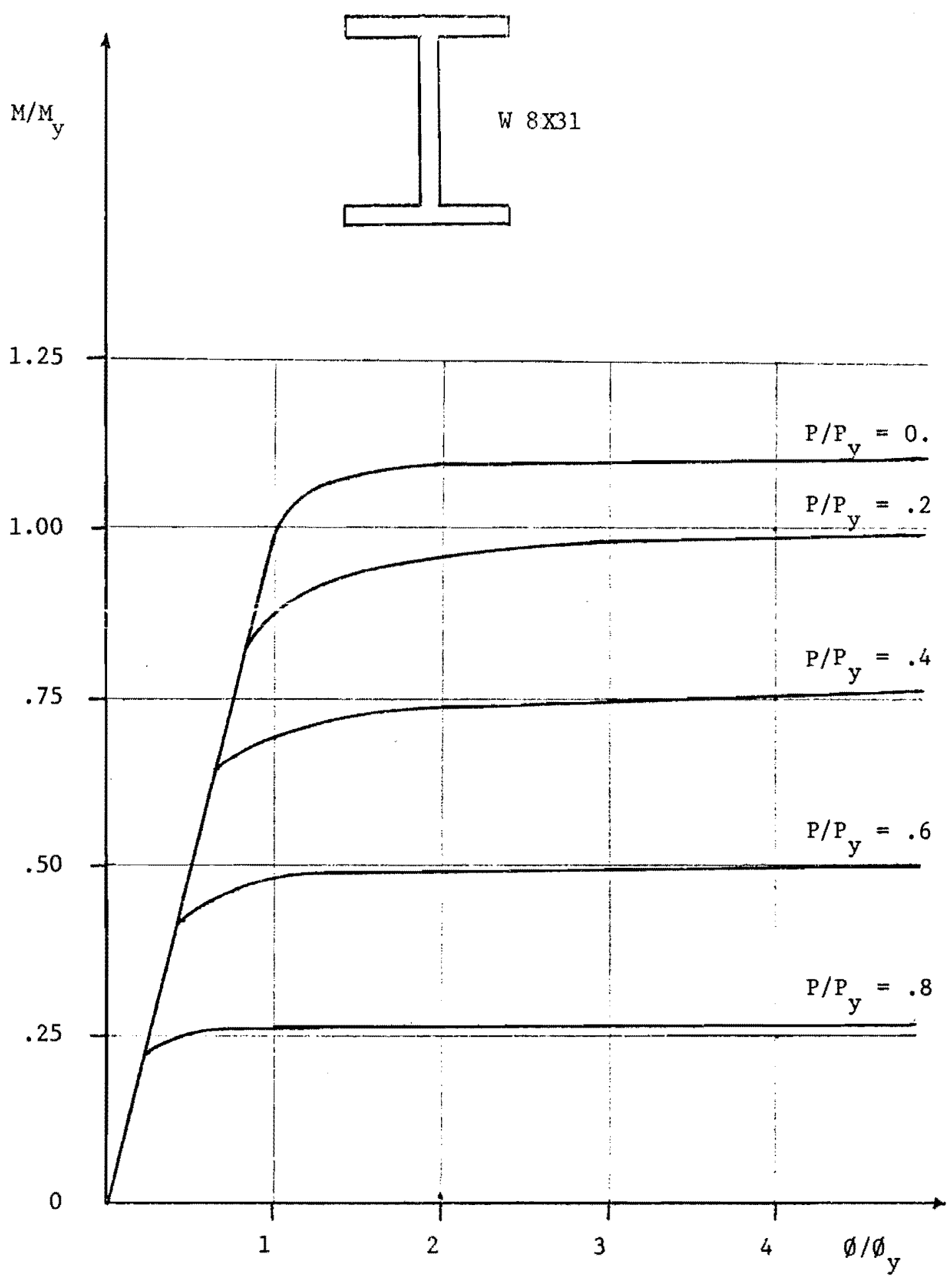

Fig. 19 M-Q-P Diagram for a W $8 \times 31$. 


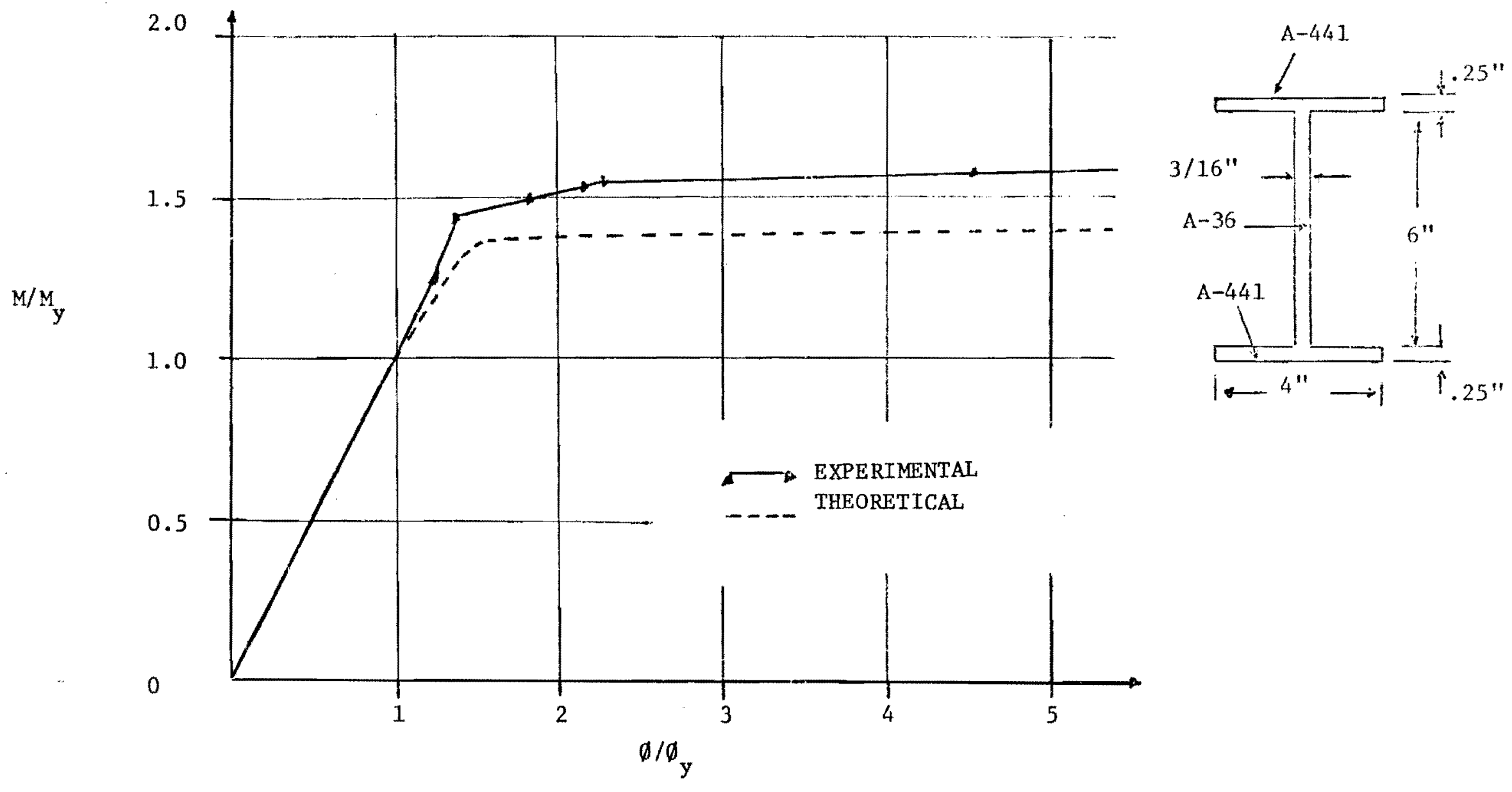

Fig. 20 Experimental and Theoretical M-1D Relationships for Cross Section T1. 


\begin{tabular}{|c|c|c|c|c|}
\hline SHAPE FACTO & 0.1397 & $04 \mathrm{E} 01$ & & \\
\hline THBUSH $p(Y)$ & 0.160 & 30103 & r & \\
\hline YUSENT Y $(Y)$ & 0.3055 & $5.5 E \quad 03$ & $k-1$ & \\
\hline ANGL PHIY & 0.4444 & $44 x-03$ & I.AD. & \\
\hline AIAVIIY CE & 0.325 & 30101 & IN. & \\
\hline & $y / x(y)$ Fuls & $\because / Y(Y)$ & $F_{i} J_{i j}$ & HAY Y Y Y \\
\hline$H I / P I I(Y)$ & $P / i^{\prime}(Y)=0$ & $P(P(Y)=$ & $=\cdot 3$ & $P / P(Y)=.4$ \\
\hline 0.250 & 0.2500 & $0 \cdot 2$ & 199 & 0.8499 \\
\hline 0.500 & 0.5000 & 0.51 & 000 & $0.1: 998$ \\
\hline 0.750 & 0.7500 & 0.74 & 499 & 0.7398 \\
\hline 1.000 & 1.0000 & 0.9 & 343 & 0.8759 \\
\hline $1 \cdot 500$ & 1.3643 & $1 \cdot 1 \%$ & 112 & 0.9216 \\
\hline 2.000 & 1.3786 & $1 \cdot 21$ & 72 & 0.9489 \\
\hline 3.000 & 1.3888 & $1 \cdot 20$ & 320 & $0.901 \%$ \\
\hline 4.000 & 1.3924 & 1.27 & 7811 & 0.9699 \\
\hline 5.000 & $1 \cdot 3941$ & $1 \cdot 2$ & $\{1:$ & 0.9741 \\
\hline & Whor fol. & $M /: 1(Y)$ & FUI: & $M / Y(Y)$ Fot \\
\hline$I I / P I I(Y)$ & $P / P(Y)=.6$ & $P / P(Y)=$ & $=.8$ & $P / P(Y)=0$ \\
\hline $0 \cdot 250$ & 0.2498 & 0.28 & 240 & 0.0000 \\
\hline 0.500 & 0.4853 & $0 \cdot 3=$ & 228 & 0.0000 \\
\hline 0.750 & 0.6090 & D $\cdot 3 t$ & 351 & 0.0000 \\
\hline 1.000 & 0.6245 & 0.38 & 361 & 0.0000 \\
\hline 1.500 & 0.5387 & 0.36 & 269 & 0.0000 \\
\hline 2.000 & 0.6449 & 0.38 & 373 & 0.0000 \\
\hline 3.000 & 0.6502 & 0.38 & 278 & 0.0000 \\
\hline $4 \cdot 000$ & 0.6525 & $0 \cdot 3$ & 281 & 0.0000 \\
\hline $5 \cdot 000$ & 0.6583 & 0.36 & 83 & 0.0000 \\
\hline
\end{tabular}

Fig. 21 Data Printout for Cross Section T1. 


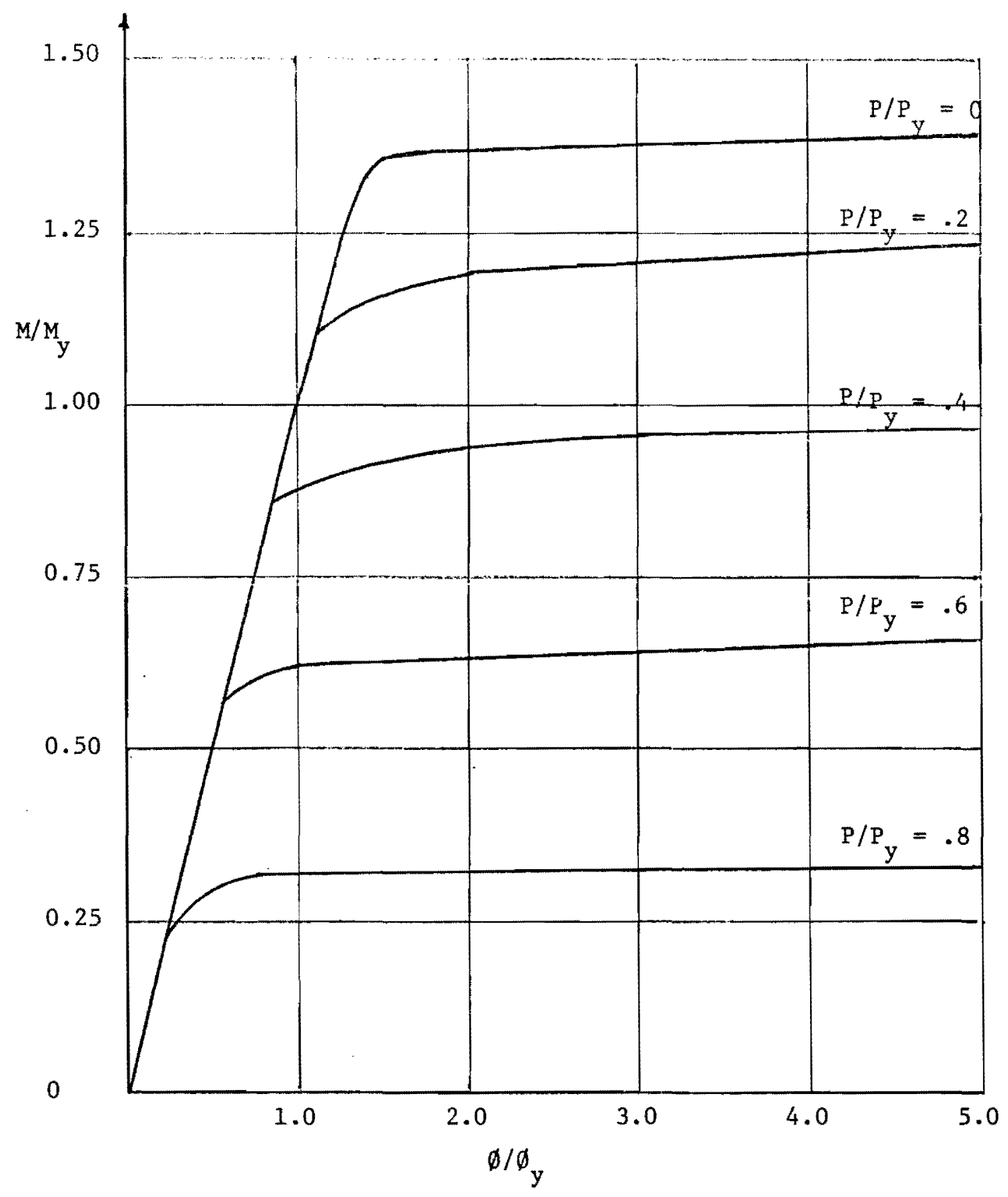

Fig. 22 M- $\emptyset-\mathrm{P}$ Diagram for Cross Section TI. 


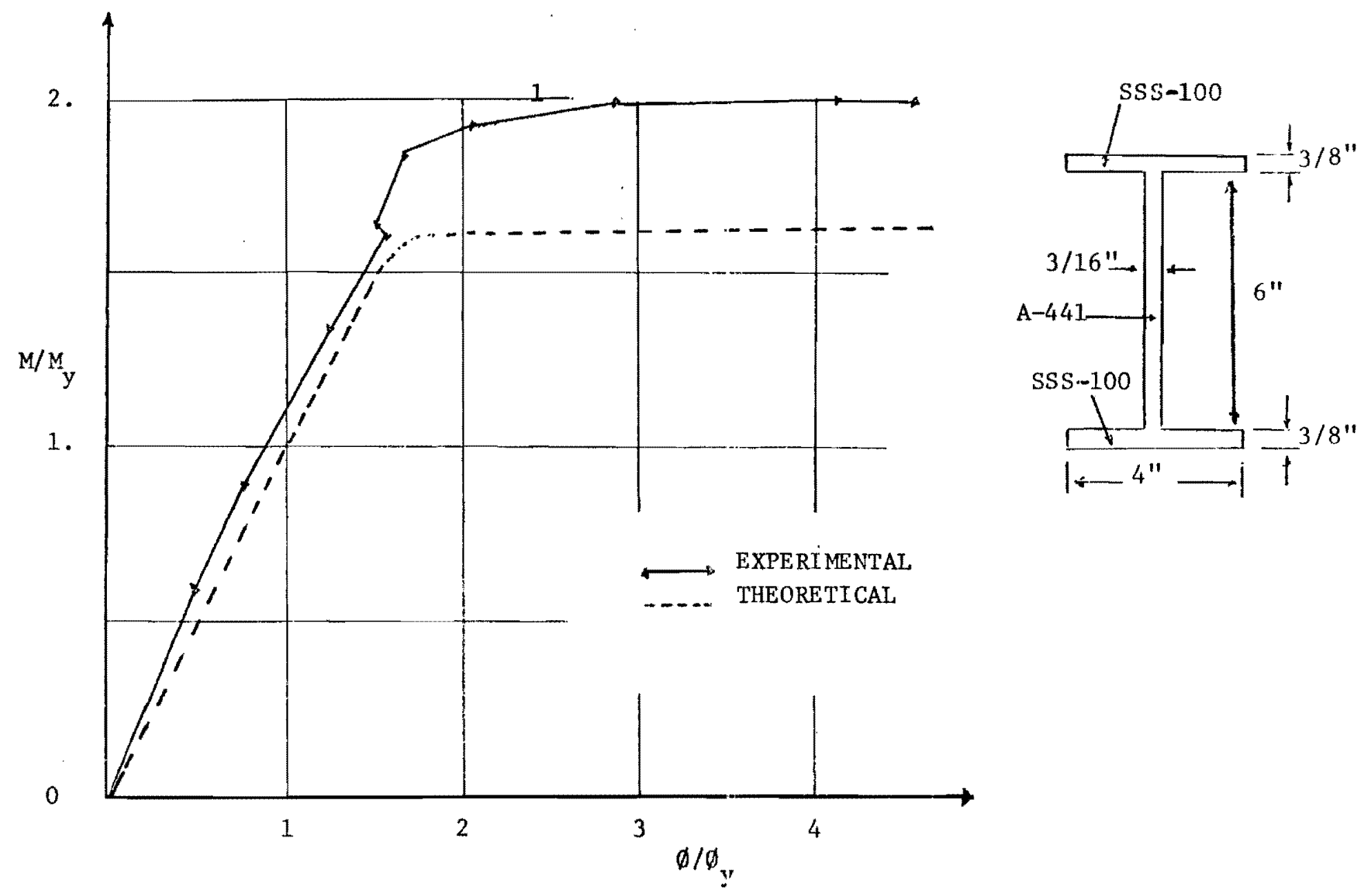

Fig. 23 Experimental and Theoretical $M-\emptyset$ Relationships for Cross Section T2. 


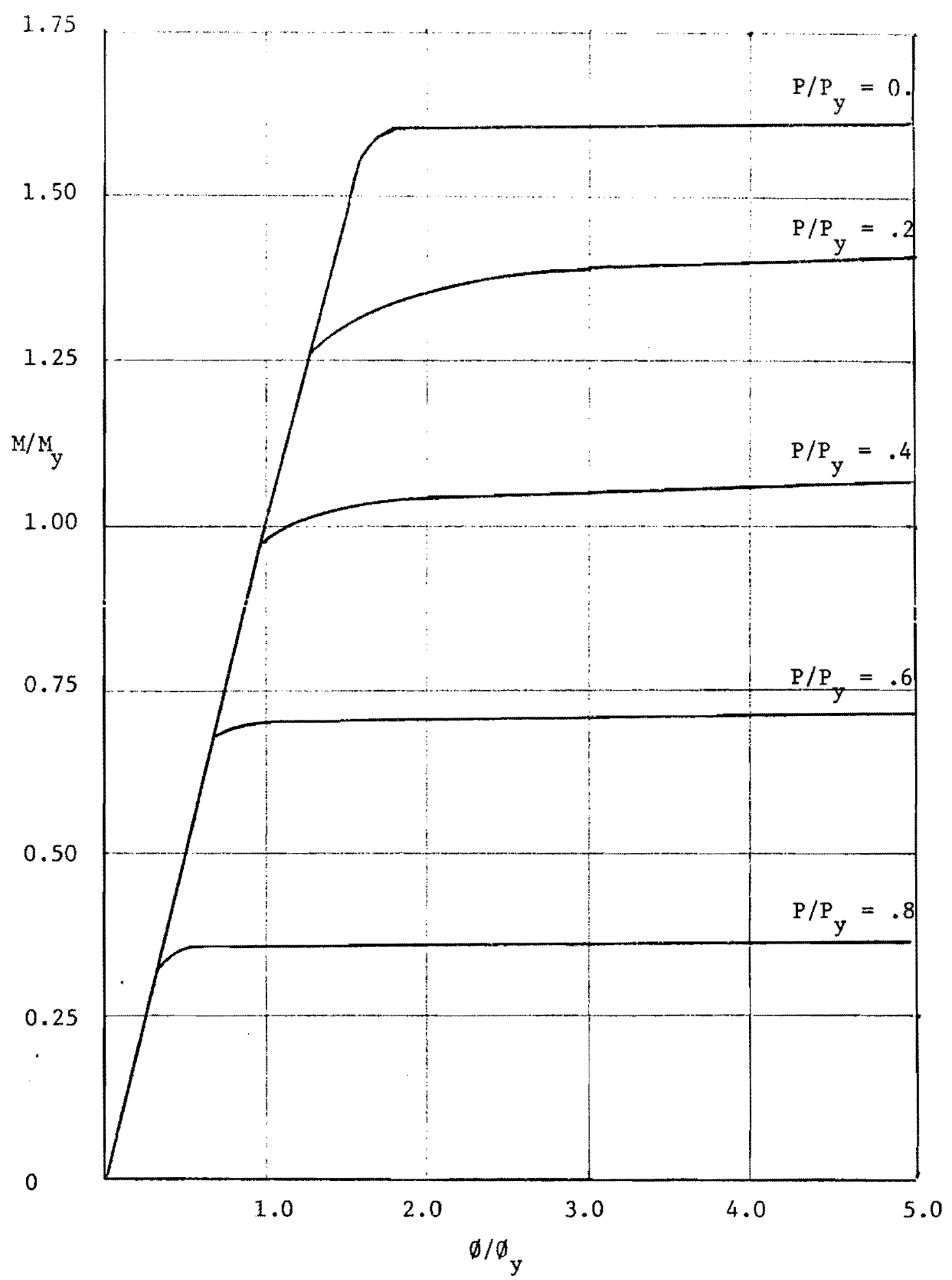

Fig. $24 M-\emptyset-P$ Diagram for Cross Section T2. 


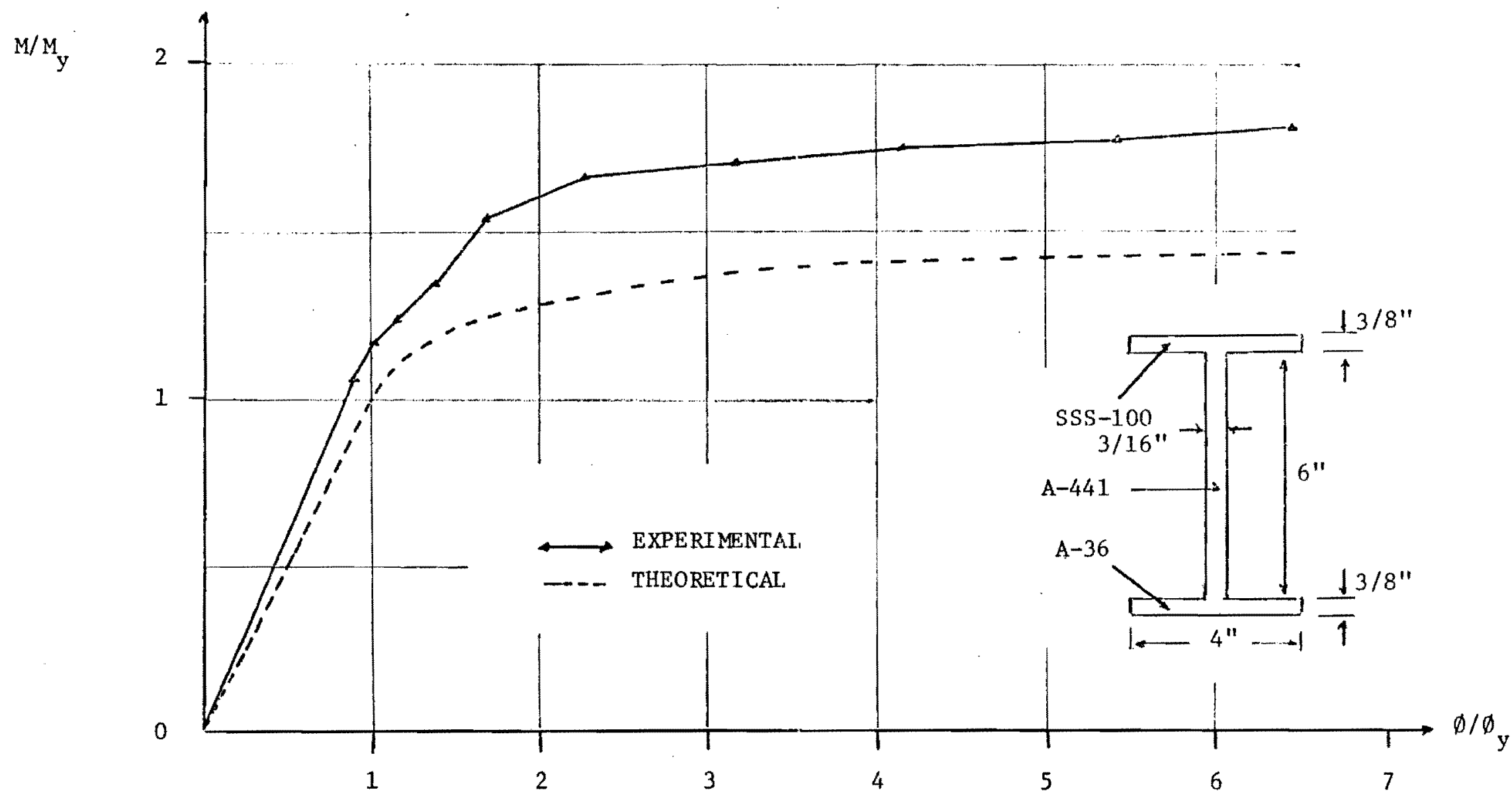

Fig. 25 Experimental and Theoretical M- $\ell$ Relationships for cross section $T 3$. 

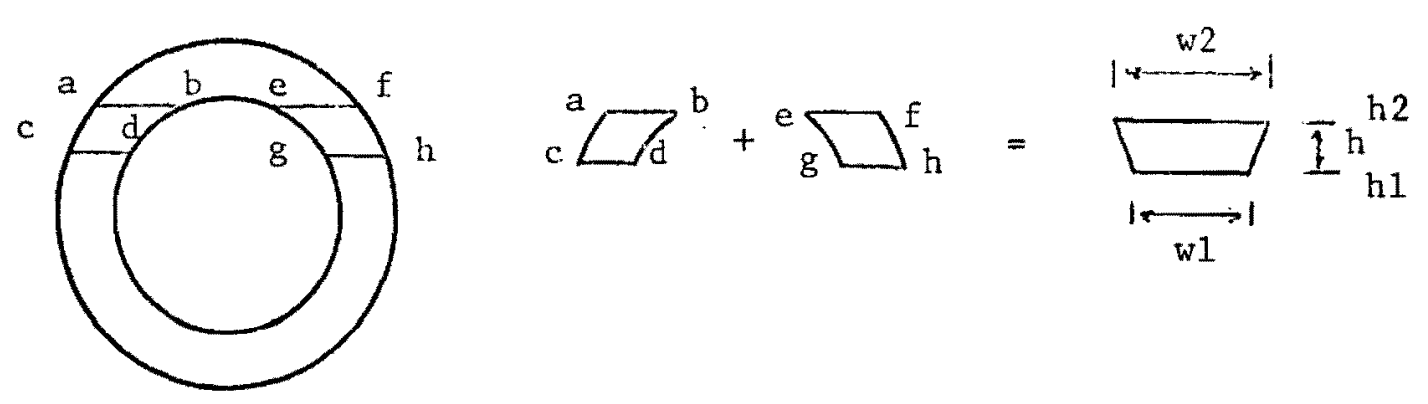

(a) Circular Sector Formation.

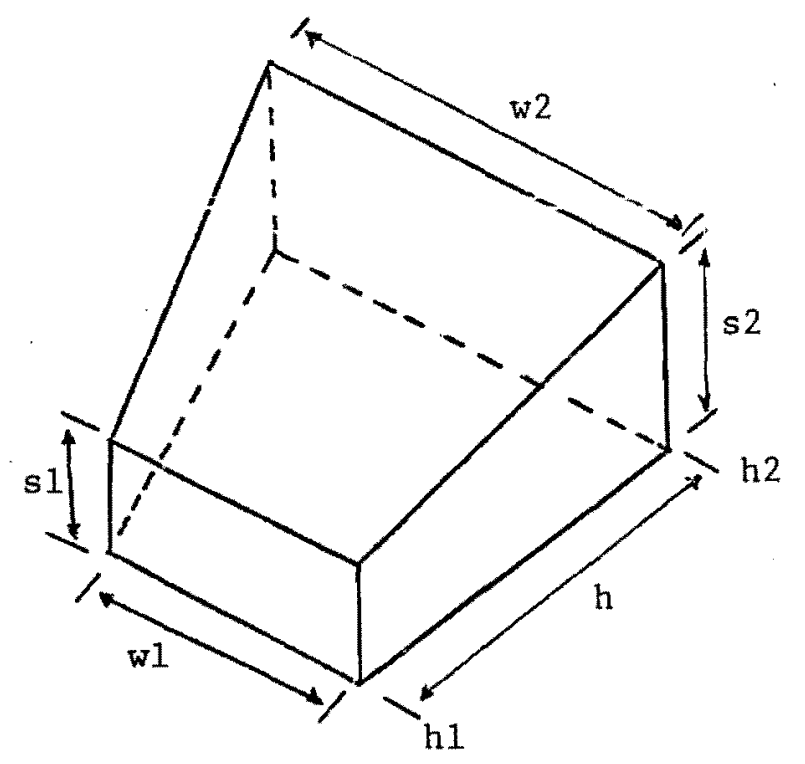

(b) Generalized Stress Block Volume.

Fig. 26 Variations for Circular Tubes. 
STEUCHUAL TUBE WUMUT-CUEVTUH-TEPUST DARA

\begin{tabular}{|c|c|c|c|}
\hline OULEL CAUIO. & $=$ & $0.700000 \mathrm{E} 01$ & IN. \\
\hline I:VOE: :ADIU & $=$ & $0.550000 \mathrm{E} 01$ & In. \\
\hline YIELD) (MAKIM & m)STRESS = & $0.360000 E 02$ & $K S I$ \\
\hline MODUL.US OF & CLASTICITY $=$ & $0.300000 \mathrm{E} 05$ & $K S I$ \\
\hline SHOTOH GEIG & $=$ & $0.400000 \mathrm{E} \quad 00$ & IV $\bullet$ \\
\hline SHAPE FACTU & $=$ & $0.131918 E 01$ & \\
\hline WTAIN AXIS & INCWENENT = & 0.107592401 & $I N$. \\
\hline HBOSI P(Y) & $=$ & $0.763406 E \quad 03$ & $\mathrm{~K}$ \\
\hline WUVENT M(Y) & $=$ & $0.2487885 \quad 04$ & $K-I N$. \\
\hline NGLE PHICY & $=$ & $0.1711284-03$ & PaD. \\
\hline & $M / M(Y)$ Ho: & $Y_{H} / X_{A}(Y) \quad F O: Z$ & HA $Y$ XOF \\
\hline DEI I $>\mathrm{SH}(\mathrm{Y})$ & $P / P(Y)=0$ & $P / P(Y)=\cdot 2$ & $P / P(Y)=.4$ \\
\hline 0.250 & 0.8 .489 & 0.8478 & 0.2467 \\
\hline 0.500 & 0.4978 & 0.4967 & 0.4967 \\
\hline 0.750 & 0.7467 & 0.7460 & 0.7080 \\
\hline 1.000 & 0.9956 & 0.9451 & 0.83111 \\
\hline 2.000 & 1.2563 & 1.1861 & $0.980 \%$ \\
\hline 3.000 & 1.9913 & 1.2239 & 1.0292 \\
\hline 4.000 & 1.3032 & 1.2365 & 1.0449 \\
\hline 5.000 & 1.3080 & 1.2423 & 1.0530 \\
\hline & $H / Y)$ FUI & $\because / U(Y)$ FOE & $W / Y(Y)$ FOR \\
\hline II P PII (Y) & $P / P(Y)=\cdot 6$ & $P / P(Y)=.8$ & $p / P(Y)=1 \cdot 0$ \\
\hline 0.250 & 0.2455 & 0.2318 & 0.0000 \\
\hline 0.500 & $0.46,96$ & 0.3037 & 0.0000 \\
\hline 0.750 & 0.5627 & 0.3301 & 0.0000 \\
\hline 1.000 & 0.6112 & 0.3446 & 0.0000 \\
\hline 8.000 & 0.6924 & 0.3696 & 0.0000 \\
\hline 3.000 & 0.7260 & 0.3802 & 0.0000 \\
\hline 4.000 & 0.7423 & 0.3853 & 0.0000 \\
\hline 5.0000 & 0.7536 & 0.3894 & 0.0000 \\
\hline
\end{tabular}

Fig. 27 M- $\emptyset-P$ Data for a 14.0 in. 0.D., .5 in. Wall Thickness Standard Tube. 


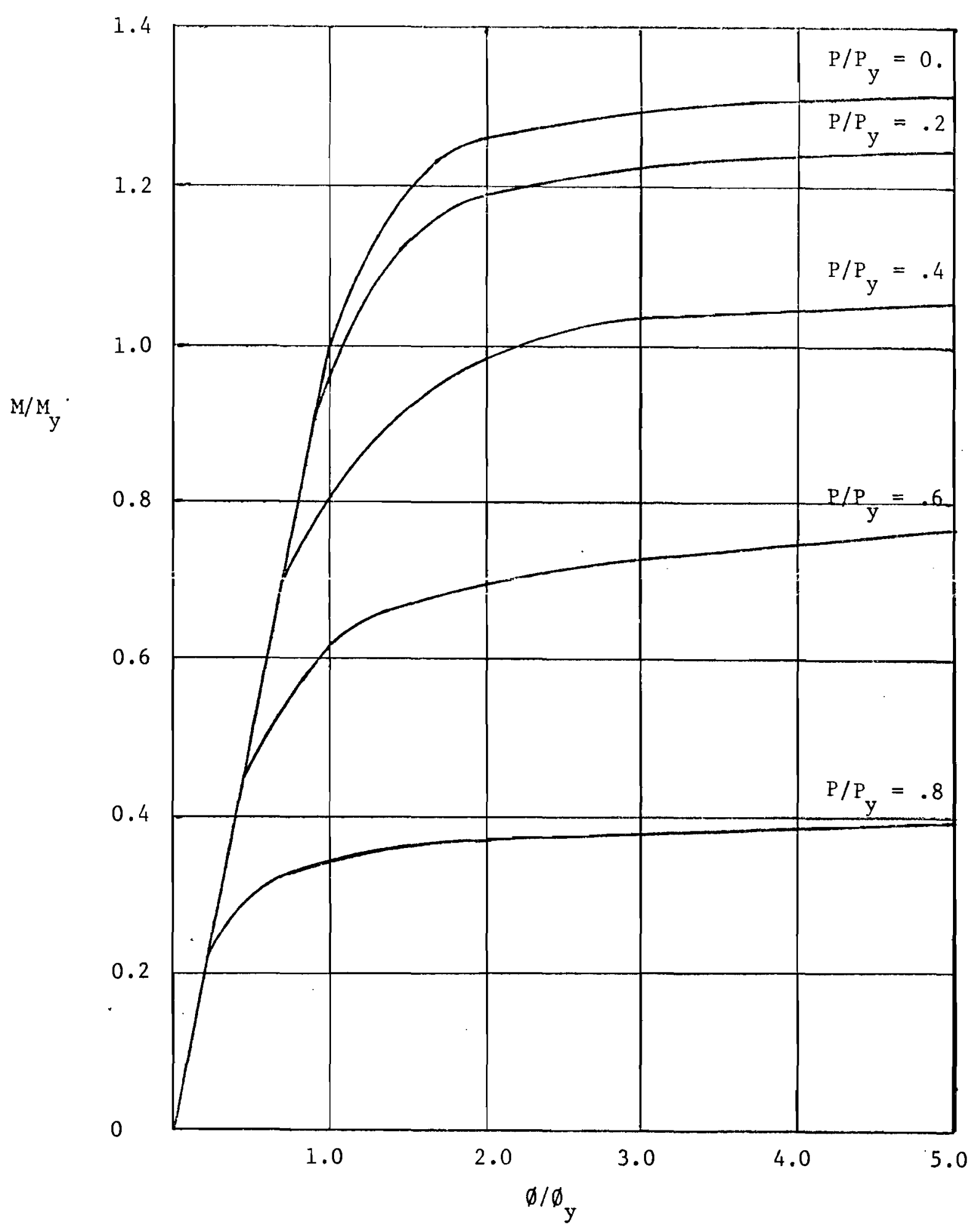

Fig. 28 M- $\emptyset-P$ Diagram for a 14.0 in. OD., 0.5 in. Wall Thickness Standard Tube. 


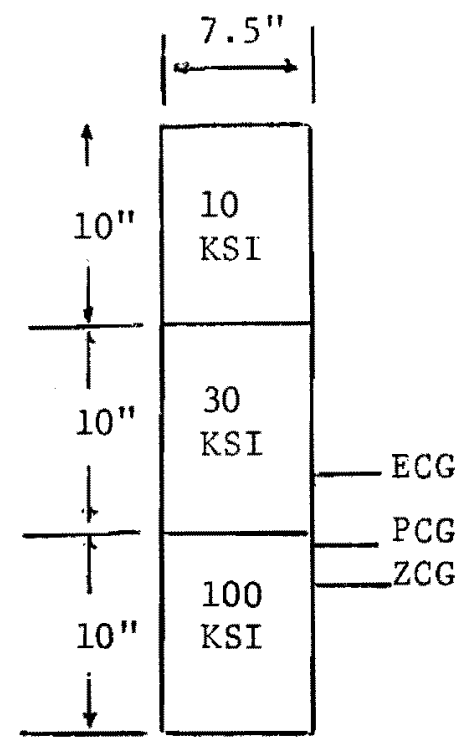

(a) PCG between ECG and ZCG.

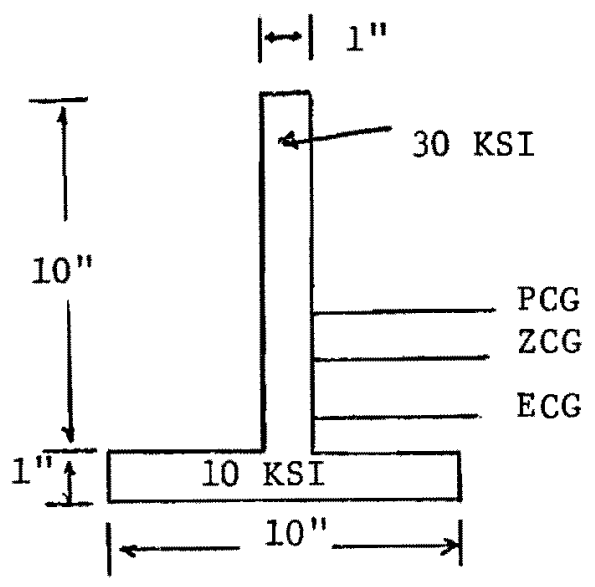

(b) PCG not Between ECG and ZCG.

Fig. 29 Possible Combinations of PCG, ECG and ZCG. 
Table 1. Values of Successive Iterations for $F(X)=e^{-x}$

\begin{tabular}{|c|c|c|c|c|c|c|}
\hline$P=3.5$ & $F(X)=e^{-X}$ & Degree 1 & Degree 2 & Degree 3 & Degree 4 \\
\hline$x$ & 1 & 2 & 3 & 4 & 5 \\
\hline 1 & 0.0 & 1.0 & - & - & - & - \\
\hline 2 & 0.1 & 0.904837 & 0.762093 & - & - & - \\
\hline 3 & 0.2 & 0.818731 & 0.773414 & 0.779074 & - & - \\
\hline 4 & 0.3 & 0.740818 & 0.784015 & 0.778534 & 0.778804 & - \\
\hline 5 & 0.4 & 0.670320 & 0.793950 & 0.778021 & 0.778811 & 0.778801 \\
\hline
\end{tabular}

Table 2. Values of Successive Iterations for $F(X)=x^{2}$

\begin{tabular}{|c|c|l|c|c|c|c|}
\hline \multicolumn{2}{|c|}{$\mathrm{P}=3.5$} & $\mathrm{~F}(\mathrm{X})=\mathrm{x}^{2}$ & Degree 1 & Degree 2 & Degree 3 & Degree 4 \\
\hline $\mathrm{x}$ & 1 & 2 & 3 & 4 & 5 \\
\hline 2 & 1.0 & 1.0 & - & - & - & - \\
\hline 3 & 3.0 & 9.0 & 11.0 & 12.25 & - & - \\
\hline 4 & 4.0 & 16.0 & 13.5 & 12.25 & - & - \\
\hline 5 & 4.5 & 20.25 & 14.75 & 12.25 & - & - \\
\hline
\end{tabular}




\section{APPENDIX A}

For asymetric cross sections the proper moment center is the elastic centroid when elastic stress conditions govern. For total plasticity of the type shown in Fig. $8 \mathrm{C}$ the plastic centroid must be used. Since all angles of curvature eventually yield this type (Fig. 8c) of strain relationship, the firal moment center for any cross section is always the plastic centroid.

For any angle of curvature the initial moment center can be assigned to the zero thiust axis and the final moment center to the plastic centroid. This change in moment center suggests a moment center shift from the zero thrust axis to the plastic centroid when the cross section is totally plastified. That this axis shift occurs only when the cross section becomes totally plastified is unlikely, and a more uniform shift as total plasticity is reached is more reasonable.

As previously mentioned, the moment center shift is not defined and, therefore, only pure bending cases are treated. However, one further solution is possible.

If the zero thrust axis initially lies on the plastic centroid, no moment center shift is possible and calculations for all thrust percentages can be made. The only criterion is that the PCG must lis between the ECG and ZCG of the cross section. Figure 29 shows that the PCG does not always lie in such a position. 
Asymmetric cross sections whose plastic centroid lies between the ECG and ZCG can be treated for bending moment and any thrust percentage when the angle of curvature whose zero thrust axis lies on the plastic centroid is used. If the PCG does not lie between the ECG and ZCG only pure bending can be treated.

The angle of curvature, $\emptyset_{\mathrm{S}}$, whose zero thrust axis lies on the plastic centroid, greatly effects the usability of the thrust calculations. If $\emptyset_{S}$ is large, all thrust percentages will ies on straight line portions of the $M-\emptyset-P$ diagrams. Since such values are of little use, these calculations are useful only if $\emptyset_{5}$ is small (less than 2). $M-\emptyset-P$ values for $\emptyset / \emptyset_{y}>2$ are really useless because of local and lateral buckling. 


\section{APPENDIX B: AITKEN'S PROCESS}

Aitken's process is a linear interpolation procedure that does not require a uniform grid. Table 1 gives values of $F(X)=e^{-X}$ over a uniform grid. Table 2 gives $F(X)=x^{2}$ over a nonuniform grid. Using Aitken's process, estimations for an unknown $\mathrm{F}(\mathrm{X})$ can be obtained by a succession of second order determinates:

$$
Y(J, I)=\frac{\left|\begin{array}{lr}
Y(L, L) & X(J)-P \\
Y(J, L) & X(L)-P
\end{array}\right|}{X(J)-X(L)}
$$

where $P$ is the point for which $F(X)$ is to be evaluated, I and $J$ are the cclum and row of the estimation matrix, [Y], respectively, and $\mathrm{L}$ denoted the column previous to $\mathrm{I}$.

The process is applied to [Y] until a convergence occurs, as in the third colum of [Y], Table 2. The convergent value is usually a very good approximation to the true value, but since no estimation of the truncation error is available, the derived value should not be accepted as exact without further investigation.

Table 1 indicates that $e^{-X}$ may be closely approximated by a third order equation over the given interval as a fairly good convergence is obtained in the fourth column of [Y]. The fifth column produces $e^{-X}$ to the same accuracy as tabulated values. Note that the $\mathrm{X}^{2}$ value (Table 2) converges in the third column of [Y] as expected (second order curve), since the degree of the function is known. After the first convergence is obtained, successive iteration 
columns yield identical results, thus continuing the process is unwarranted.

Subroutine AITKN contains the basic Aitken's process calculation. The order of operation is:

(1) A check is made for an exact $f$ it of $P$ in the data for a given function. $P$ is any value for which $F(P)$ is to be determined.

(2) If no exact fit is found the point in the table nearest to where $\mathrm{P}$ should 1ie is determined. This search guarantees that points used in the iteration will be close to and lie on each side of the unknown $F(P)$.

(3) Checks are made to varify that no points off the table are accessed.

(4) Values are transferred to the $X$ (values surrounding $P$ ) and $Y$ (values of the function $F(P)$ ) positions.

(5) The iteration is performed and the function $F(P)$ is returned as needed data. Moments for certain thrust percentages and zero thrust axes positions are returned through the $F(P)$ values. 
APPENDIX C:

COMPUTER PROGRAM LISTINGS 


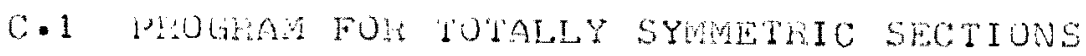

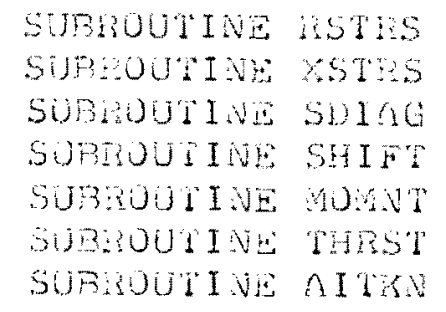

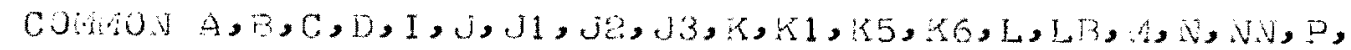

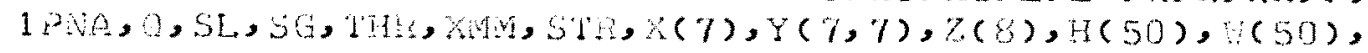
$2 S(50), X 4(50), X T(50), B C(5), T C(5), T H(5), W D(5), F Y(5)$,

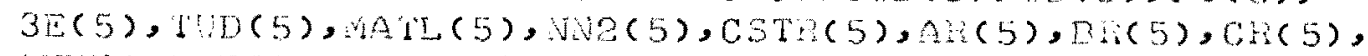
INWh(5), NSOPT $(5), \operatorname{NAOPT}(5), \mathrm{N}(5), \mathrm{VS}(15,5), \mathrm{VT}(15,5)$, HFY

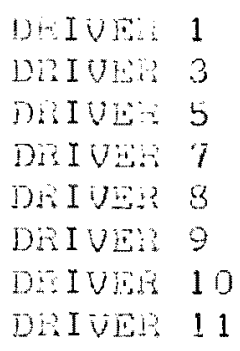

$A S T H=(N C(N)-P(N A) / K N$

PSTP = ASTEP

NITTE(5,102)SF, PY, KHY, DHIY, PNA

MTT $(5,105)$

READ 2,104$) K F, K L, S F$

CONT INUE

DO $1000 \quad L L=K F$, LSL

$S I=S T /(P U I Y * L E)$

$\mathrm{Q} \mathrm{Q}=1 \cdot / \mathrm{SL}$

$1 F(Y N-(F Y(K K) /(E(K Y) * Z 2)+T(C(K K)-P N A) / A S T E) 42,42,43$

$4 \%$

43

12

$A S I E P=(F Y(K K) /(E(K K) * Z 2)+T C(K K)-P N A) / K N$

$N N=0$

$\mathrm{PNC}=\mathrm{PNA}$

$\mathrm{NN}=\mathrm{N} \mathrm{N}+1$

CALL SDIAG

$P N B=P N A$

$P N A=P N C$

CALL, MOMNT

$X M(N N)=X M Y / X M Y$

CALL THAST

$X T(N N)=T H E / P Y$

$I F(N N-1) 13,13,14$

$14 \quad \mathrm{XT}(\mathrm{NN})=\mathrm{TH} / \mathrm{PY}$

Go 1015

$13 \quad X(N)=0$. 


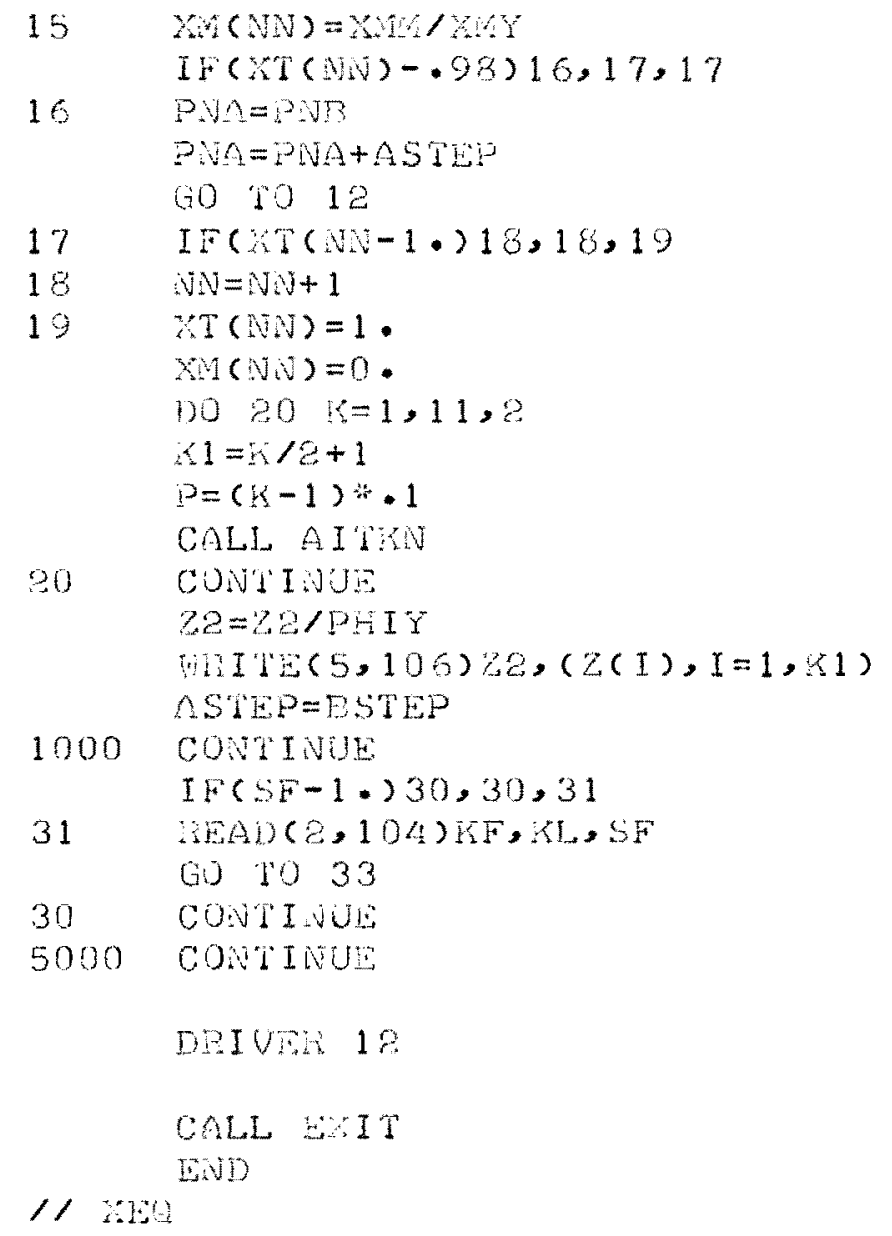


C.e PIOGEAM FOE ASYMETIC SECTIONS

SURROUTINE RSTRS

SUPBOUTINE XSTSS

STBEOUTINE SDIAG

SUJBUUTIIVL SHIFT

SUBROUTINE MOMNT

SUPROTIIIV THEST

SUBOOUTIUE AITKO

DIMUSION ZAXIS(20), ZPHI $(20)$

CONION A,B,C,D,I, J, J1, JE, J3, K, K1,K5,K6, L, LB, M, N, NN,P,

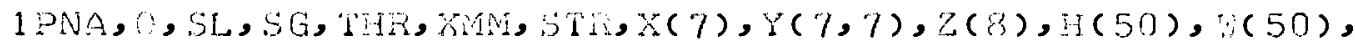
PS $(50), X(50), X T(50), \operatorname{BC}(5), T C(5), T D D(5), \operatorname{TD}(5), F Y(5)$,

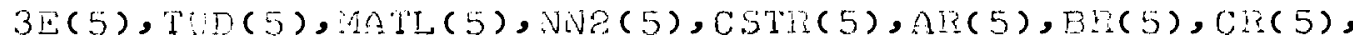
4 KNVN $(5)$, NSOPT $(5)$, NROPT $(5), \operatorname{NE}(5), \mathrm{VS}(15,5), \mathrm{VT}(15,5), \mathrm{HFY}$

DMIVER 1

DeIVER

DSIUTE 3

DII I UE: 4

DRIVES 5

DHI UEI: 6

DRIVER 7

DAIUHA 8

DPIUER 9

DEI UES: 10

DEIVEF 11

WITE(5,102)SF, PY, XMY, PHIY, ECG,PCG

$S 1 E P=A B S(Z C G-E C G) / 20$.

IF $(P G-Z C G) 23,38,24$

$23 \quad \mathrm{DI}=\mathrm{PCG}$

$\mathrm{DQ}=\mathrm{ZCQ}$

Go TO 29

$38 \quad \mathrm{PNA}=\% \mathrm{CG}$

Q0 1029

$34 \quad D 1=200$

$\mathrm{DP}=\mathrm{PCG}$

29 CONIINUE

$\operatorname{rits}(5,105)$

IF (PCG-ECG) 73,74,74

$73 \quad D 3=P C G$

GO TO 75

$74 \quad D 3=E C G$

$75 \quad A S T E M=(T C(N)-03) / X N$

BSTEP $=A 5 T K P$

$\therefore E A D(2,104) \mathrm{KF}, K L, S F$ 


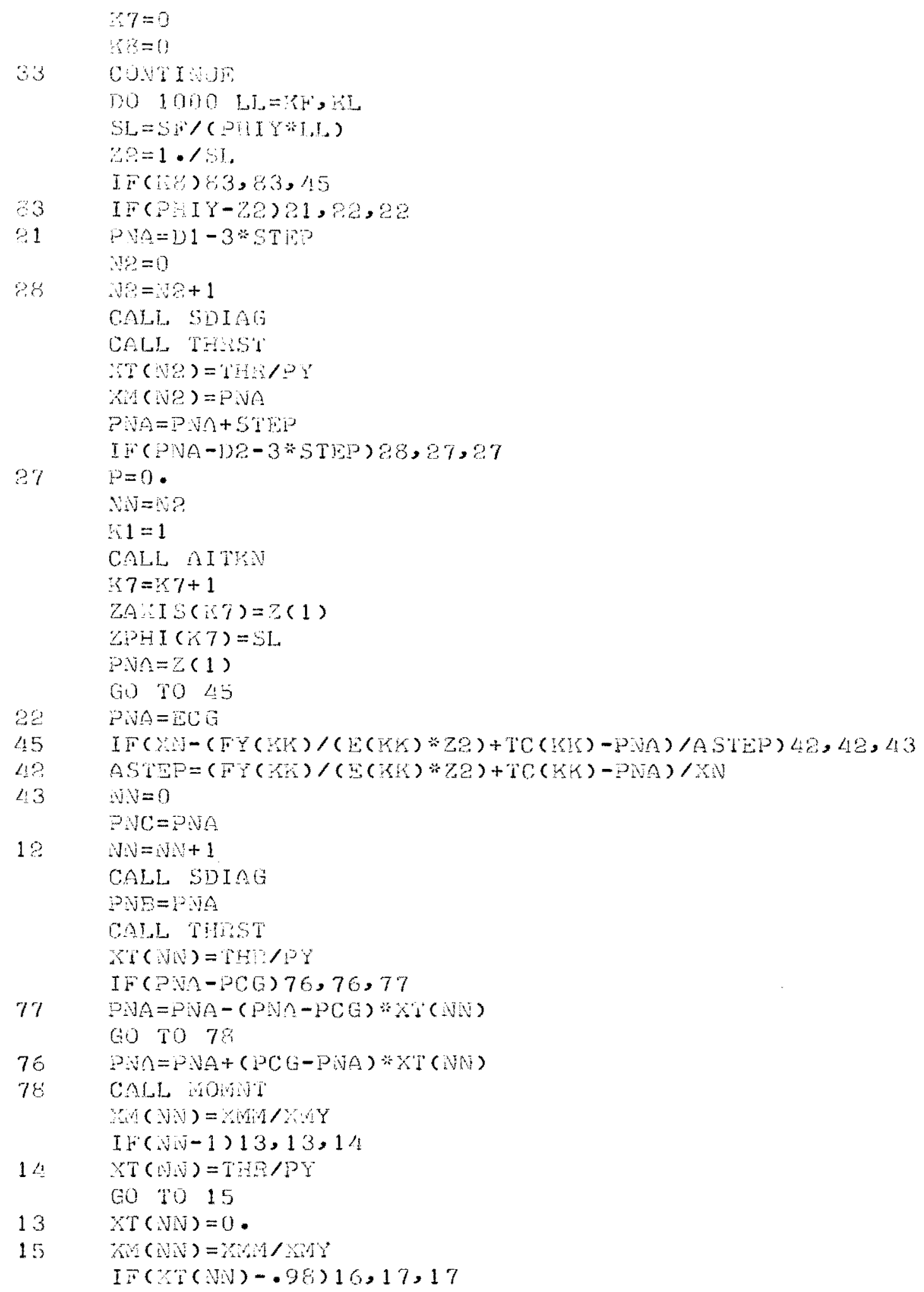




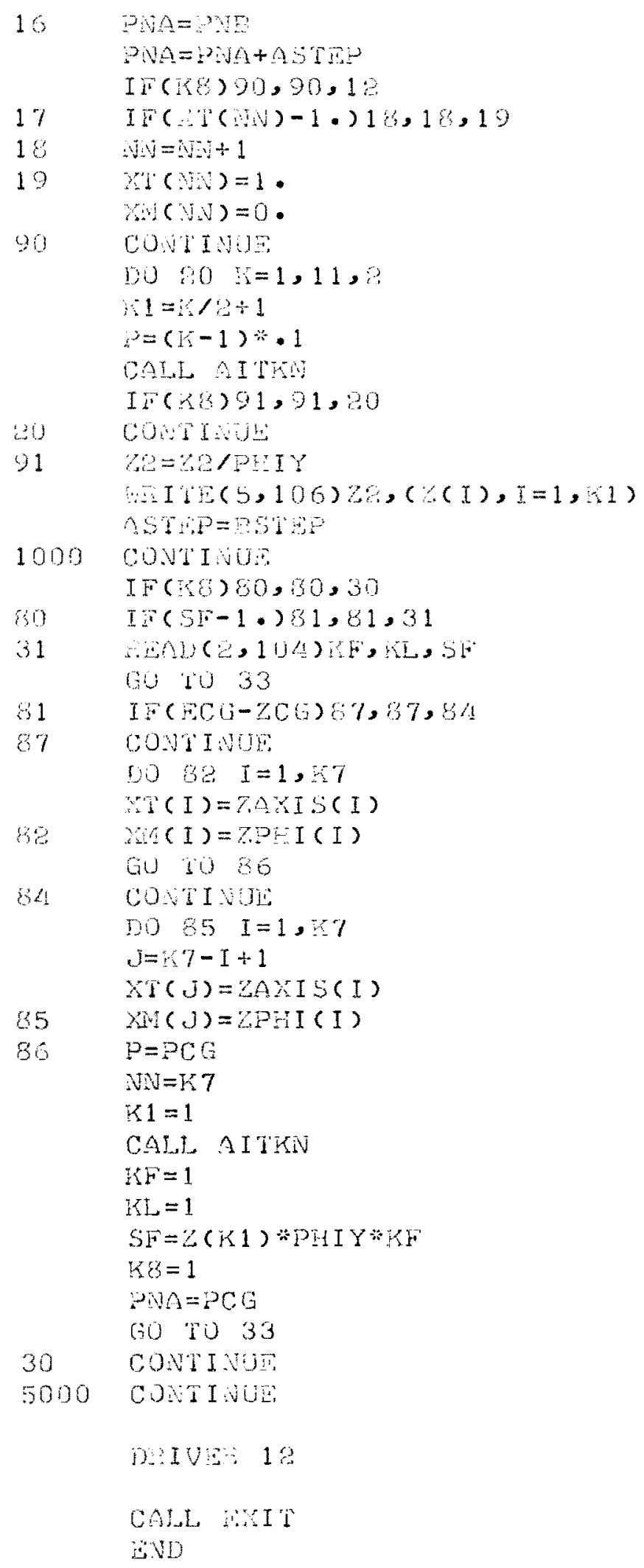


C.3 SUPROUIDES

SITBOYTIN SIITH

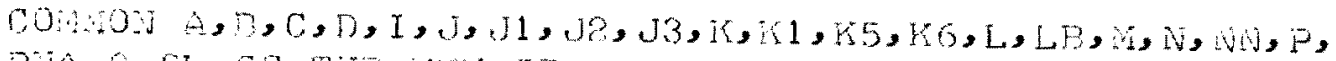

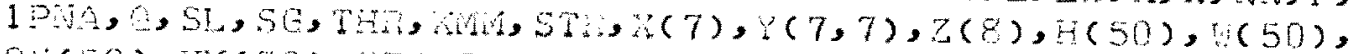
$\mathrm{PS}(50), \mathrm{W}(50), \mathrm{S}(50), \mathrm{BC}(5), \mathrm{TC}(5),[\mathrm{DD}(5), \mathrm{WD}(5), \mathrm{F}(5)$,

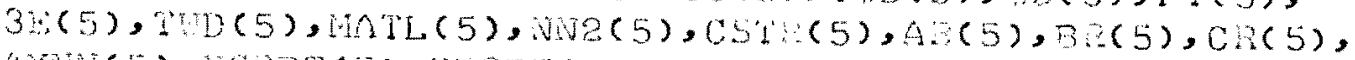
$4 \mathrm{NN}(5), \mathrm{NSUPT}(5), \mathrm{VTOPT}(5), \mathrm{NL}(5), \mathrm{VS}(15,5), \mathrm{TT}(15,5)$, MFY $H=x s$

$1 \quad \therefore=i+1$

$I F(N-F) \&, 6,7$

U IH(

2. $15=1$

$K=x+1$

$M=M+1$

DO $3 \cup 1=M, K$

$J 2=K-. I 1+H$

$\mathrm{J}_{3}=\mathrm{J}:-1$

$H(J 3)=H(53)$

$S(J 2)=S(.33)$

$\because(.9)=(.33)$

$\mathrm{r}=\mathrm{x}-1$

IF $(16) 5,5,6$

$5 \quad H(M)=11$

$($ I. $)=i n(I)$

$C=H F Y-P N A$

$S(M)=G \operatorname{IGN}(F Y(I), C)$

00 10 7

$6 \quad 6(x)=(x-1)$

$H(D)=P N A$

$z(1)=p N A$

$5(M)=0$

7 RETUEN

END 


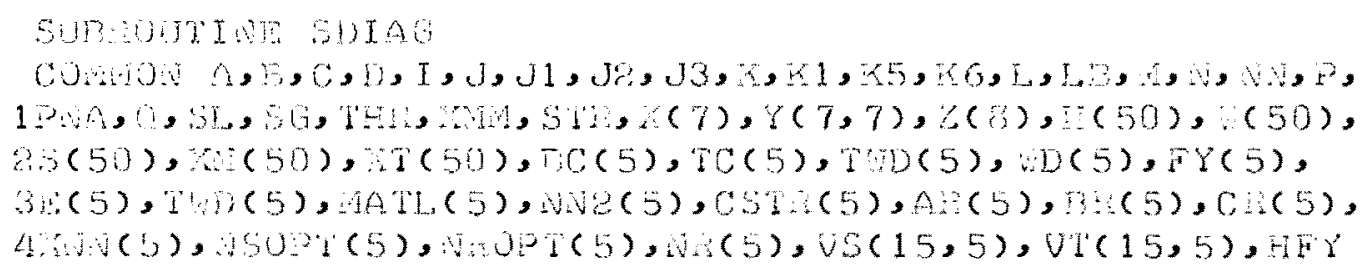




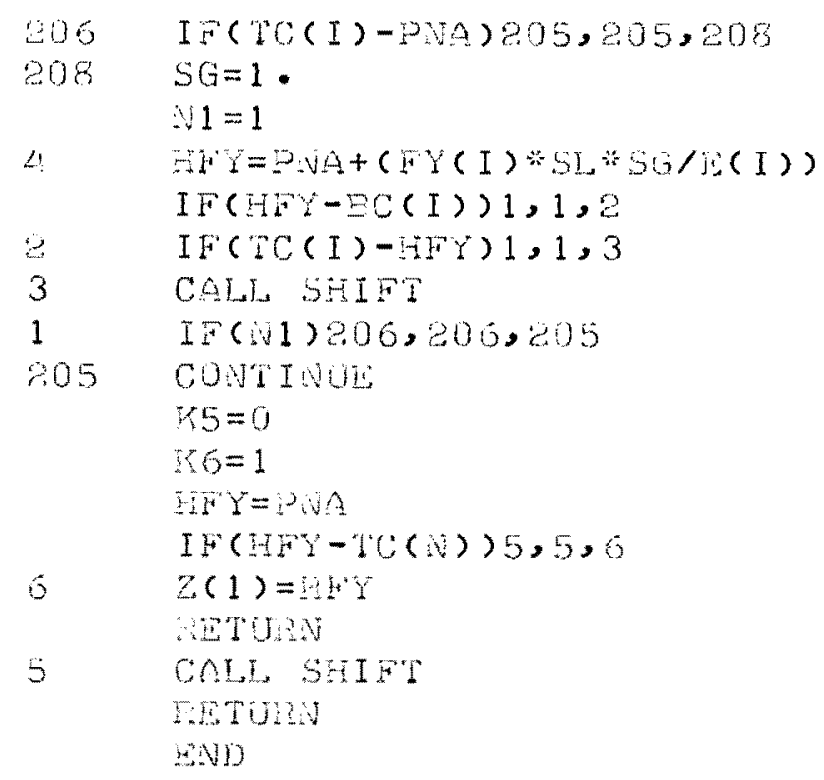

SURTout Ine $x \mathrm{stas}$

COKRON A,B,C,D, I, J, J1, Je, J3, 1 WA, SL, S6, the, $25(50), \times(50), \times 9(50), \mathrm{CC}(5), \mathrm{TC}(5), 1 \mathrm{WD}(5), \mathrm{D}(5), \mathrm{F}(5)$,

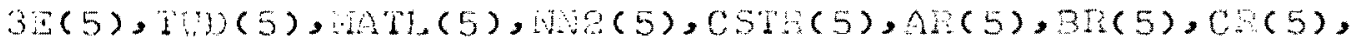

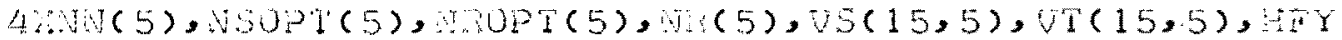

$S(K)=0$.

$\therefore=1 \mathrm{LL}(\mathrm{I})$

$5=\log (2)$

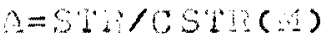

$M=I S S(I S I X(A))$

$\operatorname{IP}(A) 1,00$, ?

$1 \quad 80=-1$.

iis $S=-1$

bo 13 is 3

$2 \quad S G=1$.

$K S=1$

$3 \quad$ IF $(L P-J 1-1) 19,19,4$

$4 \quad \mathrm{~J} 3=\mathrm{L} 5+\mathrm{J} 1 \div \mathrm{KS}$

$\mathrm{J} 2=\mathrm{JS}+\mathrm{s} S$

$S(\mathrm{I})=\mathrm{VS}(\mathrm{J} 3, \mathrm{M})+\operatorname{VSS}(\mathrm{J} 2, \mathrm{M})-\mathrm{VS}(\mathrm{J3}, \mathrm{M})) *(\mathrm{STA}-\mathrm{VT}(\mathrm{J} 3, \mathrm{Mi})) /$

$1(\mathrm{Vit}(\mathrm{je}, \mathrm{m})-\mathrm{VT}(\mathrm{j} 3, \mathrm{H}))$

GO 1020

$19 \quad S(K)=F(I) * S 0$

20 EETUEN

END 


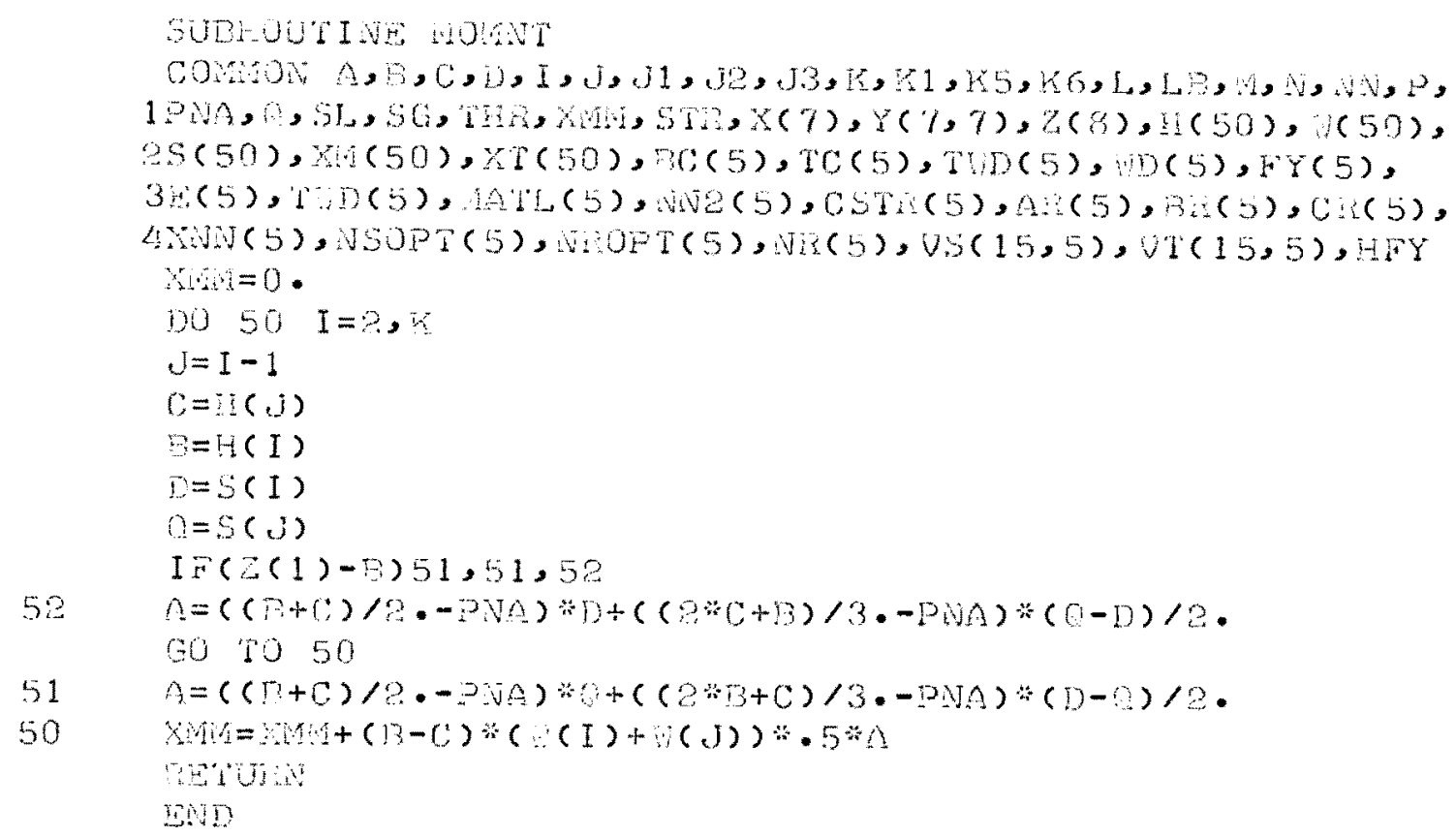

SUROUTINE prast

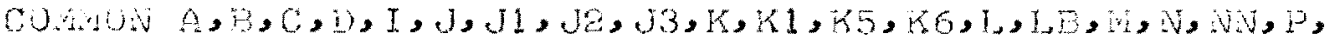
1PNA, SL, SG, THE, XMV, STH, X(7), Y $(7,7), Z(8), H(50), W(50)$, ZS $(50), X N(50), X T(50), B C(5), T C(5), T H D(5), D D(5), F Y(5)$,

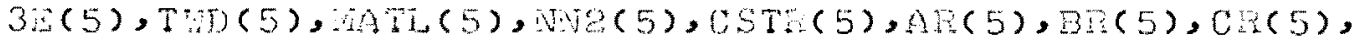
4 XNN $(5), \mathrm{NSOT}(5), \mathrm{NLOPT}(5), \mathrm{NL}(5), \mathrm{VS}(15,5), \mathrm{VT}(15,5), \mathrm{HFY}$ $T-T=0$

DO $30 \quad I=2, I$

$J=I-1$ $T I R=T H-(S(I)+S(J)) *(E(I)-I(J)) *(V(I)+V(J)) * 25$ IETUR

END

SUm?OUTLUE RSPLS

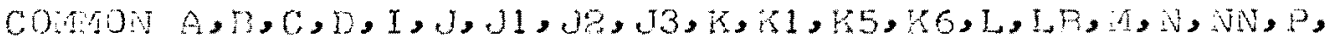

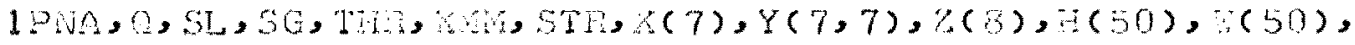
$25(50), \ldots(50), \mathrm{T}(50), \mathrm{BC}(5), \mathrm{TC}(5), \mathrm{THD}(5), \mathrm{D}(5), \mathrm{Ft}(5)$,

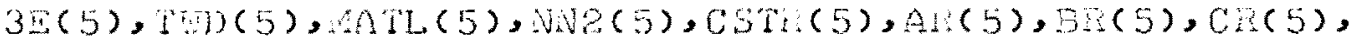

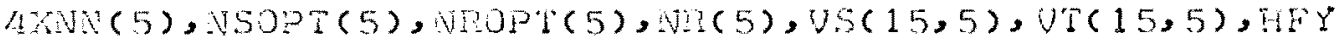
$\theta=(K)-B C(I)$

$S H=A D(I) * 0 * P+\operatorname{PN}(I) * C+C(I)$

nETUY

END 


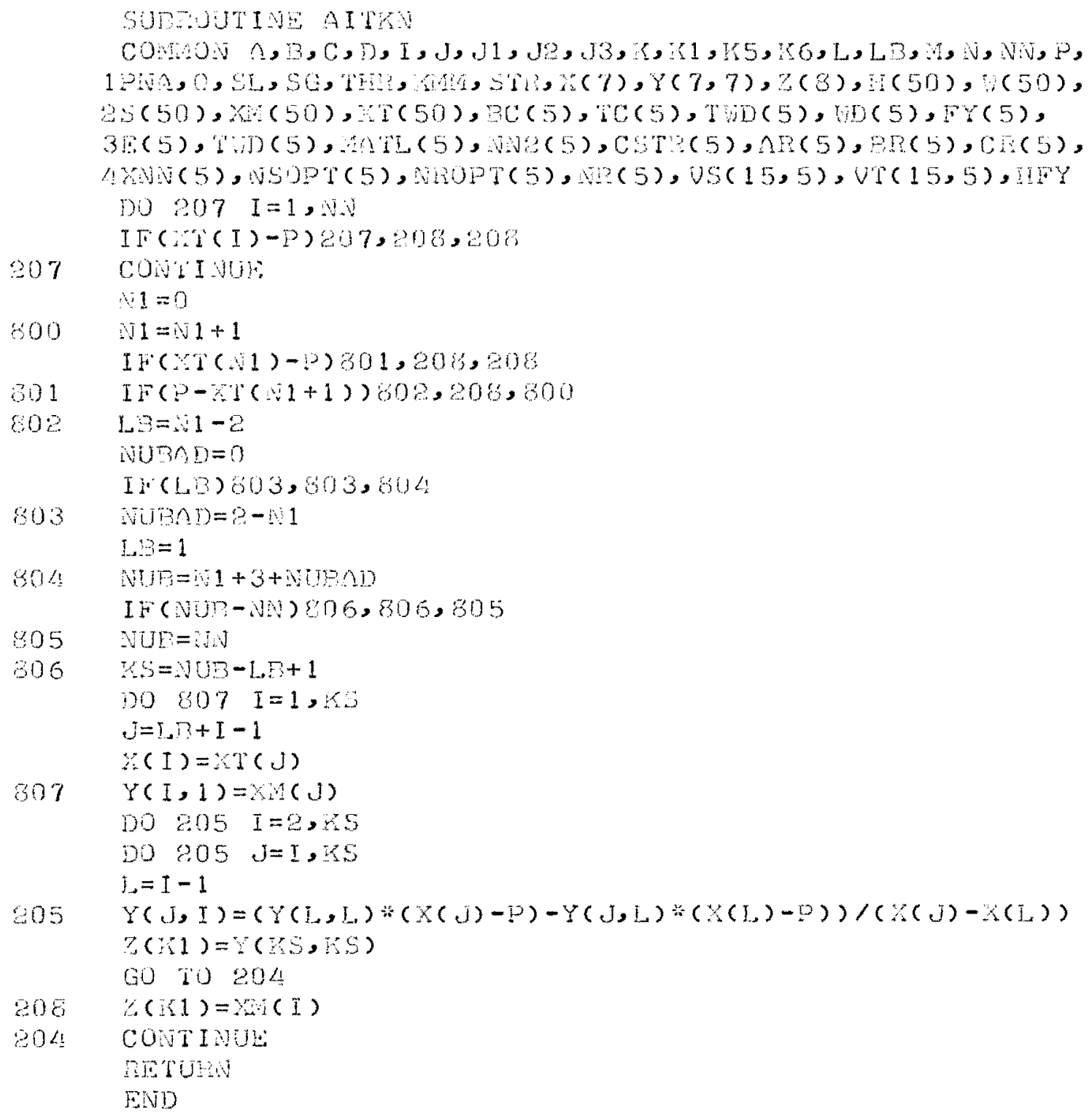




\section{DAIUHA 1}

PEAD(2,100) MPIDP?

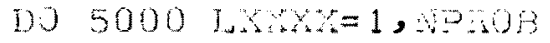

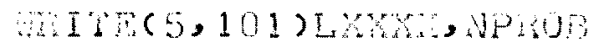

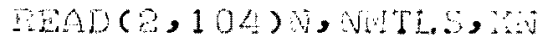

Du $59 \quad I=1$,

ACH, (I) $=0$

$\sqrt{50 P T}(I)=0$

स०० $3(I)=0$

$59 \quad \mathrm{~N}(I)=0$

$D 01 I=1,4$

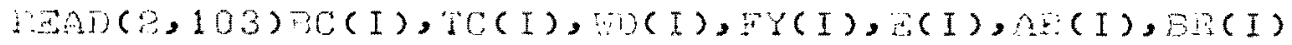
$1, \mathrm{C} N(I)$

$1 \quad I T(5,107) I, B C(I), J C(I), W D(I), F Y(I), E(I), A D(I), D E(I)$ $1, \mathrm{CH}(\mathrm{I})$

\section{DEIUP:S}

$\mathrm{BH} I \mathrm{~N}=\mathrm{R}(1)$

Do $2 \quad I=2,-1$

IF(IIIN-E(I)) $2,2,3$

$3 \quad E$ S I I $=E(I)$

3 CONT INUE

DO $\because I=1, N$

$4 \quad \operatorname{THD}(I)=\mathrm{HD}(\mathrm{I}) * \mathrm{E}(\mathrm{I}) / \mathrm{BH}$

DIIVER 3

$P Y=0$

D) $5 I=1, N$

5

$P Y=P Y+(T C(I)-B C(I)) * W D(I) * F Y(I)$

JiLIVER 4

$1+15:=0$.

$10070 \quad I=1, \mathrm{~N}$

$A H=(I C(I)-P C(I)) \approx D D(I) * F Y(I)$

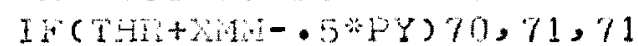

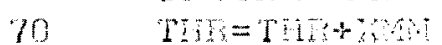

$71 \quad Z C(=P C(I)+(.5 * P Y-T H D) /(F X(I) * D D(I))$ 
MIVE: 5

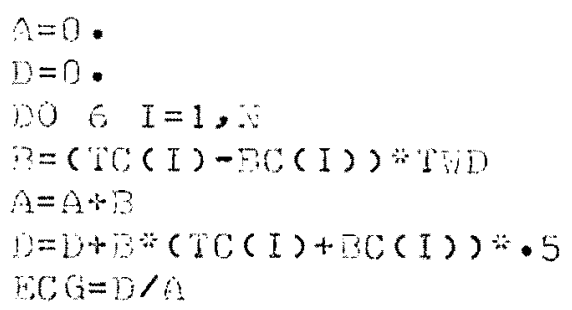

DrITig: 6

$\Delta=0$.

$\Gamma=0$.

Do $7 \quad I=1, W$

$D=(I C(I)-B C(I)) *(B D(I) * F Y(I)$

$A=A+\cdots$

$7 \quad \mathrm{D}=\mathrm{D}+\mathrm{T}) *(\mathrm{IC}(\mathrm{I})+\mathrm{RC}(\mathrm{I})) * .5$

$\mathrm{CO}=\mathrm{D} / \mathrm{A}$

\section{Dat ver: 7}

$P I Y=F(1) /(\operatorname{PCC} E(1))$

Do $8 \quad I=1, \mathrm{~N}$

IF(FY(I)-ABS(EC(I-BC(I)) MPIYE(I)) $9,10,10$

9 PHIY $=F Y(I) / A B S(E(I) *(E C G-B C(I)))$

$10 \quad \operatorname{IT}(F Y(I)-A E S(E C G-T C(I)) * 2 H Y * E(I)) 11,8,0$

$11 \quad P I Y=F(I) / A B S(E(I) *(E C G-T C(I)))$

3 CONINUE

DIIUL: 8

$S \mathrm{~T}_{-}=1 \cdot / \mathrm{PHIT}$

$P N A=F C Q$

CALL SDIAG

CALL MOLNT

$X \mathrm{WI}_{Y}=\mathrm{XWO}$ 


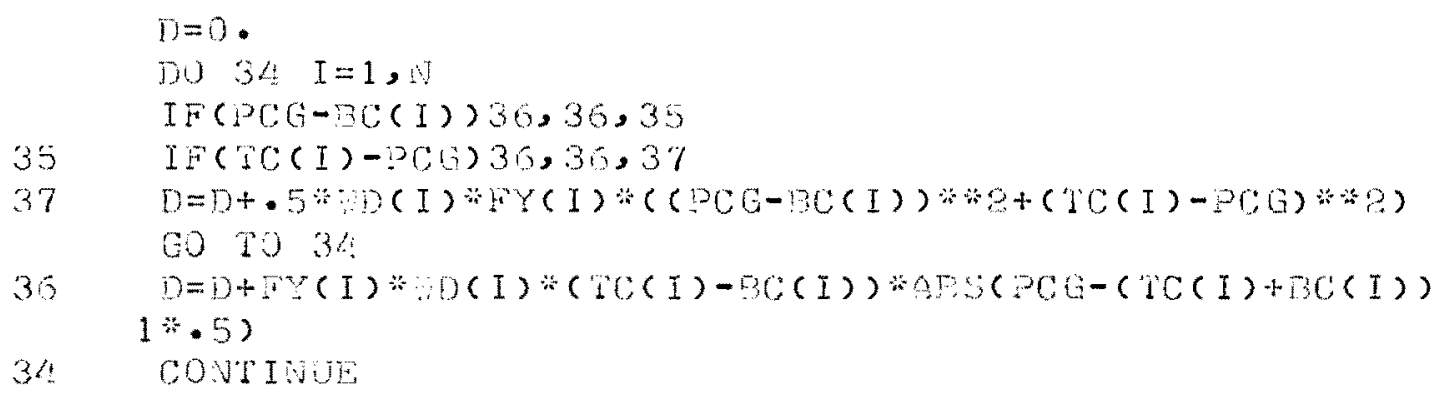




\section{DIIVER 12}

100

FOtAl $(I 4, F 10.0)$

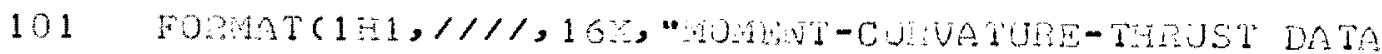

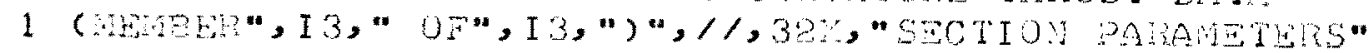

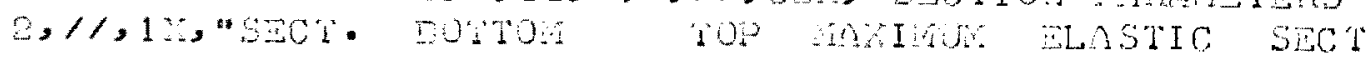

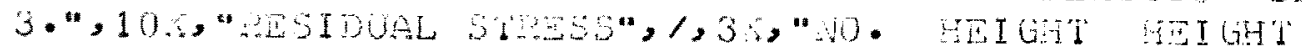

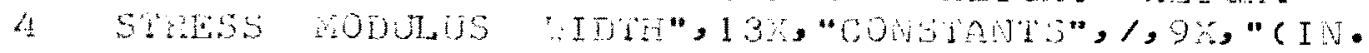
5) (IIP) (KSI) (KSI) (IL, ", 6"BR", 9., "C.:")

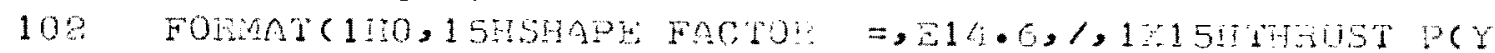

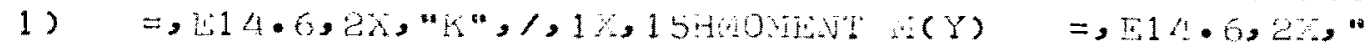

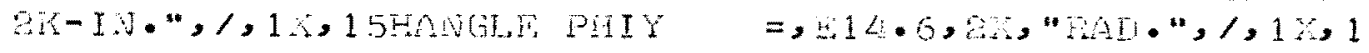

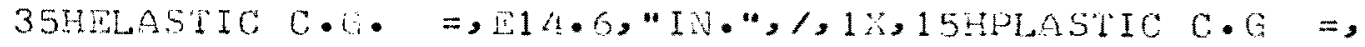
$4814 \cdot 6,2 x, " I N \cdot *)$

103 FORUAT(BF10.0)

104 FOPUAT(PIA, 10.0$)$

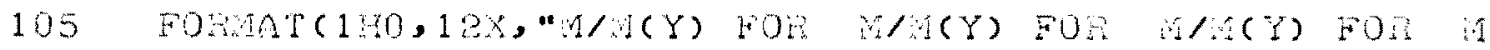

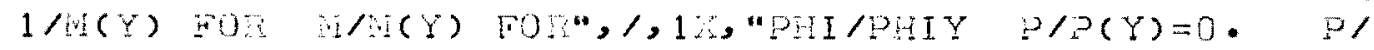
$P(Y)=.2 \quad P / P(Y)=.1 \quad P / P(Y)=.6 \quad P / P(Y)=.8 \quad P / P(Y)=$ $31 \cdot 0 *)$

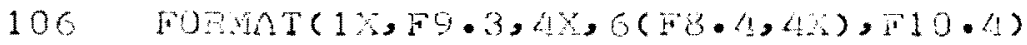

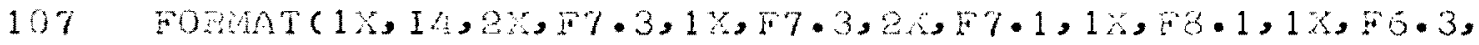
$11 \times, 3: 11 \cdot 3)$

108 FOPAT $(4 \mathrm{I}, \mathrm{F} 10 \cdot 0)$

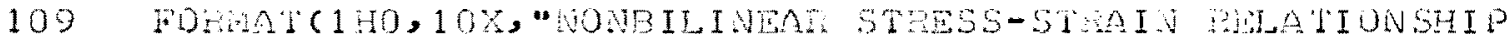
$18 *)$

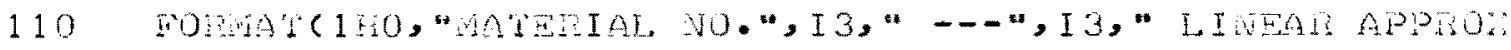

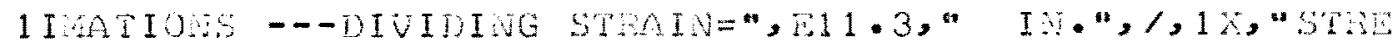
$25545=*, 3 x, 0(11 \cdot 3)$

111 FOMAT(1\%,"STAINS $=", 3 \%, 2 \mathrm{E} 11.3)$

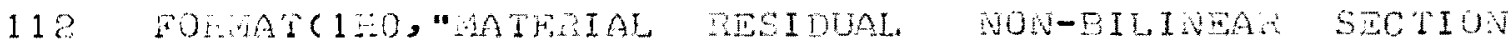

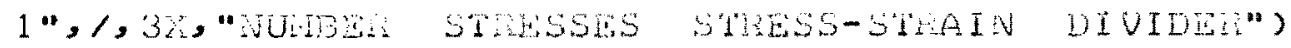

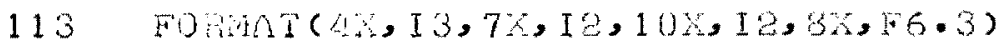




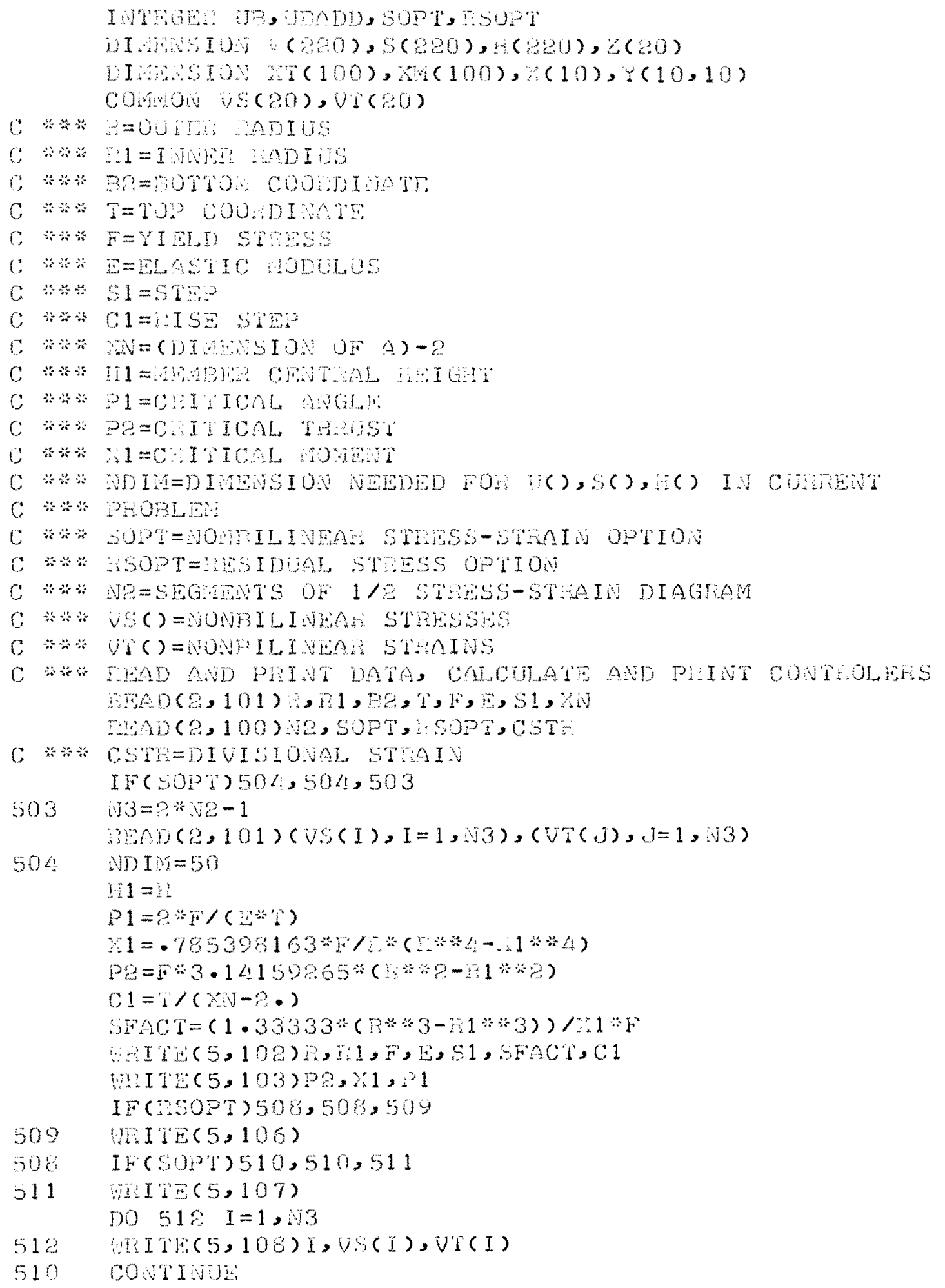




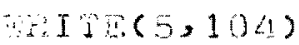

Q *

DO $223 \quad I=1$, SDI.

$\because(I)=0$.

$S(I)=0$.

$223 \quad i(I)=0$.

$\therefore \mathrm{F}=1$

$\mathrm{L}=3$

$S \mathrm{SI}=\mathrm{il}$

QEA CONTINUE

I0J $1000 \quad I, L=10, \ldots$

$32=5 F /(P 1 * 1.3)$

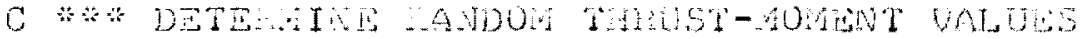

$y=0$

$P=?$

$203 \quad:=2+1$

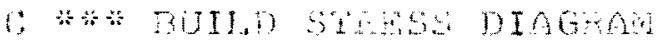

$1.1=0$

$L Q=0$

$L, 5=0$

$I I T=0$.

$x=0$

$\because=1$

$r=3+1$

$I,=0$

$I(X)=98$

217 IF( 1.1$) 400,400,401$

100 IF $(\mathrm{H}-1-H(K)) 402,402,404$

$102 \quad y(n)=3-12$

$1, \hat{1}=1$

Go 90404

401 IF(1.9)403,403,404

403 IF $(2+1-1(i)) 405,405,404$

$405 \quad 5(i)=E+1$

$1.2=1$

$404 \quad T H(1-5(5)) 219,219,218$

$210 \quad \square(n)=1$

$L=1$

505 IF( $150 P \% 501,501,500$

$300 \quad y=(t)$

COAIISH

501 IT (SOP) $18,18,500$

$500 \quad 3 i=(x)-p) / 90+1 \mathrm{~T}$

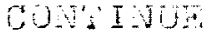

$S(x)=S 1$

$I P(i, 5) 215,215,507$

$\therefore 18 \quad S(K)=10 *(1(i)-p) / S 2$

$S 3=45 S(S(K)) / S(R)$

If(E-ADS(S(S)) ) $15,216,215$

$16 \quad 5(5)=7 \% 33$ 


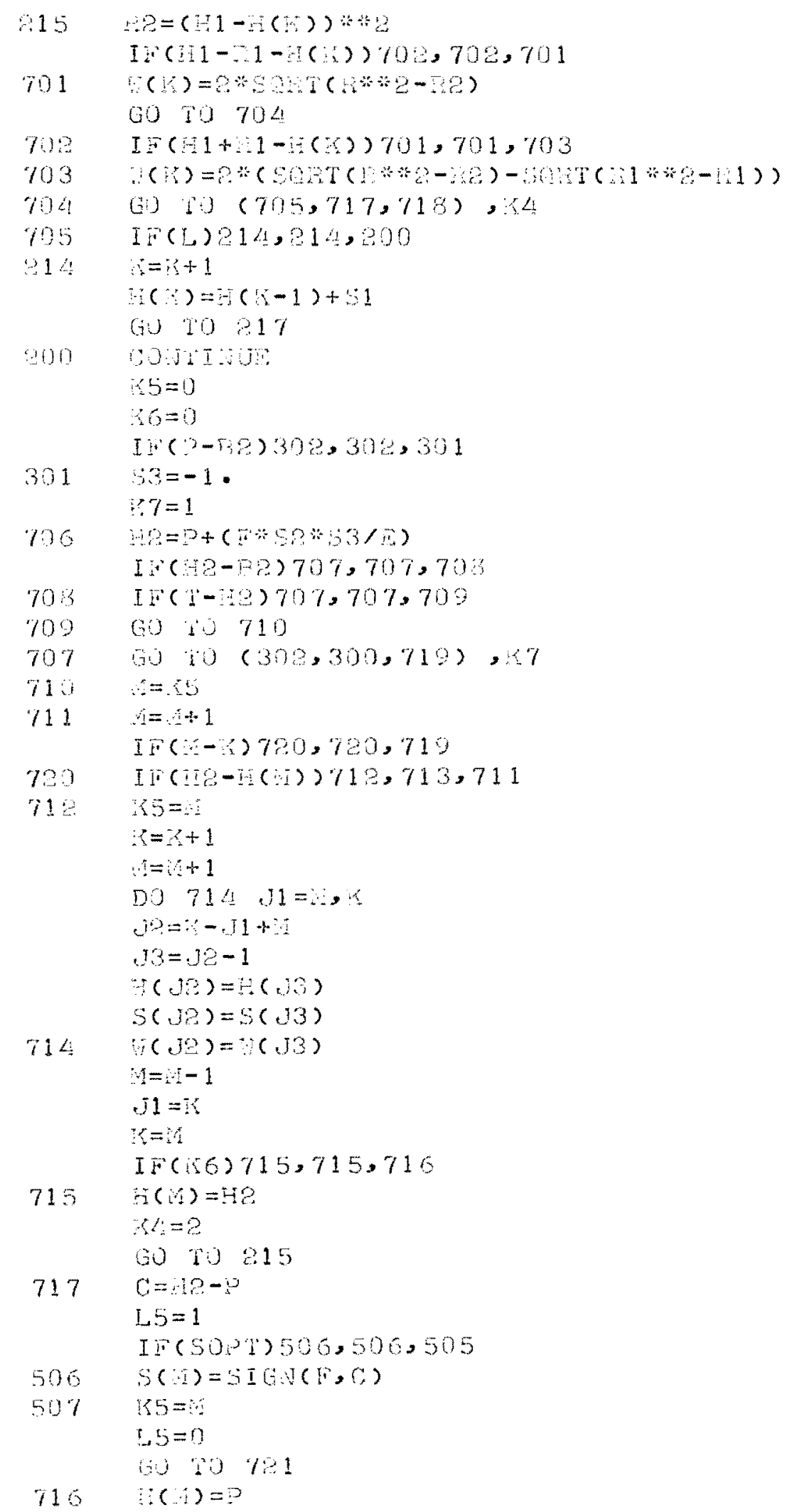




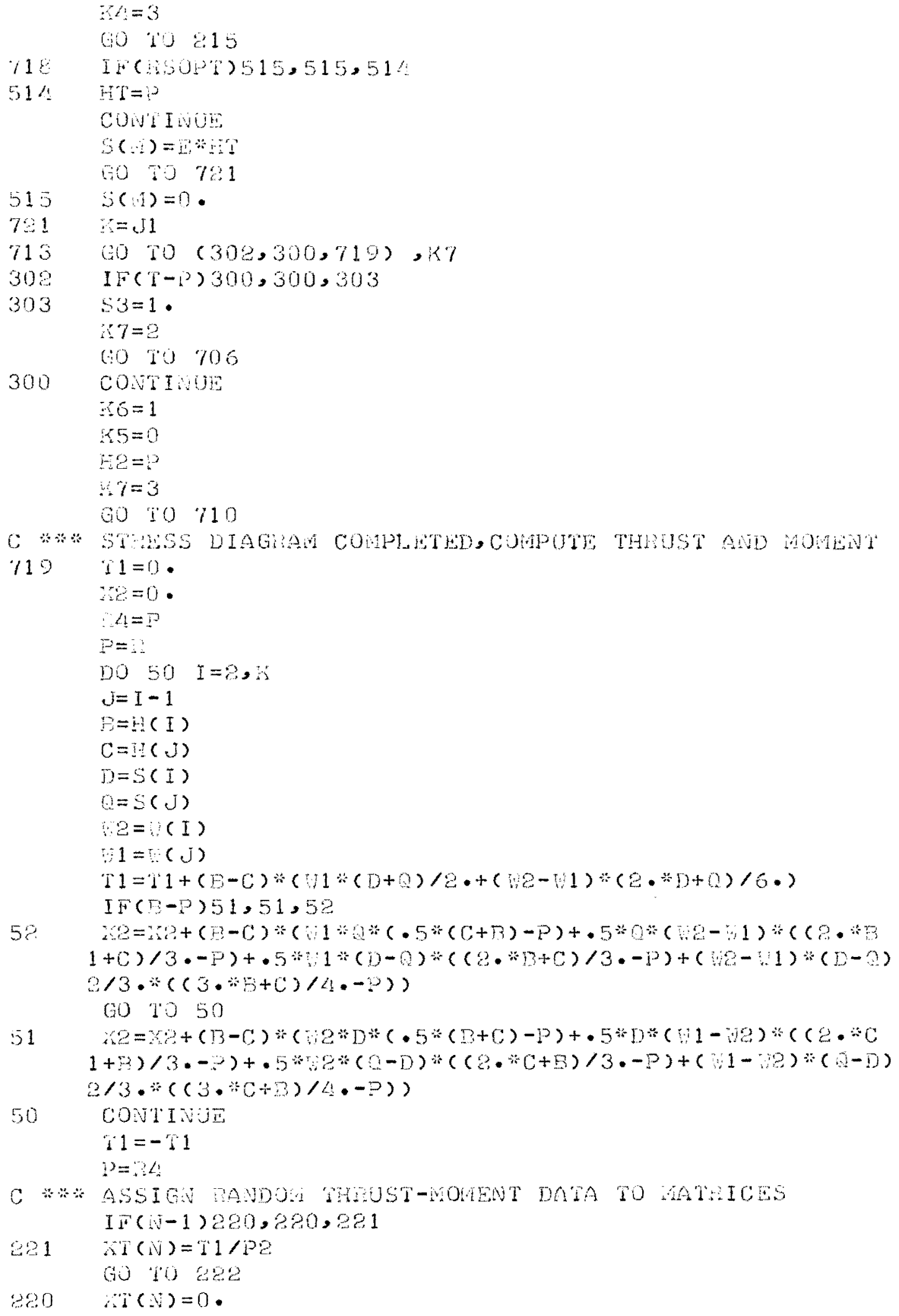




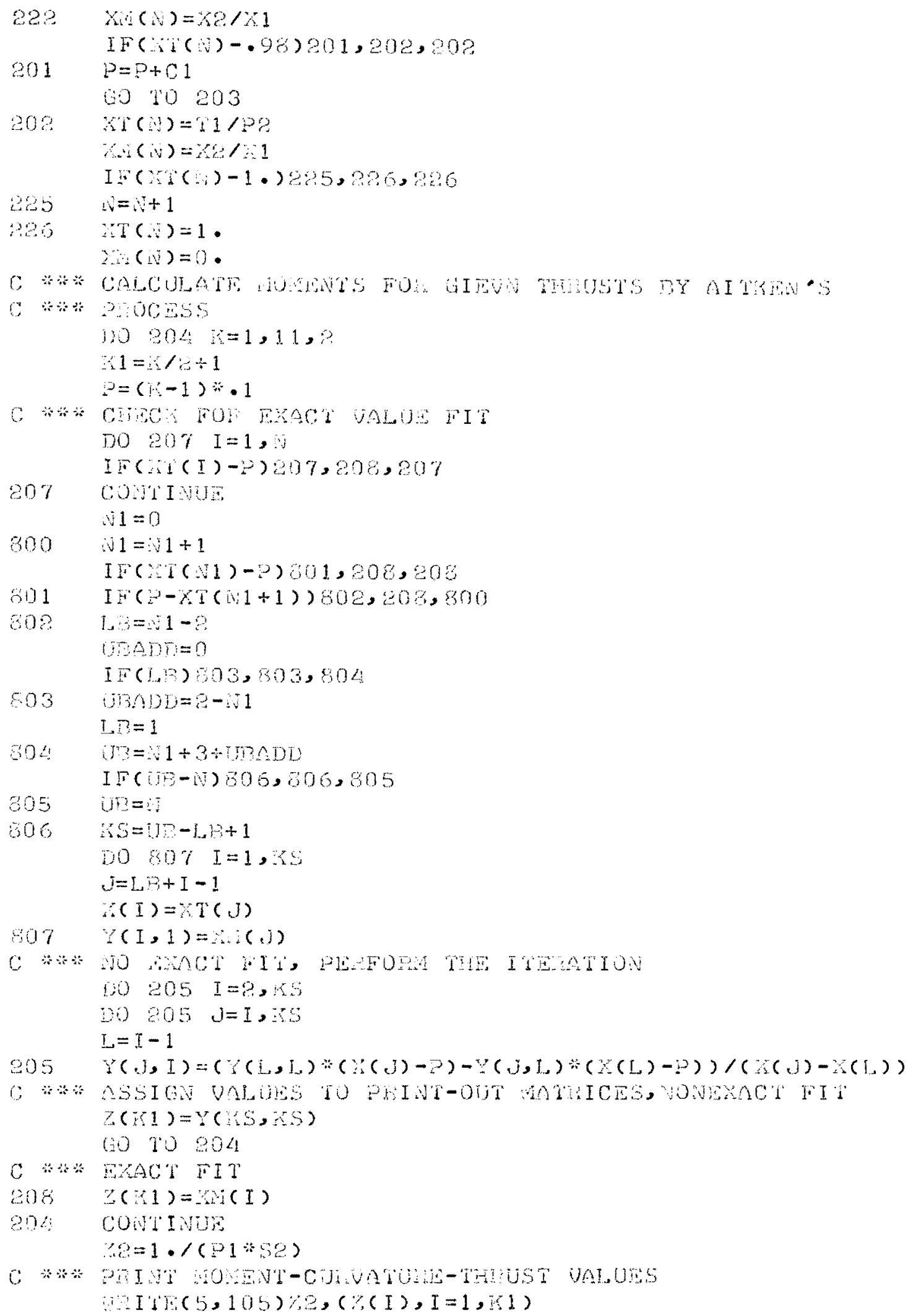




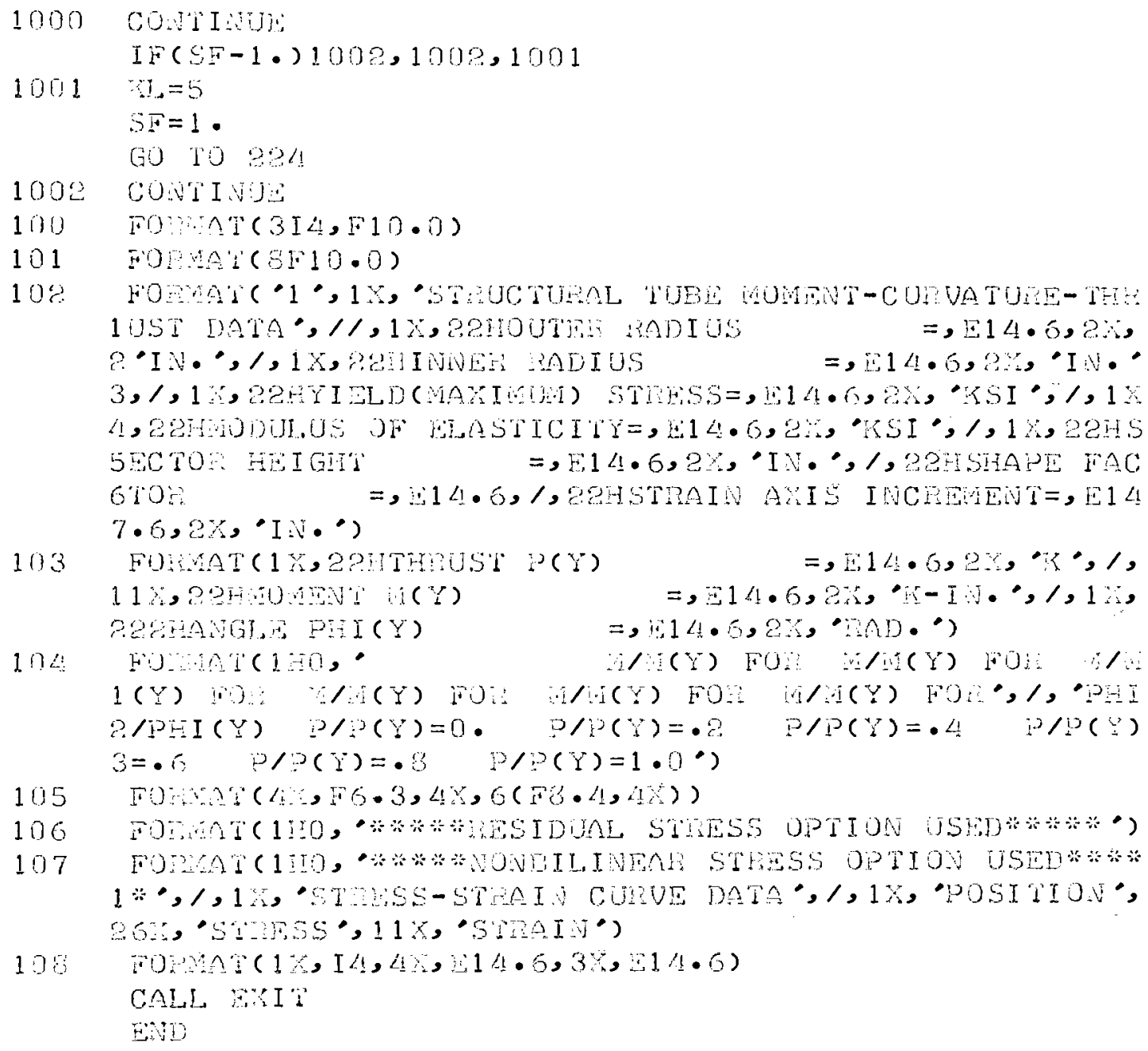


APPENDIX D:

FLOW DIAGRAMS 
D.1 TOTALLY SYMTITRIC FLON DIAGRAM

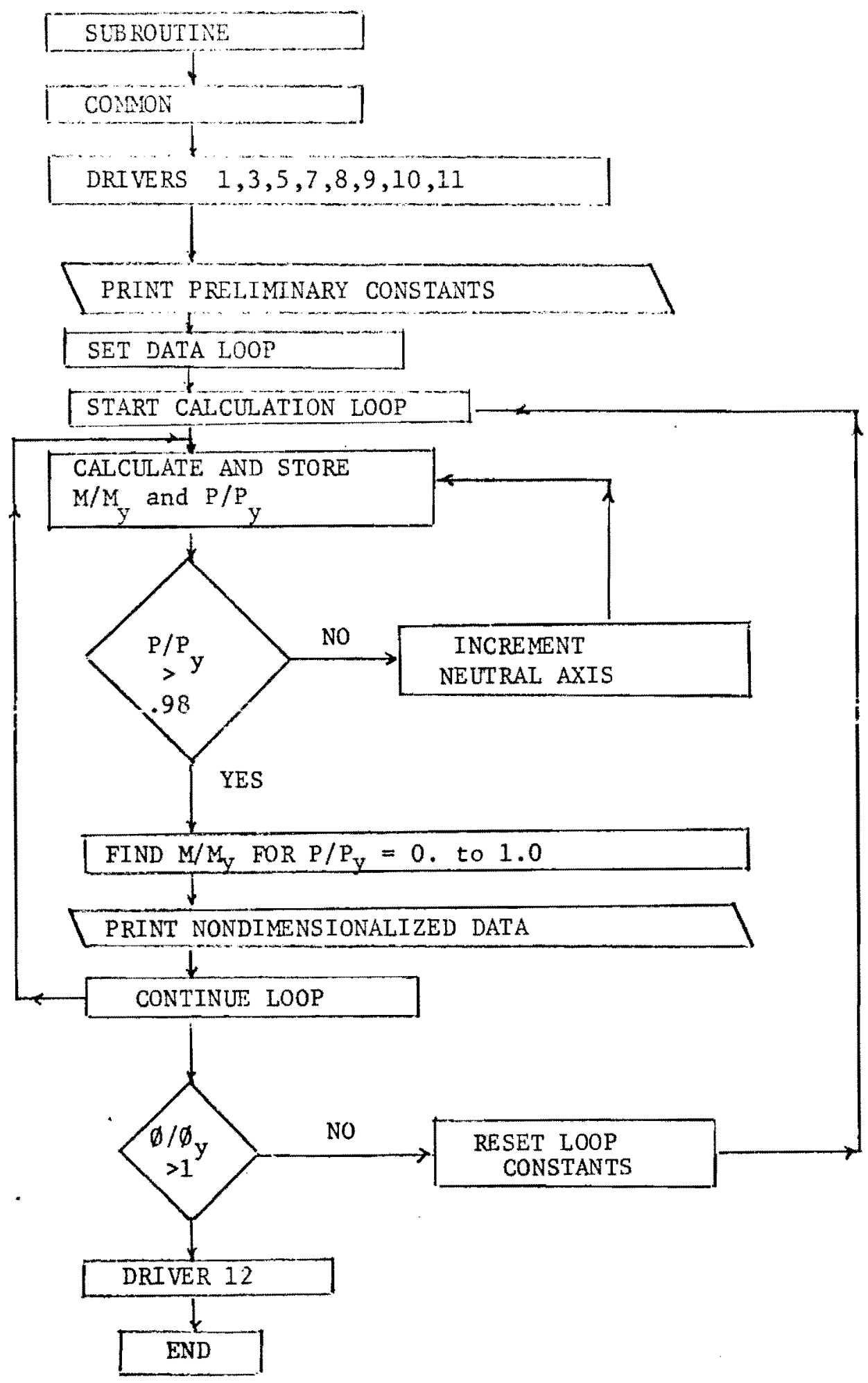




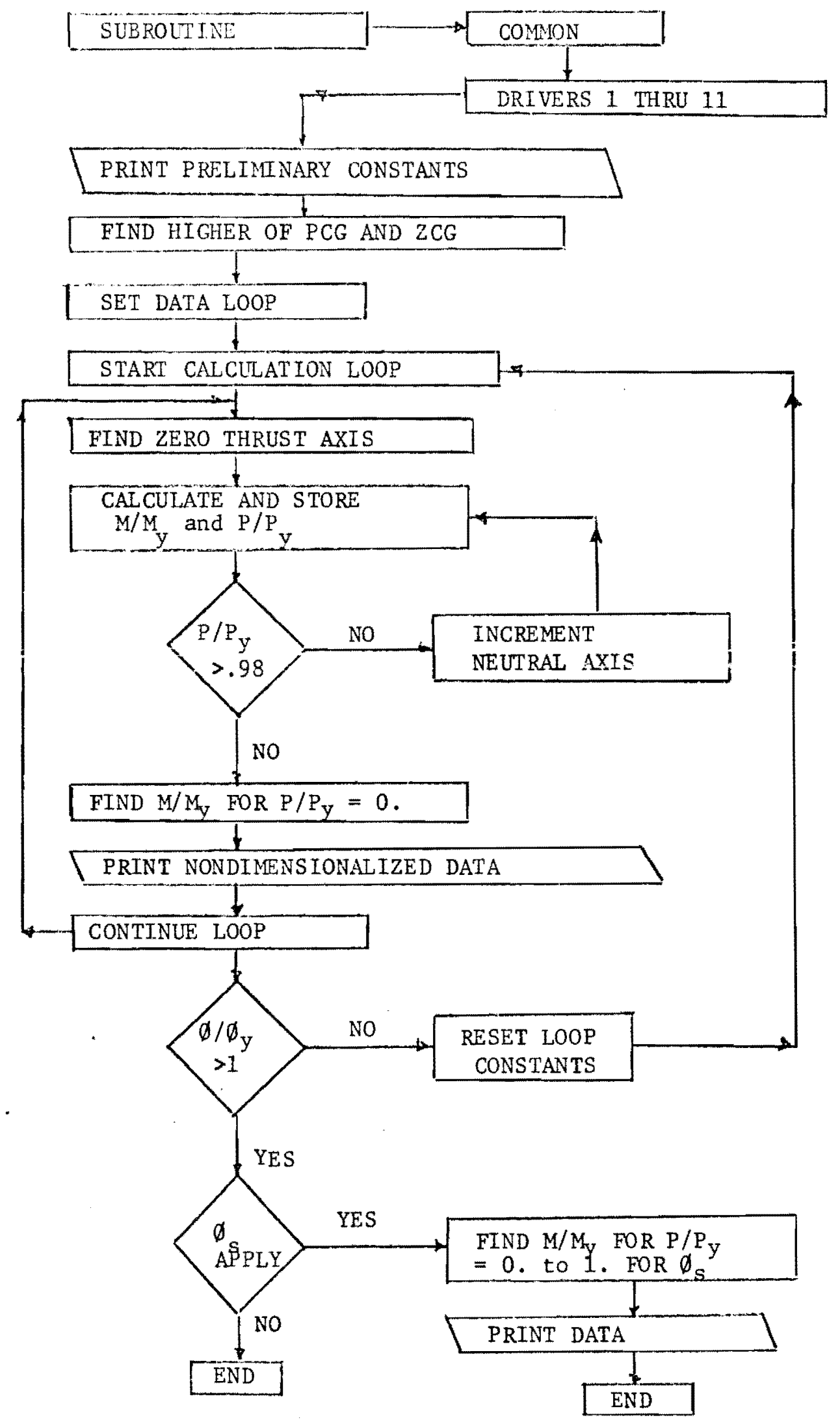


D.3 SUBROUTINES
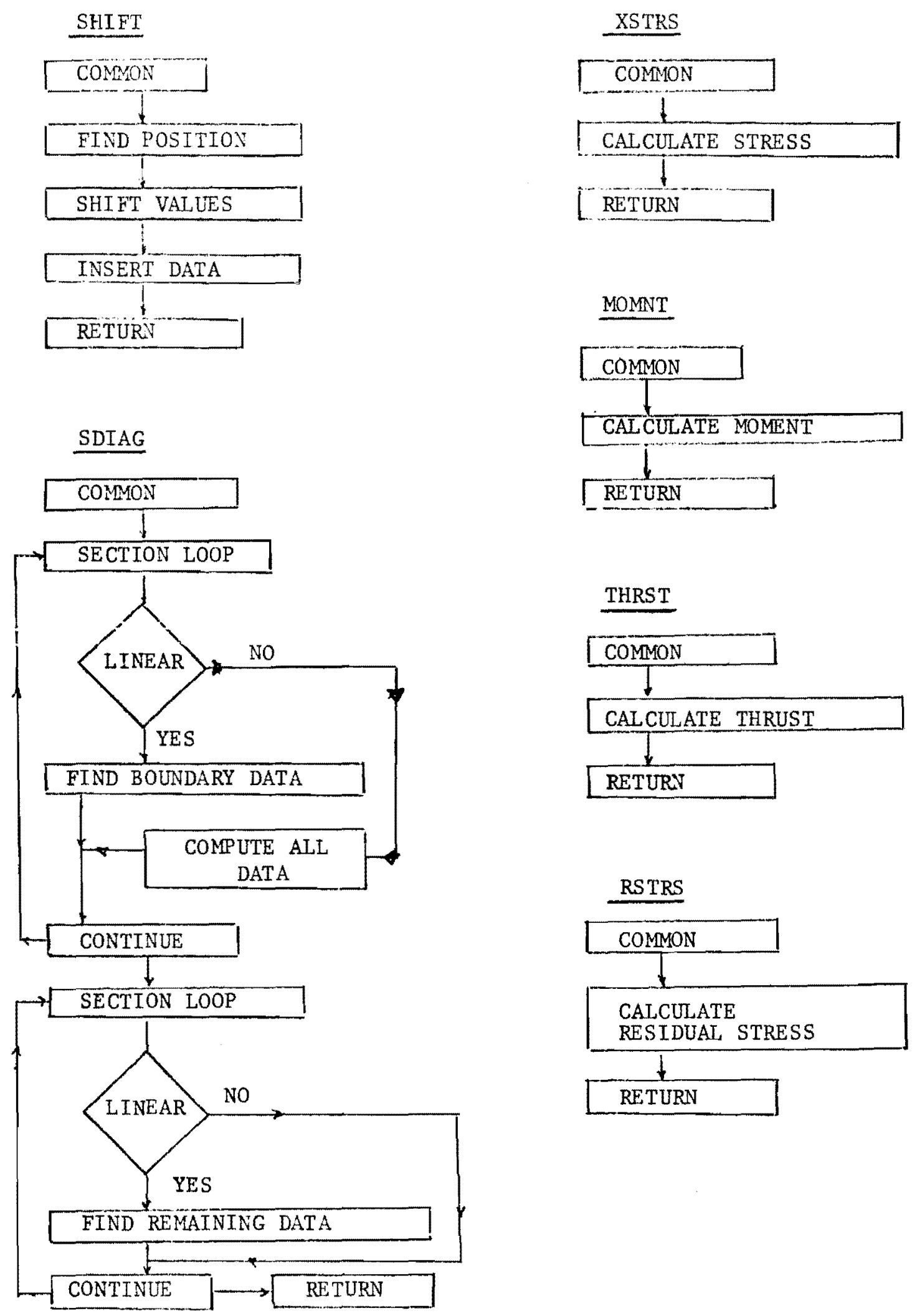


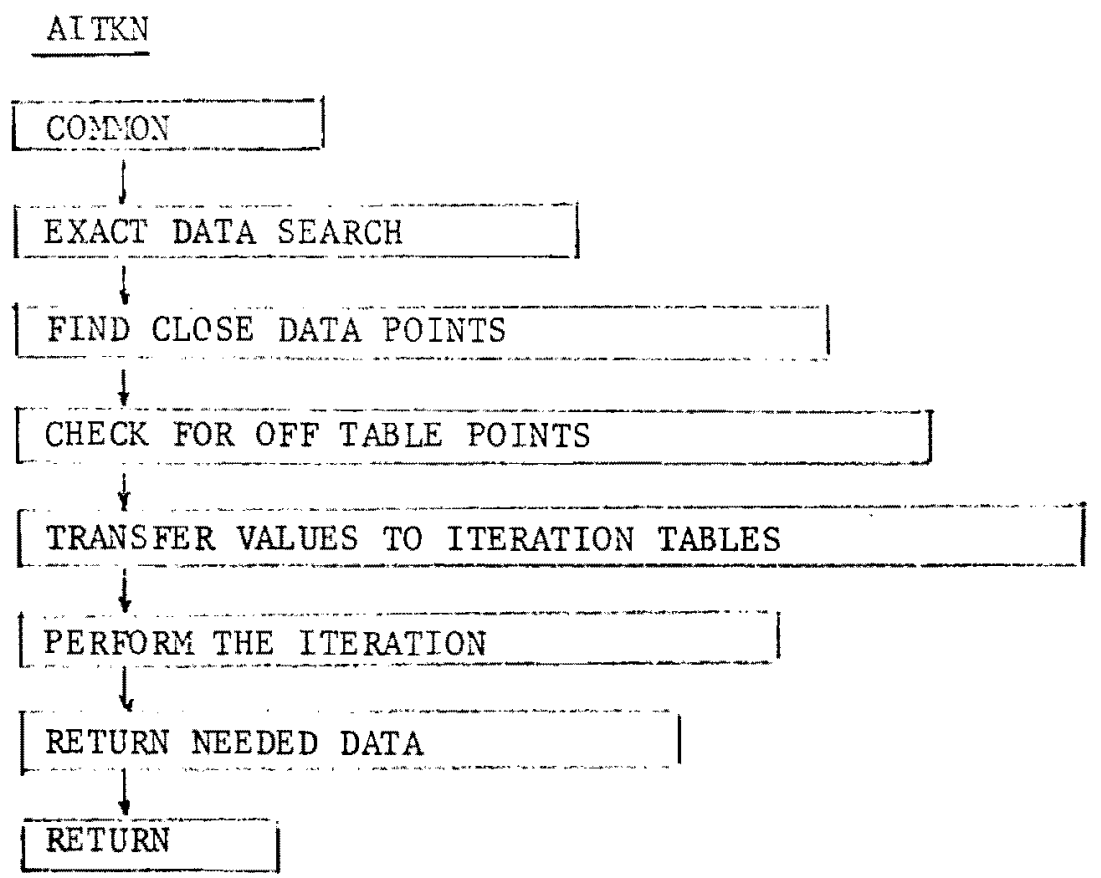

D.4 DRIVER FLOW DIAGRAMS

DRI VER 1

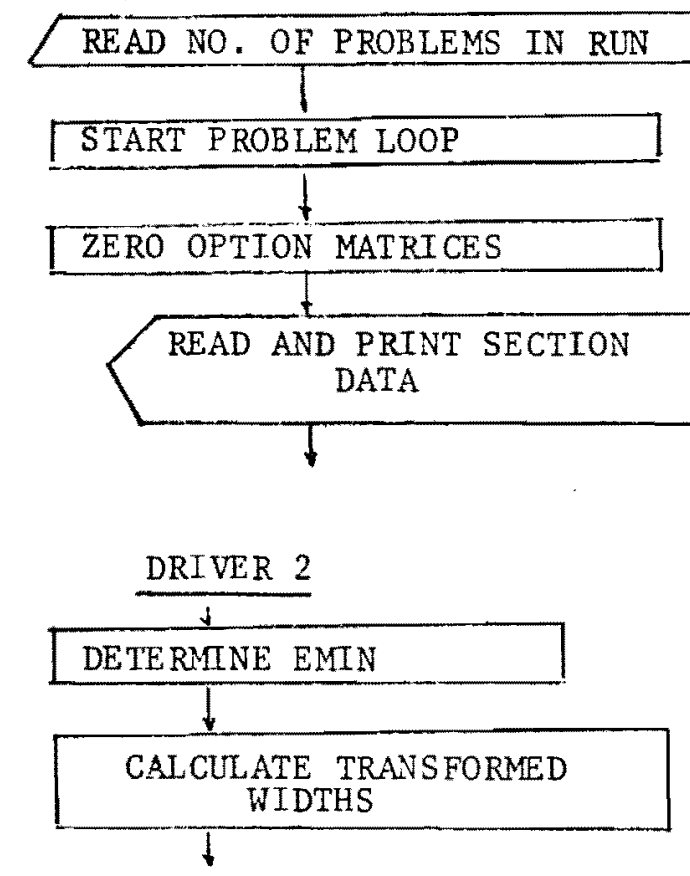

DRI VER 3
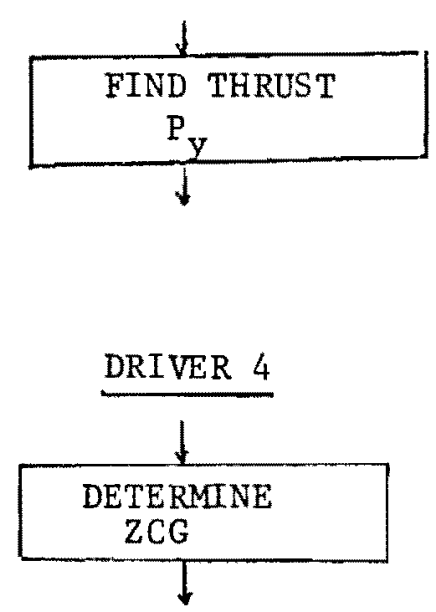

DRIVER 5

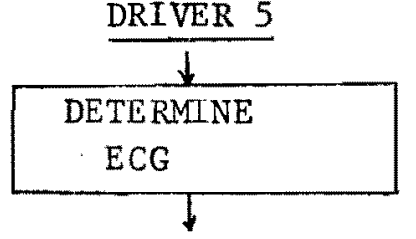




\section{DRI VER 6}
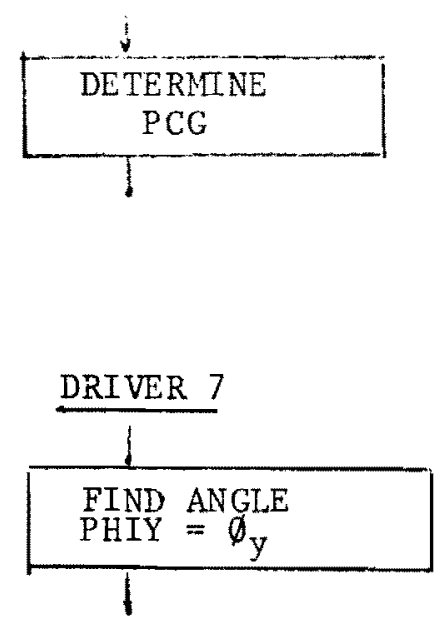

\section{DRIVER 8}
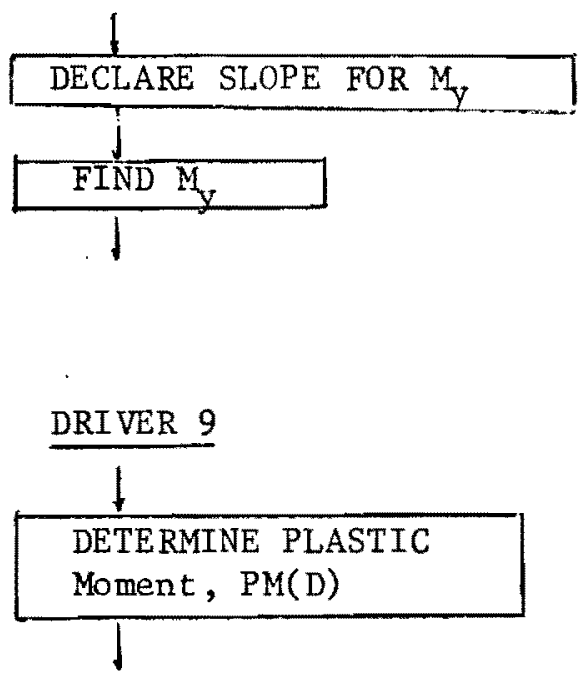

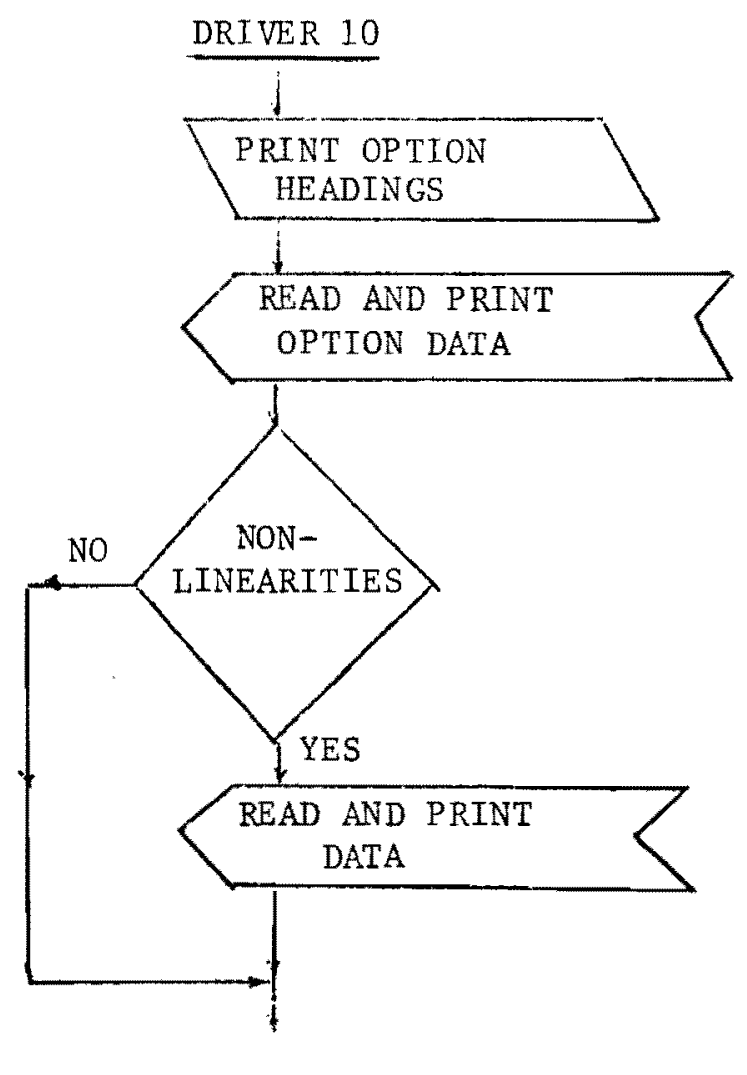

DRIVER 11

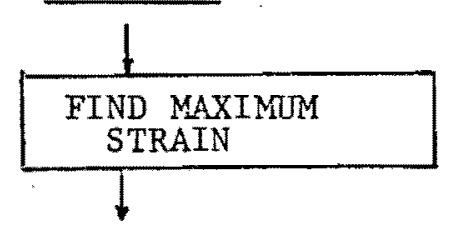

DRIVER 12

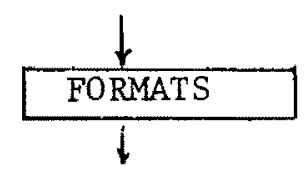


D.5 CIRCULAR TUBE FLOW DTAGRAM

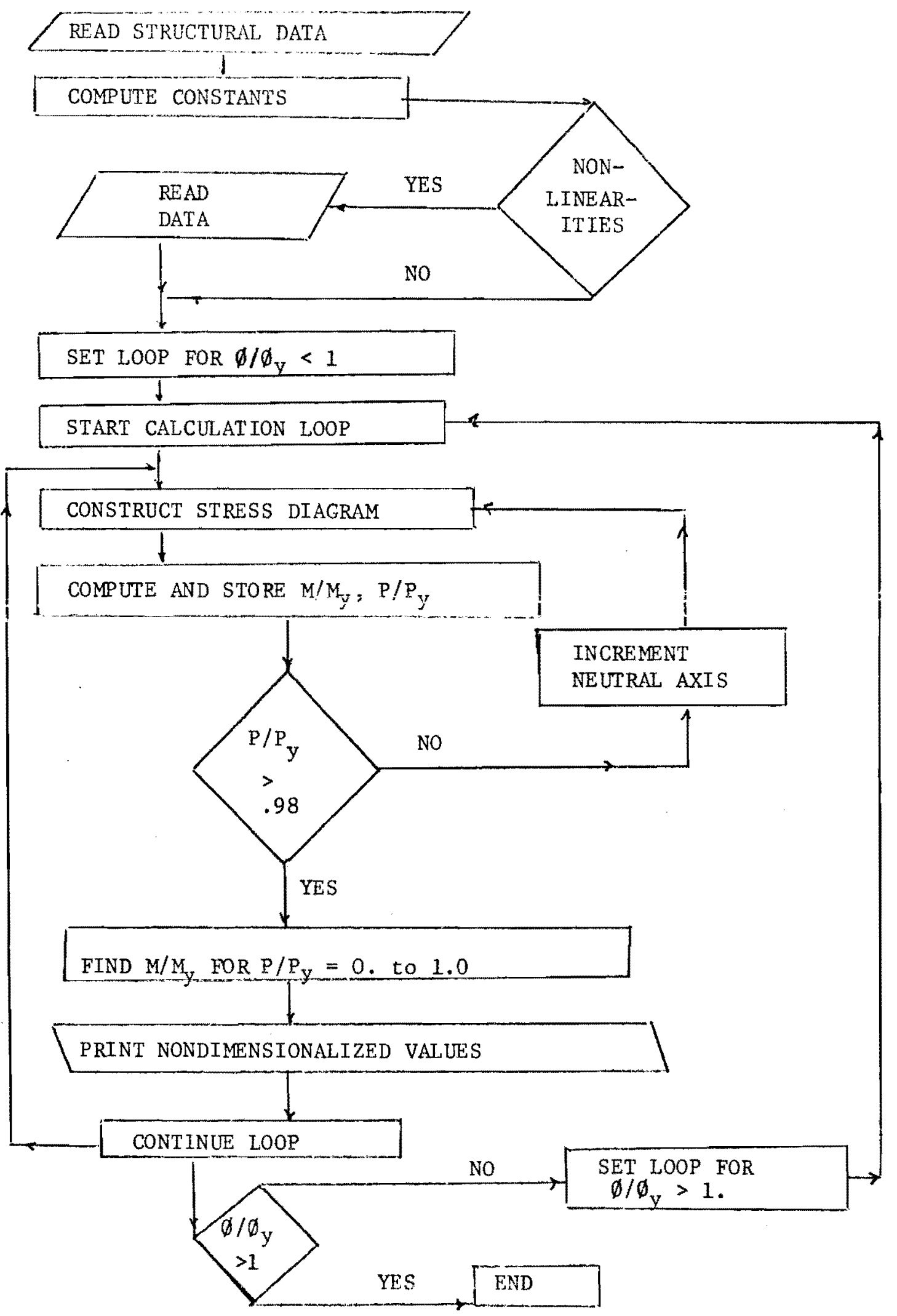


VITA

Douglas Wrenn Fiala was born in Oregon City, Oregon, on November 18,1946 , the son of Jerry and Nellie Fiala. He graduated from West Linn High School in 1965 and received his Bachelor of Science in Applied Science with emphasis in Structural Engineering from Portland State University in June, 1970. He passed the Engineer-In-Training (EIT) Examination in April, 1970. Upon graduation he was appointed as a Graduate Teaching Assistant in the Department of Applied Science, Portland State University, and served in this capacity until June, 1972. Subsequently he accepted a position with Mackenzie Engineering Inc., Portland, Oregon, as a Structural Engineer. He is a member of The Society of the Sigma Xi. 